\title{
Spatial omics to quantitatively study tissue heterogeneity
}

Citation for published version (APA):

Dewez, F. (2021). Spatial omics to quantitatively study tissue heterogeneity. [Doctoral Thesis, Maastricht University]. Maastricht University. https://doi.org/10.26481/dis.20211125fd

Document status and date:

Published: 01/01/2021

DOI:

10.26481/dis.20211125fd

Document Version:

Publisher's PDF, also known as Version of record

\section{Please check the document version of this publication:}

- A submitted manuscript is the version of the article upon submission and before peer-review. There can be important differences between the submitted version and the official published version of record.

People interested in the research are advised to contact the author for the final version of the publication, or visit the DOI to the publisher's website.

- The final author version and the galley proof are versions of the publication after peer review.

- The final published version features the final layout of the paper including the volume, issue and page numbers.

Link to publication

\footnotetext{
General rights rights.

- You may freely distribute the URL identifying the publication in the public portal. please follow below link for the End User Agreement:

www.umlib.nl/taverne-license

Take down policy

If you believe that this document breaches copyright please contact us at:

repository@maastrichtuniversity.nl

providing details and we will investigate your claim.
}

Copyright and moral rights for the publications made accessible in the public portal are retained by the authors and/or other copyright owners and it is a condition of accessing publications that users recognise and abide by the legal requirements associated with these

- Users may download and print one copy of any publication from the public portal for the purpose of private study or research.

- You may not further distribute the material or use it for any profit-making activity or commercial gain

If the publication is distributed under the terms of Article $25 \mathrm{fa}$ of the Dutch Copyright Act, indicated by the "Taverne" license above, 


\section{Spatial Omics to Quantitatively Study Tissue Heterogeneity}

Frédéric Dewez 



\title{
Spatial Omics to Quantitatively Study Tissue Heterogeneity
}

\author{
Dissertation \\ To obtain the degree of doctor at Maastricht University, \\ on the authority of the rector Magnificus \\ Prof. dr. Rianne M. Letschert, \\ in accordance with the decision of the Bord of Deans, \\ to be defended in public
} on the $25^{\text {th }}$ of November, 2021

By

Frédéric Gustave Gérard DEWEZ

Born in Douai, France, on January $21^{\text {st }} 1991$ 


\section{Promotor}

Prof. dr. Ron M.A Heeren

Prof. dr. Edwin De Pauw

\section{Copromotor}

Dr. Benjamin Balluff

\section{Assessment Committee}

Prof. dr. Maarten Honing (Chairman)

Prof. dr. Steven Olde-Damink

Prof. dr. Frederik-Jan van Schooten

Prof. dr. Gauthier Eppe, University of Liège

Dr. Brahm Heijs, Leiden University Medical Center

This research in this thesis is part of the imaging valley program which is a joint project proposal between the University of Liège and Maastricht University. This work was also supported by the LINK program of the Province of Limburg.

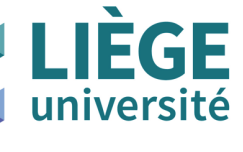


"Many of life's failures are people
who did not realize how close they
were to success when they gave up"

Thomas A. Edison

To my family 



\section{Table of content}

$\begin{array}{ll}\text { Prologue } & 9\end{array}$

$\begin{array}{lll}\text { Chapter } 1 \text { Introduction } & 17\end{array}$

Chapter 2 Precise Co-registration of Mass Spectrometry Imaging, Histology and Laser Microdissection-based Omics 41

Chapter 3 MS Imaging-guided Microproteomics for Spatial Omics on a Single Instrument

Chapter 4 Multilabel Per-pixel Quantitation in Mass Spectrometry Imaging

Chapter 5 Impact

Chapter 6 Discussion and Outlook

Chapter 7 Appendix

Summary

Samenvatting

References

List of Publications

Acknowledgements

Curriculum Vitae 

Prologue 
Biology is the study of living organisms. Organisms are highly organized and composed of one or more cells which form the basic functional units for performing specific biological functions. Cells are organized in tissues, tissues in organs, and organs in systems that enable the organism to live in, reproduce, develop and communicate with its environment.

The spatial structure and organization of cells (cytology), tissues (histology), and organs (anatomy) is thereby of utmost importance to fulfill these tasks. Fundamentally, all of these phenomena are carried out by millions of different biomolecules that are organized in complex molecular interaction networks. Obtaining comprehensive knowledge on these processes requires, therefore, large-scale analyses which generate enormous amount of data.

In recent years, high-throughput strategies have been developed using bioanalytical technologies providing rapid, sensitive, and robust measurements. These technologies enable the analysis of a wide range of biomolecules such as genes, proteins, lipids, or metabolites from biological samples (e.g., blood, urine, tissue, saliva, etc.).

Amongst these tools, mass spectrometry (MS) constitutes a powerful analytical technique which is routinely employed in biological research. The principle of MS is to physically separate molecules based on their mass-tocharge $(\mathrm{m} / \mathrm{z})$ by creating gas-phase ions. Samples can be analyzed from gas, liquid, or solid states and the measured masses can be acquired from single atoms (several daltons) to large proteins (300 000 daltons) giving qualitative and quantitative information on the elemental, isotopic and, molecular composition of organic and inorganic samples. Moreover, the continuous advances in MS technologies have increased the range of applications to pharmaceutical and biomedical research, forensic science, and biotechnology. Mass spectrometers are composed of three main components: an ionization source, a mass analyzer, and a detector. Over the years, numerous efforts have been related to the development of ionization techniques allowing the analysis of a large and broad number of compounds. Amongst these ionization techniques, two have emerged as methods of choice: electrospray ionization (ESI) and matrix-assisted laser desorption/ionization (MALDI). The ESI technology produces single or multiply charged ions from solution by generating fine droplets. The ability of this ionization technique to produce 
multiply charged molecules makes ESI especially suitable for the study of larger biomolecules. However, the analysis of biomolecules in their original biochemical context often implies the study of complex mixtures. Therefore, a separation technique such as liquid chromatography (LC) is coupled to the ESI source of the mass spectrometer (LC-MS). This technique separates and sequentially elutes the different compounds of a sample prior to their analysis by the mass spectrometer. This provides an analytical depth with high sensitivity and high selectivity enabling to obtain deep insights into the molecular content of complex mixtures. Unfortunately, this method requires samples in solution. For instance, biological fluids such as urine, blood or saliva are directly analyzed for screening. However, in the case of the study of tissues, the first step is to extract the molecules of interest in solution. Therefore, this has for consequence the loss of spatial distribution of the biomolecules within the tissue. Spatial LC-MS can be enabled by analyzing microdissected areas of interest from tissue sections. These areas are usually based on histological information.

To directly obtain spatial information on the localization of the measured molecules, mass spectrometry imaging (MSI) has been developed to apply MS analytical capabilities directly on tissue. While different ionization methods exist in MSI, MALDI is the most common one employed since it combines soft ionization of many different molecular classes with high spatial resolution measurements. MALDI-MS makes use of a previously applied organic matrix which co-crystallizes with the analytes. This organic compound absorbs and transfers the energy of the MALDI laser to desorb and ionize the biomolecules. The repetition of this process in a grid-wise manner across a surface is called MALDI mass spectrometry imaging (MALDI-MSI) which has been developed to enable the simultaneous visualization of hundreds to thousands of non-labeled molecules directly from the surface of tissue sections. This is created by storing the coordinates $\mathrm{x}$ and $\mathrm{y}$ of each individual measurements thereby enabling a reconstruction of the distribution of molecules within the tissue sample. MALDI is also suited to investigate a wide range of molecular classes such as metabolites, lipids, drugs, or proteins. Being an imaging technique, the spatially resolved mass spectrometric data of MALDI-MSI can be correlated with imaging data from other imaging modalities. The most frequently used is light microscopic imaging which is 
used to view the MSI data in its histological context. This allows associating MSI molecular profiles with the underlying cell types such as tumor cells, connective tissue, inflammatory cells, etc. Moreover, it has been demonstrated that MSI constitutes a powerful tool to investigate tissues beyond histological information, for instance to study intratumor heterogeneity. Indeed, the diversity of tumor cells within a patient plays an important role in tumor progression that can determine the outcome of the patient including prognosis, response to chemotherapy, or development of metastases. MALDI-MSI combined with statistical tools enabled to reveal tumor populations that are not distinguishable by conventional histopathological methods but are different on a molecular level.

Unfortunately, the direct analysis from tissue sections implies no additional separation steps which leads to a lower sensitivity compared to liquid-based LC-MS due to local ion competition. Moreover, on-tissue strategies analyze a very small number of cells in MSI pixel (a 50x50 $\mu \mathrm{m}$ pixel contains about 25 cells) that contribute to a low ion yield per pixel and therefore, the detection of the most abundant molecules. These compounds still constitute representative signals in biological processes but do not offer deeper insights into the molecular network interactions. An additional challenge in MSI is obtaining quantitative information since it requires additional sample preparation steps.

Combining the strengths of both techniques, i.e molecular spatial information provided by MALDI-MSI and the analytical depth with relative quantitative information provided by LC-MS would be a substantial analytical tool to delve into the metabolome, lipidome, or proteome of biospecimens. A way to couple these two technologies is to use MALDI-MSI data that provides molecular information at a micrometer scale to guide a laser microdissection system (LMD) for subsequent LC-MS experiments. However, with technological advances in MSI instrumentation that reach high-spatial resolution at a single-cell scale, the retaining of the spatial information of MSI data in the LMD requires their accurate co-registration. In my first work (Chapter 2), I, therefore, strove for an accurate coupling of these two technologies to accurately cut out regions of interest based on MALDI-MSI data that can then be forwarded to quantitative LC-MS microproteomics 
analyses. To achieve the aim of this project, I made use of the expertise from the Maastricht MultiModal Molecular Imaging Institute (M4I) and the Mass Spectrometry Lab (MSLab) of the University of Liège within the framework of the Imaging Valley Joint-PhD program.

This dual approach requires optimal instrumentation for both parts of the pipeline: MALDI-MSI and LC-MS. On the one hand, MSI instruments need to provide sensitive and rapid experiments at high-spatial resolution, and on the other hand, LC-MS systems need to be tuned for the analysis of minute amounts of samples. Therefore, in chapter 3, I demonstrated the application of this pipeline to study intratumor heterogeneity in tumor breast samples on a single instrument which is a hybrid instrument equipped with a MALDI source and an orthogonal electrospray source. MALDI-MSI was employed to highlight distinct spatial clusters of breast tumor cells based on their lipid molecular profiles and characterize these tumor subpopulations at the protein level more in-depth by LC-MS The use of this pipeline could enable to obtain deeper insights into biological processes due to a better comprehensive molecular characterization of distinct molecular regions of interest. With this pipeline, I have established a multivariate type of analysis that provides relative quantitative information in a spatial context and can be applied for large-scale analyses to different kinds of biomolecules such as lipids, metabolites, or proteins (see top panel, figure below). 


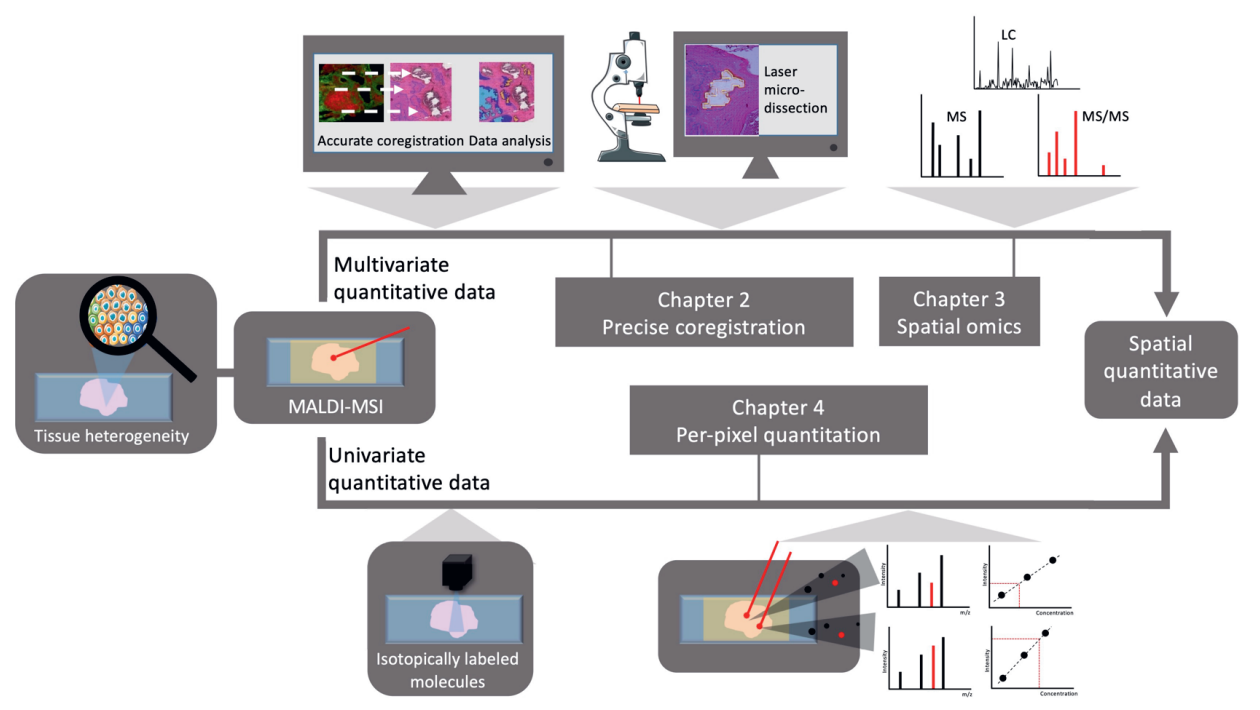

However, unlike LC-MS that provides label-free quantitative data, MALDIMSI is a semi-quantitative method since MALDI-MSI has to deal with different local noise levels and ion suppression due to the absence of chromatographic separation. Obtaining absolute quantitative information from state-of-the-art MALDI-MSI analyses involves normalizing the target molecule using an internal standard such as a structural analog or a stable isotope of the molecule of interest. The normalized intensities are then mapped to a calibration curve that is located on a separate (usually consecutive) tissue section. Unfortunately, the use of a single label and an external calibration curve does not take into account disproportional local ion suppression effects and different noise levels. New quantitative methods are therefore needed to overcome those limitations. In chapter 4, I, therefore, propose a new univariate quantitative method that addresses these issues by the use of several internal standards. These are homogenously sprayed in different concentrations onto the tissue thereby enabling the creation of internal calibration curves at every measured position which therefore accounts for local ion suppression (see bottom panel, figure below).

In summary, I propose a spatial omics workflow in chapters $\mathbf{2}$ and $\mathbf{3}$ that brings synergistically together spatial and relative quantitative information for a wide range of molecules. This will constitute a new powerful analytical method to characterize molecular changes in tissue microenvironment to 
obtain a better in-situ characterization of tissues. Likewise, a univariate absolute quantitative information method was developed in chapter 4. Being able to more accurately quantify drugs within cell populations of tissues will enhance pharmacokinetics and toxicity studies which in turn will aid in the development of more effective drugs with fewer side effects. 


\section{Chapter 1}

Introduction 


\subsection{Omics technologies towards spatial analysis}

Omics technologies are powerful approaches used in biomedical research to study a broad range of biomolecules in a multiplex and non-targeted manner in biological samples, such as body fluids or tissue specimens. Indeed, the association of both terms "omics" (derived from a Greek word which means "entire") and "technology" refers to the comprehensive study of a target molecular class ${ }^{[1]}$, such as genes (genomics), gene transcripts (transcriptomics), proteins (proteomics), and metabolites (metabolomics/lipidomics). Studies on these molecular levels aim to characterize and quantify the presence and abundance of biomolecules to better understand their dynamics, functions, and interplay in biological processes of an organism. Therefore, omics technologies are employed in a wide range of applications where they are used as a molecular profiling tool of biological samples to compare the effect of different experimental conditions, disease states, or environmental factors ${ }^{[2-4]}$.

While omics tools are nowadays able to profile thousands of molecules simultaneously (e.g. genomics can analyze all 20,000 human genes at once and beyond), most of the omics technologies are extraction-based techniques that require the homogenization of the sample in order to target and analyze the molecules of interest. Therefore, these technologies surely provide high sensitivity and deep analytical insight but lack spatial information. This is especially important in the context of biological tissue samples where many different cells are organized in a very structured way in order to fulfill a certain function.

Due to this reason, the understanding of the molecular processes in such a setting requires the comprehension of molecular abundances also in the spatial dimension. Therefore, molecular imaging techniques have been developed to keep the spatial information and investigate tissues at the microand nanoscopic level. For the analysis of tissues, conventional molecular imaging methods often employ targeted approaches such as immunohistochemistry (IHC) or fluorescence imaging that require a priori knowledge of the candidate molecules. For instance, IHC is a technique which uses antibodies that bind to specific protein domains and this implies the creation of antibodies specific to the target proteins. At the moment, these 
targeted approaches are limited to the simultaneous analysis of a dozen of molecules, however, biological processes are dynamic and carried out by millions of molecules requiring a large scale analysis ${ }^{[5]}$.

This is why over the past decade omics, as the study of the "entirety", pushed itself towards another level of complexity, namely the comprehensive molecular analysis of single-cells in a spatial context ${ }^{[6-8]}$. This enables to study local microenvironment of different cell populations that are involved in several pathways as shown in Figure 1.1. Today, the recent technological advances in omics enable to become more and more sensitive which is required in single-cell analysis and, therefore, gives access to large amount of data describing a more complete picture of the biological processes going on.

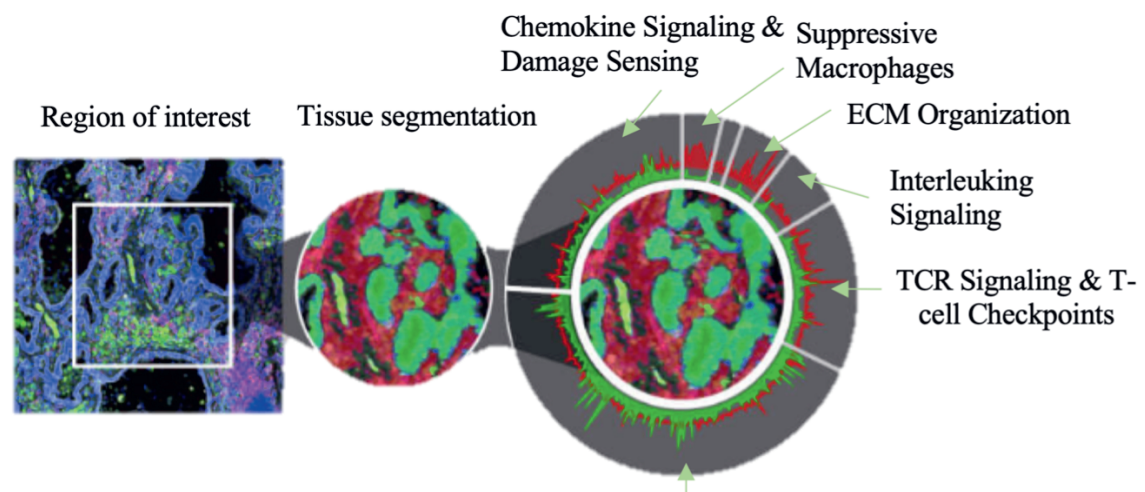

RTK Signaling \& Regulation of Cell Cycling

Figure 1.1. Pathway signaling within tissue compartments.

This figure adapted from the website GeoMx applications.

\subsection{Mass spectrometry}

Amongst omics technologies for the large-scale study of the proteome and metabolome, one of the most commonly employed is mass spectrometry (MS). The foundation of this technique was established at the beginning of the $20^{\text {th }}$ century when the German physicist Wilhelm Wien discovered that beams of ions could be deflected by a magnetic field. This observation led to extensive research demonstrating that the deflection is dependent on the 
particular mass-to-charge ratio of the ion and its velocity ${ }^{[9]}$. This was the birth of mass spectrometry.

Originally, MS was used to measure isotope abundances and elemental masses. Nowadays, MS has expanded from physics into chemistry and biology This analytical technique enables now the study of a solid, liquid, or gas-like samples where the molecules within the sample are ionized and separated by a mass analyzer according to their mass-to-charge ratio $(\mathrm{m} / \mathrm{z})$. Upon impact on the detector, the $\mathrm{m} / \mathrm{z}$-separated ions induce a current which is recorded. The result is a mass spectrum that corresponds to the plot of intensity as a function of the mass-to-charge ratio. Therefore, a mass spectrometer is composed of three parts: an ion source, a mass analyzer, and a detector. The ion source creates charged particles from the sample. Depending on the state of the analyzed material and the target molecular class, different types of ionization can be employed. Chemical or electron ionization techniques are commonly used for gas samples, while electrospray (ESI) or matrix-assisted laser desorption/ionization (MALDI) are utilized for liquid and solid biological samples, respectively. After creating the ions, these ions are analyzed by electric or magnetic fields which affect the trajectory and velocity of these charged particles depending on their mass-to-charge ratio.. Many analyzers exist in MS fields such as time-of-flight (TOF), quadrupole, ion traps, Orbitrap or Fourier transform ion cyclotron resonance (FT-ICR) that differ in experimental speed, mass resolution, sensitivity, and costs. Therefore all of these mass analyzers have their niche of application such as intact protein measurements (TOF), targeted MS (quadrupole), peptidomics and lipidomics (Orbitrap), and metabolomics (FT-ICR) ${ }^{[10-13]}$.

MS is a sensitive technique as result of more efficient ionization, a better ion transfer and detection and improvement in data analysis. For instance, Lenco et al reported the identification of 2800 human proteins in 60 minutes from $2 \mu \mathrm{g}$ HeLa proteins digest ${ }^{[14]}$. MS is selective that refers to the power of discrimination between the analyte and closely related substances. However, the comprehensive analysis of biological processes, as mentioned previously, requires the study of these biomolecules in their spatial context.

\subsection{Mass spectrometry imaging}


Mass spectrometry imaging (MSI) is an omics technology that enables to visualize the spatial distribution of a wide broad range of biomolecules such as intact proteins ${ }^{[15,16]}$, peptides ${ }^{[17,18]}$, metabolites ${ }^{[19,20]}$ or, lipids in tissue biospecimens ${ }^{[21,22]}$. To do so, the coordinates $\mathrm{x}$ and $\mathrm{y}$ of the ion beam created during the ionization process are recorded enabling the reconstruction of the molecular image (Figure 1.2). In this process, the ionization is a crucial step since it may lead to the fragmentation of the analyzed molecules. Soft ionization techniques have therefore been developed that use low residual energy resulting in fewer fragmentations which make them suitable to study higher-weight molecular classes such as intact proteins.
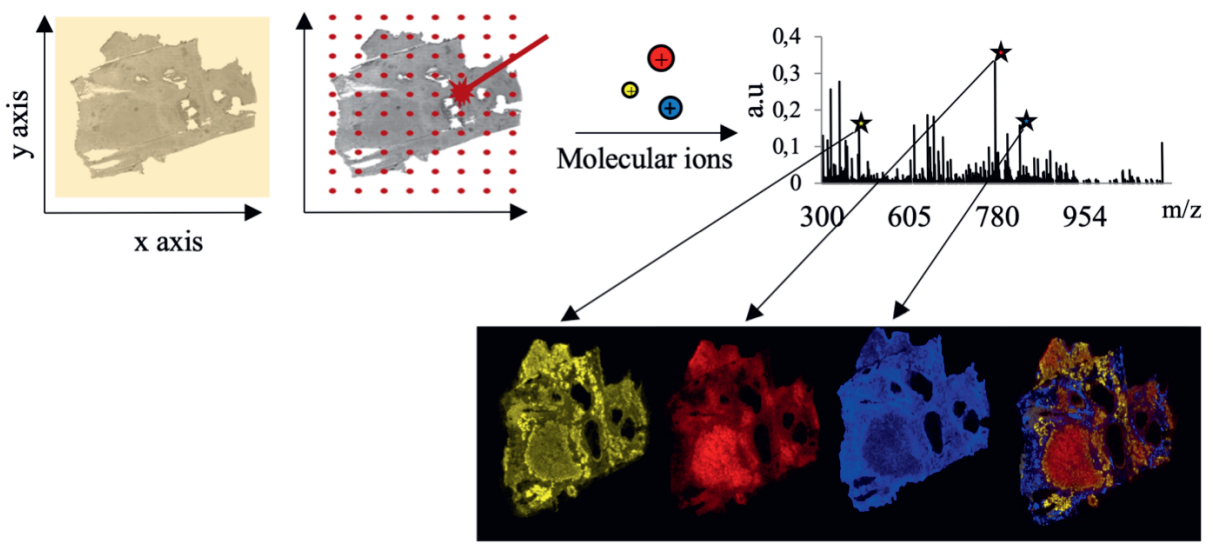

Figure 1.2. Principle of mass spectrometry imaging.

Top: From a conventional tissue section mass spectra are recorded at spatially distinct locations that enables the reconstruction of images from individual molecules. Bottom: the spatial distribution of three molecules is shown in yellow, red, and blue, with a merged image at the very right, showing the different and specific abundances of the molecules in different tissue compartments.

\section{Matrix-assisted laser ablation/desorption ionization (MALDI)}

Amongst these ionization techniques, matrix-assisted laser desorption/ionization (MALDI) remains the most commonly used ionization technique in MSI. MALDI was developed in the 1980's ${ }^{[23,24]}$. It uses a matrix which is a dissolvable, organic crystalline compound that absorbs energy at the wavelength of an irradiating laser. This chemical compound is often acidic (provider of protons) composed of conjugated double bonds for the UV or IR 
absorption and a polar group enabling miscibility in aqueous solutions. The matrix is then mixed with a solution which is composed of a mixture of water and organic solvent. The solvent is extremely important in the MALDI process because it allows the extraction of the molecules of interest. Indeed, this mixture enables both hydrophobic and hydrophilic compounds to be extracted from the sample. In the case of a tissue section, the solvent enables the extraction of the molecules of interest from the surface of the tissue where the matrix and the analytes co-crystallize during evaporation of the volatile solvent. This step is crucial in MALDI-MSI because it plays a role in the matrix crystallization where the resulting size of the matrix crystals and analyte diffusion due to excessive solvent can be a potential limiting factor for high spatial resolution experiments (see Matrix Application). Once the analytes have co-crystallized with the matrix, the sample is exposed to a pulsed laser beam resulting in desorption and ionization of the analytes by proton transfer or deprotonation after absorption of the laser energy by the matrix crystals which minimizes the fragmentation of the target molecules. The ions are then transferred for their separation to the mass analyzer (Figure $1.3)$.

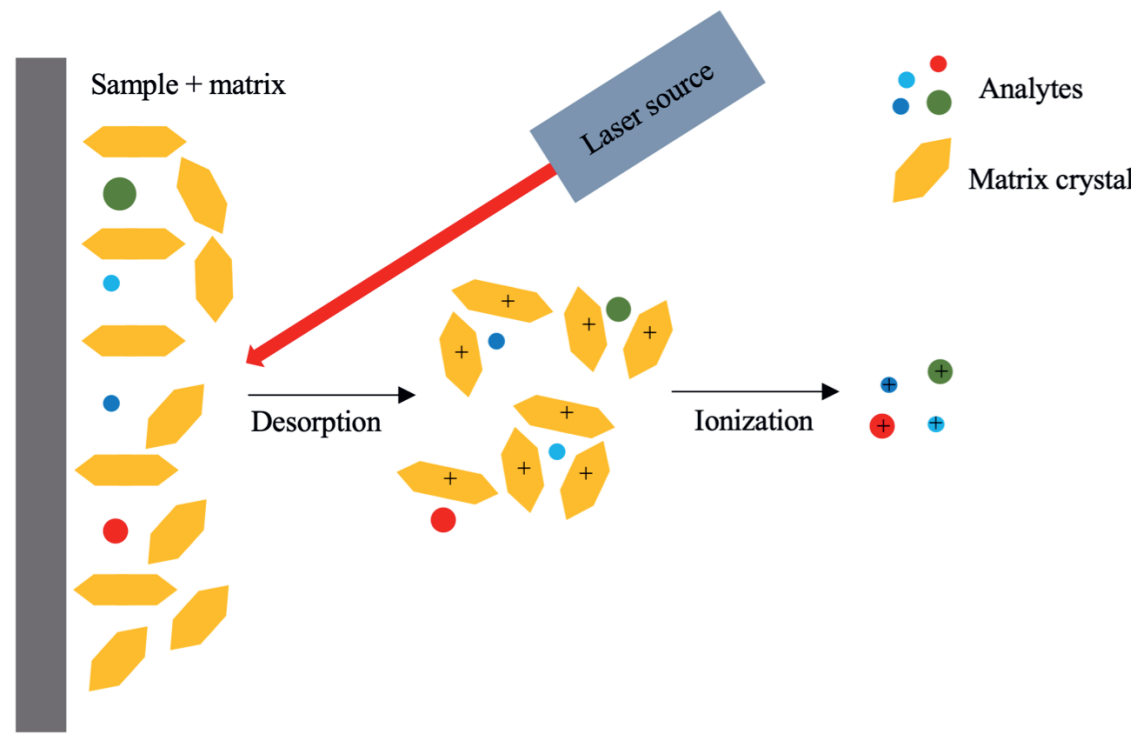

Figure 1.3. Principle of Matrix-Assisted Laser Desorption Ionization process. A chemical compound, called matrix, is mixed with the sample or applied onto a tissue section that facilitates the extraction of the molecules of interest using a selected solvent composition. After evaporation of the solvent and co- 
crystallization of the organic compound with the analytes, the sample is exposed to irradiation by a UV or IR laser. Matrix crystals with the analytes are then desorbed and photoionized thereby enabling the creation of molecular ions.

\section{Mass analyzers}

Several mass analyzers are available in MSI such as time-of-flight (TOF), quadrupole, ion traps, orbitrap or Fourier transform ion cyclotron resonance. Nowadays, several mass analyzers have been coupled enabling to combine their advantages. For instance, quadrupole-time-of-flight (Q-TOF) combines the advantages of the quadrupole and the time-of-flight mass analyzers. This coupling offers high sensitivity, good resolution, and high repetition rates provided by the TOF analyzer with high compound fragmentation efficiency of the quadrupole. The first commercialized instrument was available in 1996 ${ }^{[25]}$. Briefly, a quadrupole $1(\mathrm{Q} 1)$ is used as a mass filter or as a transmission field to transmit the ions to the collision cells (Q2) where the ions can be fragmented by collision with a neutral gas (collision-induced dissociation, CID). The time of flight of the ions is then measured and translated into massto-charge by the TOF analyzer (Figure 1.4) ${ }^{[26]}$. This hybrid mass analyzer provides mass resolution of 10,000-50,000. In this thesis, this hybrid mass analyzer was used in form of the MALDI HDMS synapt G2-Si (Waters, Manchester, UK) (Chapter 2) and the timsTOF flex (Bruker Daltonik, Bremen, Germany) (Chapter 3). These two mass spectrometers also are equipped of an ion mobility cell which enables to separate isomers, isobars and conformers species. Many different technologies exist but the principle is the separation of ions based on their interaction with a buffer gas in the presence of a low electric field. This specificity was not used in this thesis. In chapter 4, another type of hybrid mass analyzer was used: here, the quadrupole was coupled to an Orbitrap mass analyzer that offers high mass accuracy $(<2-3 \mathrm{ppm}$ ), a high mass resolving power (up to 240,000 at $\mathrm{m} / \mathrm{z} 400$ ), and a high dynamic range. This makes it suitable for the analysis of complex mixtures of biological samples. In this thesis, the Q-Exactive plus (Thermo Fisher Scientific, Germany) was selected for its capability of separation and identification of isotopically labeled compounds (Chapter 4). 
A

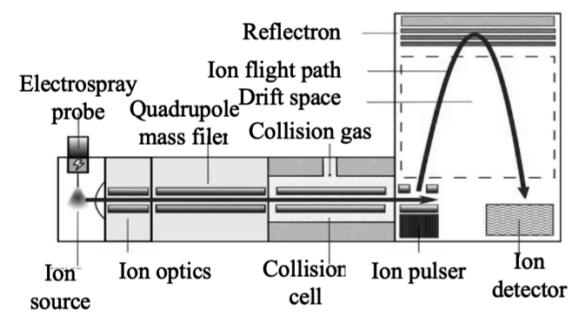

B

HCDcell C-trap

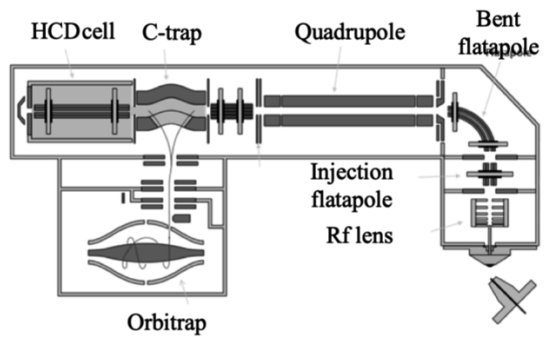

Orbitrap

Figure 1.4. Schematics of hybrid mass analyzers: quadrupole/time-of-flight (A) and quadrupole/orbitrap mass spectrometers (B).

(A) taken from https://europepmc.org/article/med/31530964 and (B) from https://planetorbitrap.com/q-exactive-plus.

\section{Sample preparation in MALDI mass spectrometry imaging}

One of the essential steps in MALDI-MSI is sample preparation since which at least involves the application of the matrix. Overall, the direct analysis of biological tissues requires the sample preparation to preserve the tissue integrity and the spatial distribution of the molecules ${ }^{[27-29]}$. Careful sample handling is therefore required to prevent and control molecular degradations and delocalizations. Indeed, many factors can influence the reproducibility of the experiments after tissue collection such as environmental conditions (humidity, temperature, time post-mortem ... etc) or delocalization of the analytes that can lead to inaccurate spatial distribution and therefore wrong biological interpretations.

\section{Sample collection and storage}

The first step of the sample preparation concerns tissue collection. The tissues need to be stabilized to stop all biological processes and can be embedded to facilitate the mounting and the sectioning. Several methods have been developed such as snap-freezing, optimal cutting temperature polymer (OCT), gelatin, heat-based stabilization (Denator ${ }^{\mathrm{TM}}$ ), carboxymethylcellulose (CMC), or formalin-fixed paraffin embedded. The latter has been widely used in tissue preservation for histology purposes but due to the molecular crosslinking of proteins and removal of the paraffin (several washing steps are required that can remove endogenous compounds), this method remains challenging in MSI ${ }^{[30]}$. Freezing remains the main stabilization method 
suitable for MSI. This consists of dipping the entire targeted organ in liquid nitrogen or isopentane to snap freeze the tissue for $30-60$ seconds ${ }^{[31,32]}$. The frozen tissue is then stored prior to analysis at $<-20^{\circ} \mathrm{C}$. In this thesis, a human breast tumor sample (Chapters $\mathbf{2}$ and $\mathbf{3}$ ) and a pig colon tissue (Chapter 4) were snap-frozen and used for the different analyses.

\section{Tissue sectioning}

The next step of a typical MSI workflow is the sectioning of the tissue samples. When using fresh frozen tissues, a cryostat needs to be employed to obtain thin tissue sections from the frozen sample which are then deposited by thaw mounting on regular or indium tin oxide (ITO) glass slides. The sectioning is usually performed to obtain sections between 10 and $20 \mu \mathrm{m}$. In this work, sections of $12 \mu \mathrm{m}$ were used providing a compromise between thick sections that are more easily manipulated but take longer to dry while thinner sections are more difficult to handle but provide higher quality mass spectra [33]. The sectioning is usually performed within a temperature range of $-5^{\circ} \mathrm{C}$ to $-30^{\circ} \mathrm{C}$ depending on the type of tissue. In this work, breast tumor sections were obtained at $-30^{\circ} \mathrm{C}$ due to the extensive fat content of breast tissue that tends to melt at warmer temperatures (Chapters $\mathbf{2}$ and $\mathbf{3}$ ) while colon tissue sections were collected at $-20^{\circ} \mathrm{C}$ (Chapter 4).

\section{On-tissue digestion}

For some applications, extra sample preparation steps are needed in order to target specific molecules such as peptides. MALDI-MSI produces mainly singly charged ions which are problematic in terms of sensitivity when investigating the spatial distribution of intact proteins directly from frozen tissue sections. Indeed, the study of peptides enables to use reflectron mode instead of linear mode in the case of intact proteins resulting in higher mass accuracy. Or simply, the use of FFPE material where the study of intact proteins is not possible. The application of an enzyme before the MALDI experiment enables to cleave the proteins into peptides that are more easily ionized ${ }^{[27,34]}$. Prior to enzymatic application, washing steps are performed to remove salts and small molecules that can interfere as ion suppression with the molecules of interest. Many washing protocols have been developed in order to maximize sensitivity and maintain the localization of the target molecules ${ }^{[32,33,35]}$. The most common washing procedure consists of several 
dipping steps in an increasing ethanol series ${ }^{[36,37]}$. Several studies showed that washing steps enable better detection of peptides ${ }^{[34,38,39]}$. When using FFPE material, an extra step of antigen retrieval is usually performed in citric acid at $10 \mathrm{mM}$ and $\mathrm{pH} 6.0$ at $121^{\circ} \mathrm{C}$ for 20 min to undo the cross-linking formed by the fixation with formalin. However, this step can also be performed with fresh frozen tissues to reduce the steric barriers to access the proteins ${ }^{[40]}$. Different strategies have been developed to perform on-tissue digestion. Most recent studies use an automated sprayer to apply the enzyme such as trypsin on top of the tissue followed by incubation for several hours or overnight at $37^{\circ} \mathrm{C}[41]$.

\section{Matrix application}

In order to analyze the tissue sections using MALDI-MSI, this requires the application of a thin matrix layer on top of the tissue. Matrix application protocols need to be optimized to ensure high quality of the mass spectra while keeping the spatial distribution of the molecules of interest for highquality images. First of all, the choice of matrix plays an important role. For instance, sinapinic acid (3,5-dimethoxy-4-hydroxycinnamic acid, SA) is used for high molecular weight compounds while $\alpha$-cyano-4-hydroxycinnamic acid (CHCA) and 2,5-dihydroxybenzoic acid (DHB) are more commonly employed for low molecular weight species ${ }^{[31,42-45]}$. The way of application is also a crucial step because it influences the specific crystallization phenotype of the matrix where matrix crystal sizes can prevent MSI cellular resolution experiments (Figure 1.5). Indeed, controlled parameters enable to obtain different crystal sizes (range from 1 to $30 \mu \mathrm{m}$ ) ensuring high-spatial resolution experiment with good sensitivity ${ }^{[46,47]}$. Different combinations of solvents can also be used to ensure the best extraction yield of the molecules of interest while maintaining a small lateral diffusion (Figure 1.5) ${ }^{[32,48]}$. Finally, the application of a homogenous layer of matrix is required to ensure high-quality images. Recent advances in this field by the introduction of automatic sprayers and sublimation devices which provide nowadays high reproducibility between experiments ${ }^{[49,50]}$. 


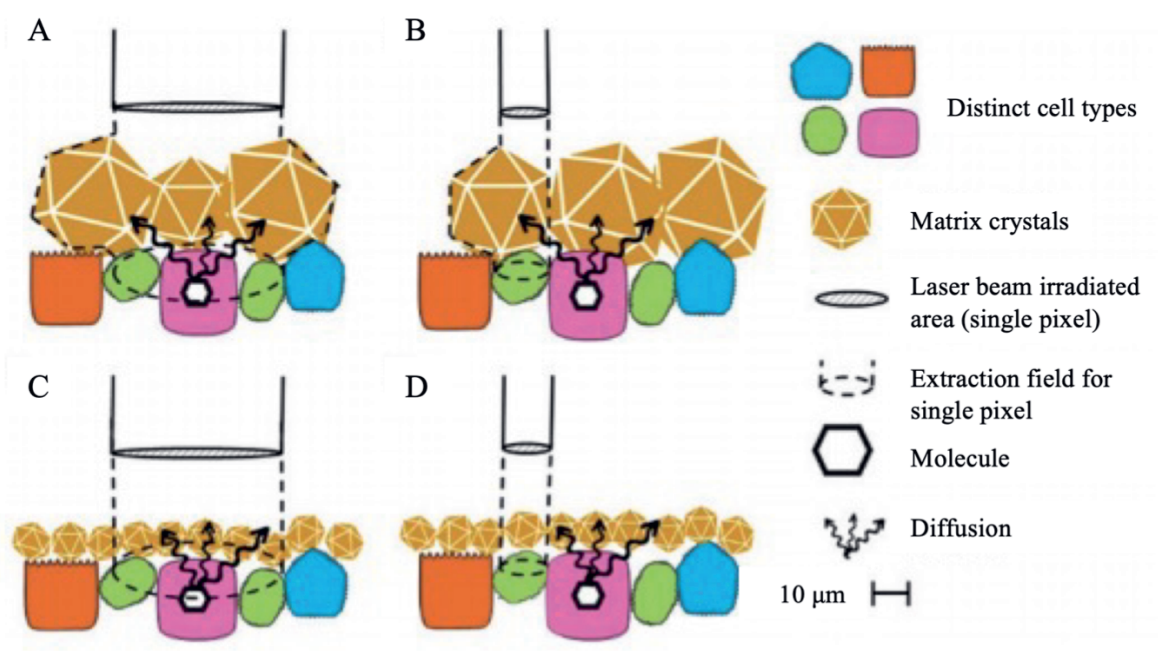

Figure 1.5. Importance of matrix crystal sizes and lateral diffusion during solvent extraction for high spatial MALDI-MSI experiment.

(A). In this example, the matrix crystals are bigger than the laser beam irradiated area and the cells, this prevents to achieve single-cell MSI experiments. (B). Here, the matrix crystals are bigger than the cells but smaller than the laser beam area which does not allow MSI experiments at cellular resolution. (C). Here, the laser beam irradiated area is the limiting factor. (D). Finally, matrix crystal sizes and the laser beam enables highspatial MSI experiments at single-cell level. Figure taken from ${ }^{[51]}$.

\section{Quantitative MSI}

MSI is a semi-quantitative technique that enables to map biomolecules on top of tissue sections. However, due to variation in local ion suppression, extraction efficiency, and isobaric interferences, no absolute quantitative information is provided (Figure 1.6B). Moreover, MALDI-MSI has to deal with additional effects related to the MALDI process itself such as variations in analyte extraction from tissue, crystallization, desorption, and ionization (Figure 1.6A) ${ }^{[52]}$. Nonetheless, strategies have been developed to quantify and map molecules on tissue sections, termed quantitative mass spectrometry imaging (Q-MSI). These approaches usually make use of an internal standard which is a molecule that shares chemical properties with the target compound. Applying this internal standard at known concentration to the sample enables to quantity the target molecule based on the intensity ratio between the target 
molecule and the internal standard. The internal standard can be applied insolution, sprayed on or beneath control-tissue, incorporated into homogenate tissue or loaded on a slide before imprinting. ${ }^{[33-58]}$. Another approach also makes use of a "pseudo internal standard" to evaluate the response of the detected signal that depends on various factors such as tissue heterogeneity, micro environment, or matrix application ${ }^{[59]}$. In chapter 4, an extension of the internal standard approach will be investigated where several isotopicallylabeled versions of the target molecule will be used in combination to address the degree of non-proportional relationship between intensities of the target molecule and its single internal standard, observed when their concentrations start to differ too much.

A

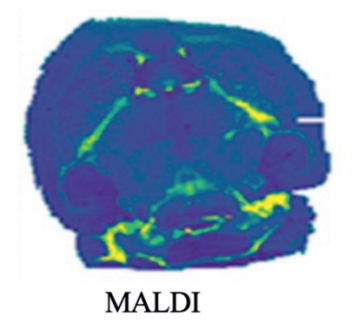

B

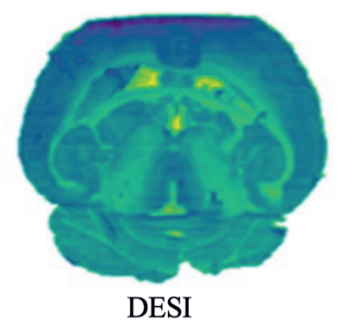

Ion images of uniformly deposited analyte

\section{Figure 1.6. Ion suppression in MSI.}

Olanzapine was coated homogeneously on mouse brain tissue sections prior to matrix-assisted laser desorption ionization (MALDI) mass spectrometry imaging (A) and desorption electrospray ionization (DESI) (B). Single ion images of olanzapine showed relative region suppression effects due to anatomical features present in brain tissue sections but also by the use of different ionization methods. Figure taken from [47].

\section{Data Analysis}

The MSI community puts a lot of effort into the optimization of sample preparation and the improvement of instruments' performance. Another extremely important aspect in an MSI workflow is the targeted and efficient analysis of the complex data generated. The actual data analysis is preceded by a few processing steps, which include at the intra-experiment level spectral pre-processing (baseline subtraction, smoothing, alignment, binning, etc.), peak picking, and spectrum-wise normalization ${ }^{[60-62]}$. For data mining from 
MSI data, two different approaches can be distinguished in order to extract relevant information: supervised and unsupervised methods. The supervised approach uses previous knowledge in form of annotations or sample labeling to extract single discriminatory $\mathrm{m} / \mathrm{z}$ values or patterns that are related to the previous knowledge. For instance, regions of interest within samples or whole samples can have been labeled by another imaging modality. The aim is then to establish a model that will perform a recognition task in unknown (with respect to the label) samples. To do so, the supervised approach requires to perform univariate statistical testing and discriminative analyses to identify discriminating $\mathrm{m} / \mathrm{z}$ values that can be used to create classifiers. These classifiers are then trained using machine learning algorithms such as linear discriminant analysis (LDA), random forests, or neuronal networks. These can then be used to classify and predict on a pixel or sample level.

On the other hand, unsupervised approaches do not require a priori knowledge at the pixel or sample level. These approaches are more used to explore the data by using algorithms that group pixels or samples based on their spectral similarity. The different methods can fall into three subcategories: 1) factorization methods (such as nonnegative matrix factorization (NMF), or principal component analysis (PCA)), 2) clustering methods (k-means, hierarchical clustering, bisecting k-means), and 3) manifold learning methods (t-Stochastic Neighborhood Embedding (t-SNE)) [63]. These methods differ in their computational expenses, the ability to model non-linear structures in the data, their susceptibility for imbalances in true classes in the data, the pre-determination of expected components, and their ease of use (availability in vendor software, parameterization). Non-negative matrix factorization provides a good trade-off between all aspects and, together with its sybling methd PLSA (probabilistic latent semantic analysis), has proven to provide valuable results from MSI data ${ }^{[64]}$.

That is why in chapter 2, I have used NMF as unsupervised approach to highlight distinct molecular tumors subpopulations based on their mass spectral profiles. Using clustering optimization criteria, such as the Silhouette coefficient, this enabled the detection of three distinct clusters within the tumor areas. Since this method is not available in the data analysis software of the instrument, I employed in chapter $\mathbf{3}$ another type of unsupervised clustering: k-means. This is also a partitioning of the MSI data but here, first, 
the means are randomly calculated based on a number that is set by the user (for instance $\mathrm{k}=3$ ), then clusters are iteratively created by associating every observation to the nearest dynamic centroid.

As mentioned above, the clusterings that were performed in Chapters $\mathbf{2}$ and $\mathbf{3}$ were restricted to tumor areas in breast tissue sections in order to spatially describe molecularly distinct intra-tumoral areas. This step requires to obtain the histological information by coregistration of MSI data to a stained image.

\subsection{Coregistration to other imaging modalities}

The use of soft ionization techniques such as MALDI in MSI maintains the integrity of the tissue section which allows a further investigation of the tissue by other imaging modalities. Even more, the interpretation of MALDI-MSI data actually necessitates the correlation with additional histological information to relate the molecular profiles to the underlying cell types. Different strategies have been developed to correlate histology and MSI data. First attempts performed the histological staining on a consecutive section [15]. The use of an untouched, raw tissue section allows any type of staining but the spatial shift in $\mathrm{z}$ introduces some uncertainties because the histological features might not properly match the molecular information provided by MSI. Another approach is to stain the section prior to the MSI experiment ${ }^{[65]}$. However, the washing steps involved in the staining can compromise the molecular class that can be analyzed by MSI. In fact, only a few histological dyes are compatible with MALDI-MSI, and most of these stains are insufficient in terms of histological information. Consequently, the most common approach consists of staining the tissue section right after the MALDI-MSI experiment ${ }^{[66,67]}$. This enables a good correlation by using the exact same tissue section. Also, this allows performing the staining with any type of dyes.

The correlation with histological information requires the coregistration of the microscopic image with the molecular information provided by MSI. With constant technological advances in MSI resolution, the need for accurate coregistration becomes crucial in MSI workflows. Image registration consists of the selection of one image as a reference to which other images are aligned using linear and non-linear geometric transformations. The image registration 
can be intensity-based or feature-based ${ }^{[68]}$. The latter makes use of common features represented as control points that are visible both in the reference image ("fixed" image) and the images to coregister (named "moving" images). Several reference points are selected manually or automatically enabling to perform geometric transformations of the moving images (Figure $1.7)$.

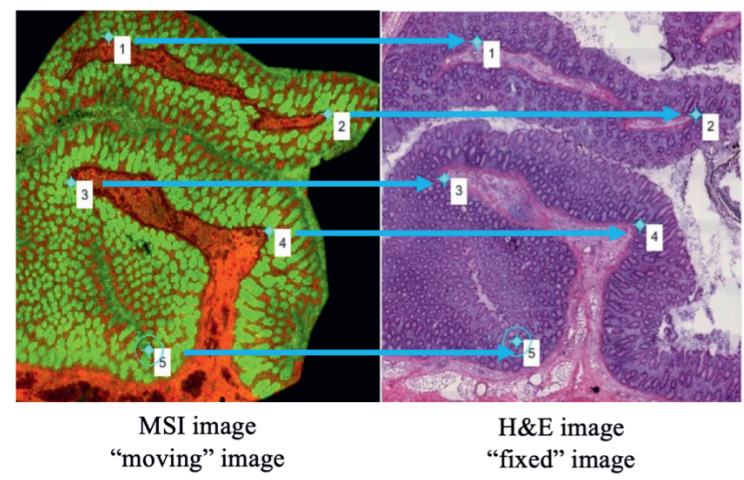

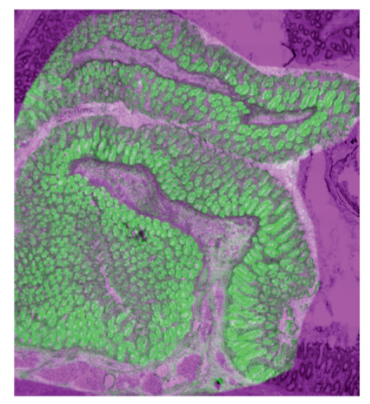

Coregistered images

Figure 1.7. Image registration by control point matching between "moving" and "fixed" image (feature-based coregistration).

Five control points were selected using matching morphological features visible in both, the MSI data as well as the histological staining image, in order to create the geometric transformation of the "moving" MSI image.

Intensity-based registration can also be performed by comparing intensity patterns in images via correlation metrics. Algorithms begin with coarse resolutions subdividing the image into large blocks proceeding to finer resolutions after several iterations using an interpolation method ${ }^{[68]}$.

The images to coregister can differ in position, orientation, or scale depending on the anatomical differences or manipulation of the tissues, respectively. Since affine transformations best model physical deformations of tissue sections such as translation, rotation, scaling, and shearing (Figure 1.8), it is the most commonly used transformation in MSI ${ }^{[69-73]}$. 


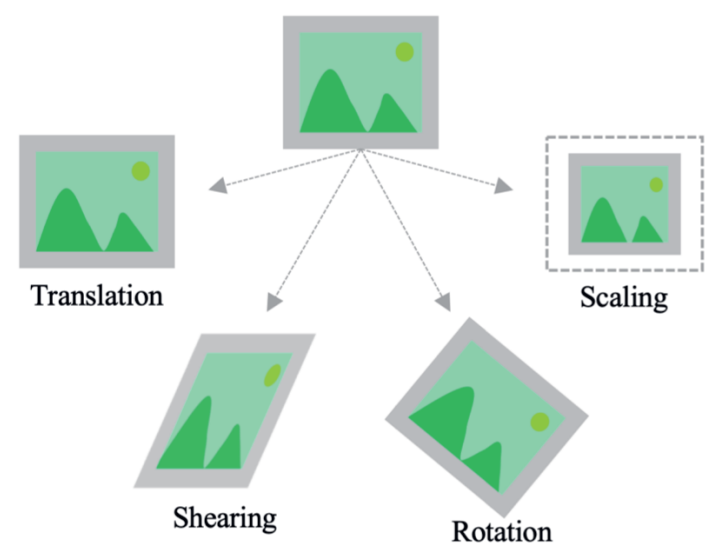

Figure 1.8. Affine registration on a 2D plane by linear transformations.

Examples of linear transformations that can be performed such as translation, rotation, scaling, and shearing.

However, in a histological context, local deformations in the tissue section can appear such as folds, tears, or local compression. This requires non-linear transformations, also called elastic transformation that captures local deformations ${ }^{[71,74]}$. It has also been shown that the combination of featurebased and intensity-based remains the most accurate registration method. Indeed, several studies suggest a better coregistration accuracy while combining both algorithm classifications ${ }^{[73,75,76]}$.

Image registration is mainly used to couple MSI with other imaging modalities. This has been applied in many different fields. For instance, Abdelmoula et al. established an automatic registration of MSI data to magnetic resonance imaging data ${ }^{[71]}$. Image registration has also been used to perform an image fusion between MSI data and microscopy images enabling to predict the spatial distribution of ions at higher spatial resolution [77].

\subsection{Laser microdissection}

Image registration is also of importance in laser microdissection (LMD) where images obtained by MALDI-MSI have been used to guide a dissection of certain areas from tissues ${ }^{[78-80]}$. A LMD system is a light microscope combined with a laser that enables the excision and collection of tissues down to single cells. This technology has been mainly employed to obtain samples 
from heterogeneous starting material based on the visualization of the tissue's morphology after histological or immunofluorescence staining ${ }^{[81,82]}$. MSI data has great potential to complement a tissue's dissection by an LMD system based on untargeted molecular information. Moreover, due to the lack of separation steps in MSI, the molecular characterization of the tissue section is limited and this coupling would enable the integration of MSI data with other analytical technologies. However, this information transfer requires a sufficiently accurate coregistration step between MSI data and the LMD system to maintain the spatial information obtained by MSI (Chapters 2 and 3). The needed spatial accuracy of coregistration is thereby determined by the MSI pixel size. If this is achieved, MALDI-MSI could highlight regions that are molecularly distinct and pass that information to an LMD system for their dissection and analysis by other omics technologies.

\subsection{Integration with other omics technologies.}

The direct analysis from tissue sections limits the analytical depth of MALDIMSI. The absence of chromatographic separation leads to ion competition resulting in poor molecular characterizations. Moreover, MALDI-MSI analyzes a small number of cells producing a low amount of ions, therefore, MALDI-MSI detects mainly high abundant or ionization-affine molecules (Figure 1.9) ${ }^{[83]}$. Even if changes in these abundant molecules can represent different biological states, they do not offer deep mechanistic insights into the underlying biochemical processes.

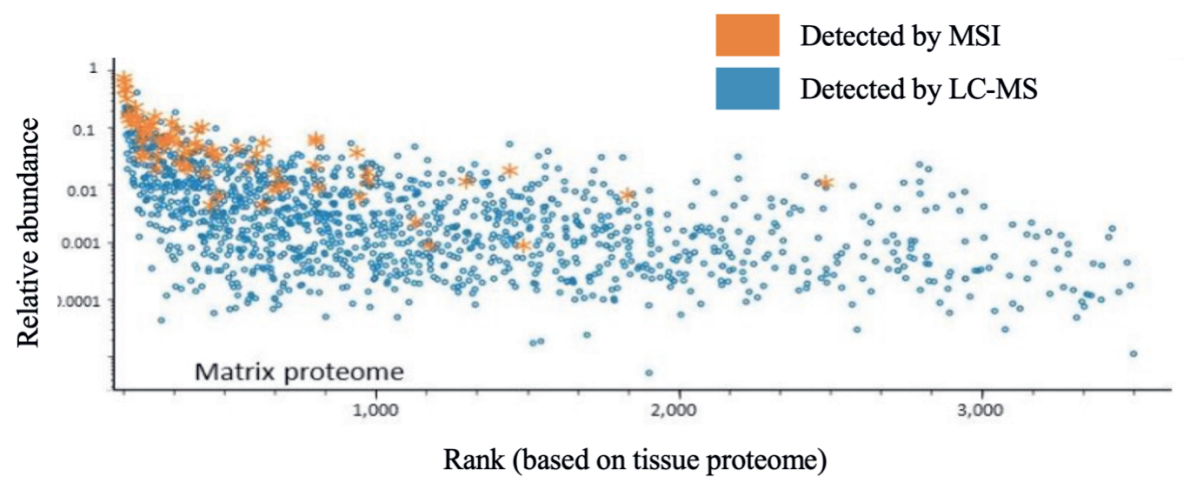

Figure 1.9. Comparison of protein relative abundances between MSI and LCMS.

Proteins identified from 10 human tissues by LC-MS (blue) were plotted 
against MSI markers extracted from the literature (orange). Figure adapted and taken from [73].

Being a non-destructive technique, MALDI-MSI not only enables an integration with other subsequent imaging modalities but also facilitates a coupling with other omics technologies that offer a better molecular characterization of the very same sample. Liquid-chromatography-mass spectrometry (LC-MS) is one of the most common techniques used in omics. A broad range of biomolecules such as metabolites, lipids or proteins can be studied with LC-MS however in this thesis I will focus only on the study of proteins (Chapters $\mathbf{2}$ and $\mathbf{3}$ ).

\section{Towards microproteomics}

Proteomics is the large-scale analysis of proteins. The proteome is the entirety of proteins that are involved in all cellular processes in an organism and there exist over one million. Proteomics studies can provide deep insight into biological processes by analyzing the expression, the degradation, the modification, the interaction, or the identification of these proteins. However, extracting, separating, and detecting proteins remains challenging due to the diverse physicochemical properties of amino acids (charge state, isoelectric point, hydrophobicity) that are the building blocks of proteins, their spatial conformations, or their post-translational modifications. Therefore, the study of proteins in biological samples such as tissues or cells implies the investigation of complex protein mixtures. This complexity can be reduced by sample prefractionation that enables to select the proteins of interest based on their physicochemical characteristics such as by 1-2D electrophoresis or affinity enrichment using antibodies. Ultrafiltration can also reduce sample complexity by removing high molecular weight proteins. Then, these fractions are submitted to high-throughput technologies that have been developed to investigate proteomes in biospecimens. The most common technique is mass spectrometry associated with liquid chromatography (LCMS). There are two main approaches for mass spectrometry-based proteomics: top-down and bottom-up. Top-down is the analysis of intact proteins while bottom-up approaches investigate the peptides from digested proteins. The analysis of peptides is explained by an easier ionization and a 
higher fragmentation efficiency than intact proteins. In this thesis, I will use the most widely used technique which is the bottom-up approach and focus on the analysis of peptides after tryptic digestion. Constant advances in microsampling and miniaturization have led to an increased sensitivity and in turn to a decrease in required minimal sample amount, which allows nowadays the analysis of even single cells ${ }^{[84]}$.

\section{Sample preparation in microproteomics}

To obtain a high protein identification rate and reliable quantitative data, intensive sample preparation is required to obtain a good protein/peptide recovery. Sample preparation in microproteomics is challenging due to the handling of minute amount samples. Since small sample sizes are more susceptible to protein loss, high recovery of peptides is key for reproducibility. In this thesis, for instance, on average only 2000 cells were harvested and processed in order to perform microproteomics. Due to these small sample sizes, several steps that are usually part of the proteomics workflow needed to be adapted. While detergents such as Triton X-100, Tween 20, or octyl glucoside associated with mechanical stimulus are usually used to lyse cells and extract the protein content, this step can be omitted and replaced by other solutions to extract and solubilize proteins such as acetonitrile, ammonium carbonate, or Rapigest ${ }^{[85,86]}$. Protein precipitation is also commonly used in proteomics sample preparation. But once again, this leads to a high risk of protein loss and can be omitted. Then reduction and alkylation of the cysteines are performed in order to reduce the disulfide bonds of the proteins to prevent inter- and intra-molecular disulfide formation between cysteines. This results in the denaturation of the proteins that lose the tertiary structure which results in a better accessibility of the amino acids to cleave by a protease. Trypsin is the most common enzyme used in LC-MS analysis. It hydrolyzes only peptide bonds where the carbonyl group is followed by arginine or lysine except for the presence of proline positioned before arginine or lysine. Finally, peptide enrichment and clean-up are performed before the analysis. This step is needed in the case of lowabundance proteins to enable their successful detection and identification. After this step, salts and buffers are removed using graphite C-18 tips ${ }^{[87]}$. 
In-solution digestion results in a large number of peptides that can cause an increase in the complexity of the sample and hence in the ionization competition. Therefore, liquid-chromatography is performed prior to the mass spectrometry experiments to separate and elute the peptides one after the other in order to reduce the sample's complexity.

\section{Liquid-chromatography}

Different techniques have been developed to fraction a complex mixture of which liquid-chromatography (LC) has become the most common method to separate peptides. As the name refers to, liquid-chromatography employs a column that contains a polar mobile phase and a non-polar stationary phase. While the role of the mobile phase is to transport the molecules through the column, the stationary phase, which is a solid phase, has the role to retard the travel time through the column by adsorption and desorption. The material of the stationary phase hence defines the interaction of the molecules with it therefore the type of separation. Many columns have been developed enabling the separation of the molecules according to the size, chemical properties such as polar or non-polar or charged states. High-performance liquid chromatography (HPLC) is an advanced type of LC. The difference between traditional LC and HPLC is that the solvent in LC moves by the force of gravity while in HPLC systems, the solvent travels under high pressure obtained by pumping. This results in a faster separation. Nowadays LC usually refers to HPLC.

LC coupled with MS is commonly used in high throughput analyses. This enables physical separation capabilities by LC before injection into the mass spectrometer. However, the interface creating the ions from a continuous flow from LC into gas phase has been a challenge for a very long time. This has changed with the development of electrospray ionization.

\section{Electrospray ionization}

Electrospray ionization (ESI) is a technique that transfers charged molecules from a liquid state into gas phase using electrical energy. This ionization method was developed in the 1980's by Masamichi Yamashita and John Fenn [88]. The ionization process involves many steps. After the LC separation, the solvent containing the analytes is injected by a mechanical syringe pump into 
a needle to which a high voltage is applied. This causes a strong electric field from the needle nozzle to the mass spectrometer inlet. The electric potential in the inside of the needle leads to the creation of ions in the solvent which upon exit of the needle will disperse into fine charged droplets by the electrospray. Due to the use of large amount of solvent, the ion formation requires extensive solvent evaporation. The latter is obtained by the application of a nebulizing gas that reduces the droplet size until the charged droplets become unstable due to electrostatic repulsion (Rayleigh limit) which has for consequences to eject the droplets into the gaseous phase (Coulomb fission). The ions are then transferred to the mass analyzer of the mass spectrometer. The mechanism is shown in Figure $1.10^{\text {[89]. }}$

As ESI produces multiple-charged ions and mass spectrometers measure molecules based on their mass-to-charge-ratio, ESI extends the mass range of the analyzer and facilitates the analysis of large peptides or proteins.

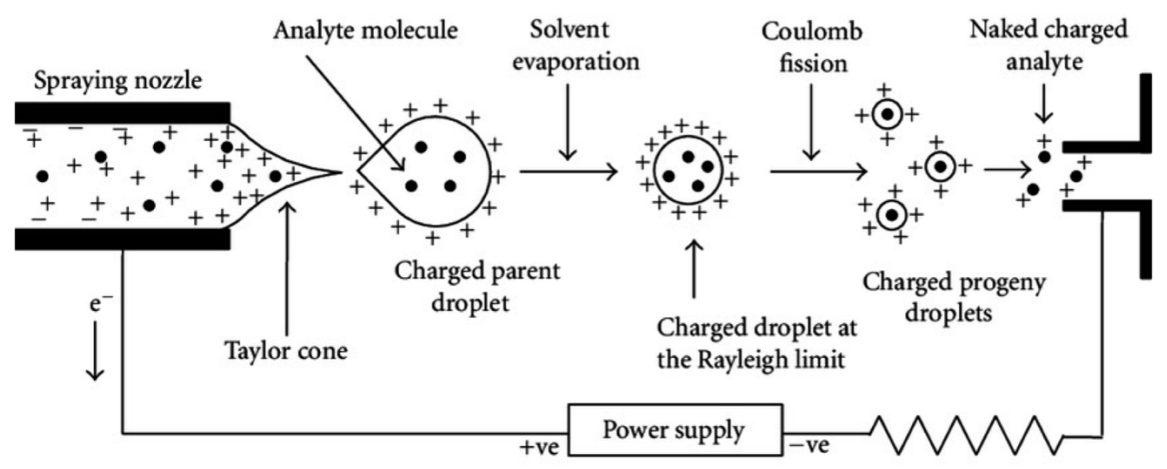

Figure 1.10. Electrospray ionization process.

Schematic representation of the electrospray ionization process. Figure taken from [79].

\section{Identification and quantitative information in LC-MS}

For identification, peptides are detected by the mass spectrometer and selected for identification by fragmentation based on their intensities using tandem mass spectrometry (MS/MS). Tandem mass spectrometry works as following: a precursor ion of a specific mass-to-charge ratio is selected (MS1) by the first mass analyzer, then fragmented (MS2) to generate product ions that are separated by a second mass analyzer before detection. Fragmentation of gas-phase ions can be performed in many various ways such as in-source 
fragmentation, collision-induced dissociation, electron capture, and transfer methods etc... This results in different types of fragmentation and thus in different information about the structure and the composition of the molecule. In the case of peptides, this fragmentation produces different types of fragment ions depending on the site of cleavage. Fragments containing the Nterminus are called a, b, c while fragments containing the $\mathrm{C}$-terminus are

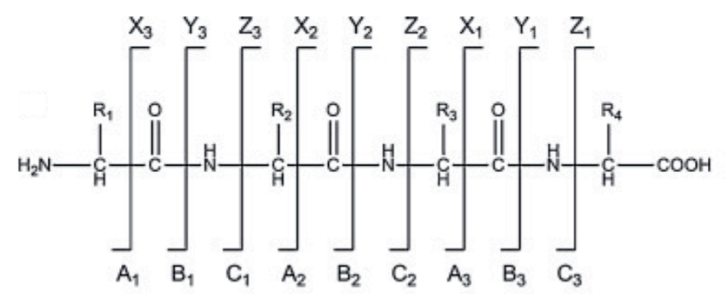

labeled x, y or z (Figure 1.11) ${ }^{[90]}$.

Figure 1.11. Nomenclature for peptide fragments.

Peptide fragment ions are indicated by $\mathrm{a}, \mathrm{b}$ or $\mathrm{c}$ if the charge is retained on the $\mathrm{N}$-terminus and by $\mathrm{x}, \mathrm{y}$ or $\mathrm{z}$ if the charge is retained on the $\mathrm{C}$-terminus. Figure taken from [80].

In this thesis, collision-induced dissociation was employed, this method produces mainly $\mathrm{b}$ and y ions (Figure 1.12) ${ }^{[91]}$.

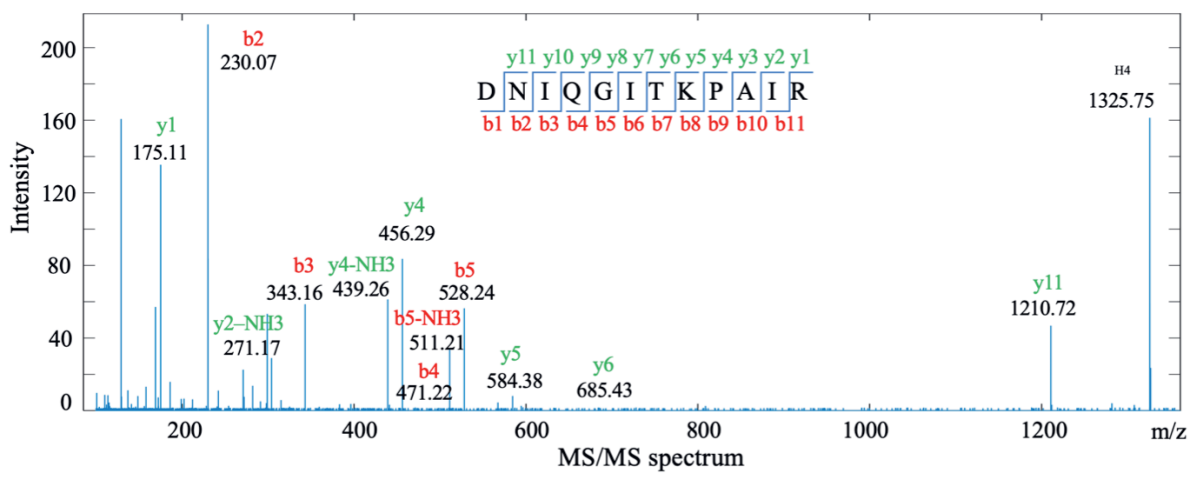

Figure 1.12. MS/MS spectrum of Histone $\mathrm{H} 4$ peptide.

Collision-induced dissociation fragmentation spectra of the peptide histone H4 (DNIQGITKPAIR.

These ions are then used as inputs for database search to identify their sequences. Finally, the identified peptides are assembled and compared to protein sequences stored in databases. 
LC-MS analyses have also the advantage to provide label-free quantitative information, i.e. to enable relative protein quantification without isotopic labels for inter-sample comparisons. Therefore, sample preparation becomes easier, cheaper, faster, and applicable to any samples which makes this technique compatible with clinical research workflows since isotopic labeling is limited to cell cultures and animal models. Two different strategies have been developed to provide label-free quantitative proteomics. The first approach is spectral counting which implies a counting and a comparison of the number of peptide fragment spectra (MS/MS) of a protein ${ }^{[92]}$. The second approach consists of the measurement of the chromatographic peak areas corresponding to the peptides/proteins of interest ${ }^{[93]}$.

The identification of peptides requires high mass resolution to avoid contamination of spectral counting by nearby peptides that lead to inaccurate quantification. Moreover, label-free quantification approaches are dependent on the chromatographic method employed up-front. Indeed, the partitioning into fractions is prone to change slightly in the analysis of different samples and thus poses problems in the quantitative calculations. Therefore a new approach has been developed by Cox et al for generic label-free quantification [94]. They introduced a new algorithm called "MaxFLQ" that implements a "delayed normalization" using a dominant population of proteins that do not change drastically between experiments making it suitable for any type of upfront separation of proteins. This enables to compare, to identify and, to quantify thousands of proteins for comparison between samples.

In this thesis, I used quantitative microproteomics in chapter 3 to characterize tumor subpopulations that have been highlighted by MALDI-MSI. This was done with a new state-of-the-art mass spectrometer which uses the Parallel Accumulation Serial Fragmentation (PASEF) technology. This technology, combined with ion mobility separation (TIMS), enables to synchronize the quadrupole with the elution time of the TIMS for high-speed MS/MS acquisitions (up to $100 \mathrm{kHz}$ ) which allows obtaining a high number of identifications with label-free quantitative data of thousands of proteins. The same machine also allows performing MSI.

But in order to link microproteomics and MSI, this requires the microdissection of the regions of interest. In order to retain the spatial 
information between MALDI-MSI and the laser microdissection system, a precise coregistration between these two technologies is required, which is addressed by the next chapter. 


\section{Chapter 2}

Precise Co-registration of Mass Spectrometry Imaging,

Histology, and Laser Microdissection-based Omics ${ }^{1}$

${ }^{1}$ F. Dewez, M. Martin-Lorenzo, M. Herfs, D. Baiwir, G. Mazzucchelli, E. De Pauw, R. M. A. Heeren, B. Balluff.

Analytical Bioanalytical Chemistry, 2019. 


\subsection{Abstract}

Mass spectrometry imaging (MSI) is an analytical technique for the unlabeled and multiplex imaging of molecules in biological tissue sections. It therefore enables the spatial and molecular annotation of tissues complementary to histology. It has already been shown that MSI can guide subsequent material isolation technologies such as laser microdissection (LMD) to enable a more in-depth molecular characterization of MSI-highlighted tissue regions. However, with MSI now reaching spatial resolutions at the single-cell scale, there is a need for a precise co-registration between MSI and the LMD.

As proof-of-principle, MSI was performed on a breast cancer tissue and segmentation on the lipid data was performed to detect molecularly distinct segments within its tumor areas. After image processing of the segmentation results, the coordinates of the MSI detected segments were passed to the LMD system by three co-registration steps. The errors of each co-registration step were quantified and the total error was found to be less than 13 micrometers. With this link established, MSI data can now accurately guide LMD to excise MSI-defined regions of interest for subsequent extract-based analyses. In our example, the excised tissue material was then subjected to ultrasensitive microproteomics in order to determine predominant molecular mechanisms in each of the MSI highlighted intratumor segments.

This work shows how the strengths of MSI, histology, and extract-based omics can be combined to enable a more comprehensive molecular characterization of in situ biological processes. 


\subsection{Introduction}

Mass spectrometry imaging (MSI) is a powerful tool for the non-labelled and parallel imaging of hundreds to thousands of molecules in a single biological tissue sections. It allows obtaining cell-type specific molecular patterns and conversely the annotation of tissues based on their molecular profiles ${ }^{[95]}$. The latter capability has, for instance, been used for the chemical and spatial description of tumors to reveal molecularly distinct tumor cell populations [96].

Image co-registration has already performed in MSI. This has enabled researchers increasing the MSI resolution mathematically, to fuse 3D MSI data to the MRI space, to align multiple MSI datasets from a single sample, or to guide MSI experiments based on the tissue's morphology [71, 77, 97, 98]. Likewise, few studies have already used MSI to guide laser microdissection (LMD) systems to isolate regions of interest (ROI) from the target tissue, but no information on the accuracy of spatial co-registration has been evaluated or reported ${ }^{[79,99]}$. Since MSI now routinely reaches a spatial resolution of 10 $\mu \mathrm{m}$ on commercial systems, the co-registration accuracy becomes crucial in order to retain the detailed spatial information provided by MSI in the LMD system.

Here we present an accurate co-registration (considering the currently achievable spatial resolution) of MSI to LMD on the same tissue section and after hematoxylin and eosin staining. We will show how this system can be used to comprehensively and accurately characterize tumor subpopulations defined by MSI, using subsequent microproteomics.

\subsection{Experimental section}

\section{Tissue material}

Residual (fresh) breast cancer tissue was collected by the Tissue Biobank of the University of Liege, directly frozen in liquid nitrogen and then stored at $80^{\circ} \mathrm{C}$. The standardized protocol was approved by the Ethics Committee of the University Hospital Center of Liege. Informed consent was obtained from the participant included in this study. A cryo-section of $12 \mu \mathrm{m}$ thickness was thaw-mounted on a polyethylene naphtalate (PEN) membrane slide (Leica Microsystems, Wetzlar, Germany) and stored at $-80^{\circ} \mathrm{C}$ until analysis. 


\section{Mass spectrometry imaging}

All solvents, if not stated otherwise, were purchased from Biosolve (Dieuze, France). First the membrane slide was desiccated for $30 \mathrm{~min}$ at room temperature. Several fiducial markers were applied next to the tissue using water-based Tipp-Ex (BIC, Paris, France) for later co-registration purposes. $5 \mathrm{mg} / \mathrm{ml} \alpha$-cyano-4-hydroxycinnamic acid (Sigma Aldrich, St. Louis, MO, USA) in $70 \%$ acetonitrile and $0.2 \%$ trifluoroacetic acid was sprayed in eight layers using an HTX-TM sprayer (Chapel Hill, NC, USA) onto the tissue section with a constant flow rate of $0.1 \mathrm{ml} / \mathrm{min}$ and at a speed of 1300 $\mathrm{mm} / \mathrm{min}$. The breast cancer section was measured with a MALDI HDMS SYNAPT G2-Si (Waters, Manchester, UK) which is compatible with nonconductive PEN membrane slides. The experiment was performed in positive mode and at $70 \mu \mathrm{m}$ spatial resolution within a mass range of $\mathrm{m} / \mathrm{z} 350-1600$ in which mostly lipids are detected. Red phosphorus was used for external calibration.

\section{Staining and optical images}

Directly after the MSI experiment a digital high-resolution image of the slide with matrix was obtained with a microscopic slide scanner (Mirax Desk, Zeiss, Jena, Germany), subsequently referred to as the optical image.Then the matrix was removed with 70\% ethanol and stained for hematoxylin and eosin (H\&E) used as standard protocol (Milli-Q water: $3 \mathrm{~min}$, hematoxylin: $90 \mathrm{~s}$, tap water: $3 \mathrm{~min}$, eosin: $30 \mathrm{~s}$, tap water: $3 \mathrm{~min}, 100 \%$ ethanol: $1 \mathrm{~min}$, xylene: $30 \mathrm{~s})$. The H\&E stained tissue section was not covered with a coverslip but immediately scanned with the same microscopic slide scanner and stored at $80^{\circ} \mathrm{C}$ until LMD. This resulted in a digital optical image, subsequently referred to as the H\&E image. Both digital high-resolution images were downscaled 1:4 for better handling using the scan viewer software (Pannoramic Viewer, 3DHISTECH Ltd., Budapest, Hungary) which resulted in a pixel size of $2.076 \mu \mathrm{m}$ for $\mathrm{x}$ and $2.084 \mu \mathrm{m}$ for $\mathrm{y}(12,235 \mathrm{x} 12,189 \mathrm{dpi})$.

\section{Co-registration, data analysis and image processing}

These images were imported together with the MSI data into Matlab R2017b (MathWorks, Natick, MA, USA) for co-registration of the images (MSI, optical and H\&E; Figure 2.1), data analysis, and image processing with the Image Processing toolbox (v.10.1). All image co-registrations were 
performed using affine geometric transformation (command fitgeotrans). Every spectrum of the MSI data was normalized to its total ion current. Tumor-associated spectra were clustered using non-negative matrix factorization (NNMF) where each pixel is assigned to the component with the highest score. After image processing of the segmentation results (ESM, Figs. S3 and S4), the coordinates of the regions belonging to the segments were recalculated with respect to the coordinates of the fiducial markers in the optical image and written into an XML file for compatibility with subsequent LMD system.

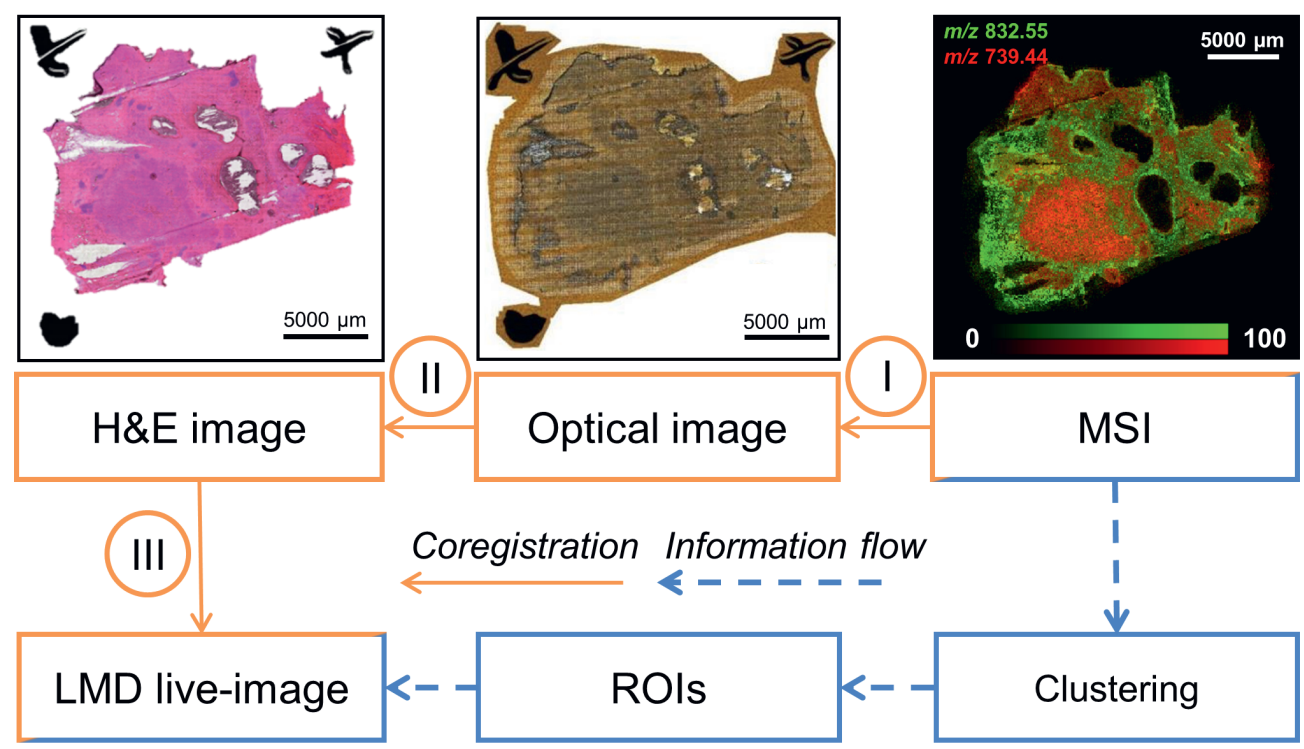

Figure 2.1. Co-registration steps from mass spectrometry imaging (MSI) to laser microdissection (LMD).

Several co-registration steps are needed in order to transfer spatial information from MSI to the LMD system (orange arrows). First, the MSI data was co-registered to the high-resolution optical image of the tissue section via the visible laser shots in the matrix (Supplementary Figure 1) directly after the MSI experiment (I). The optical image was then further matched to its high-resolution H\&E image via fiducial markers (II). Finally, coordinates in the H\&E image were recalculated using fiducial markers that are both visible in the H\&E image and in the LMD live image (III). The established link between MSI, histology, and LMD allows transferring region-of-interest information from MSI, for instance spatial segments 
identified by a multivariate clustering of the spectra, to the LMD system (blue-dashed arrows).

\section{Laser microdissection}

Laser microdissection was performed using a Leica LMD 7000 (Leica Microsystems, Wetzlar, Germany). This system supports the import of external coordinate information of areas to be cut out in form of an XML file. Areas were dissected from the H\&E stained tissue sections with the following settings: wavelength: $349 \mathrm{~nm}$, power: 20 , aperture: 45 , speed: 15 , specimen balance: 0 , head current: $100 \%$, and pulse frequency: $501 \mathrm{~Hz}$. The microdissected regions were collected in $0.5 \mathrm{ml}$ centrifuge tubes and stored at $-80^{\circ} \mathrm{C}$ until further analysis.

\section{Microproteomics analysis}

For every MSI-segment, a total of $0.3 \mathrm{~mm}^{2}$ dissected material was prepared and analyzed by an optimized LC-MS/MS protocol for bottom-up proteomics of very small samples ( 2000 cells) using an ultra-performance liquid chromatography (UPLC) 2D nanoAcquity (Waters, Corp., Milford, USA). This was done as described previously ${ }^{[100]}$, but without paraffin removal and antigen retrieval due to the use of fresh frozen tissue sections.

Protein identification and label-free quantification (LFQ) were performed using MaxQuant v.1.5.6.5 with the following settings: Uniprot reviewed human database, trypsin digestion with maximum two missed cleavage sites, methionine oxidation as variable modification and carbamidomethyl cysteine as fixed modification, a minimal peptide length of seven amino acids, at least two peptides per protein (of which at least one is unique), and a maximum false discovery rate of $1 \%$. The label-free intensities were normalized using the MaxLFQ algorithm ${ }^{[94]}$.

Data analysis was performed with Perseus v.1.6.2.2 ${ }^{[101]}$. Proteins identified as 'reverse', 'only identified by site' or 'potential contaminants' hits were removed. The LFQ intensities were $\log 2$-transformed and z-scored before performing a hierarchical clustering of the proteins with the following settings: Euclidean distance, complete linkage, based on a preprocessing with k-means with 300 clusters, 10 iterations and 1 restart. Under- and overexpressed proteins were selected based on z-scores being exclusively $\leq$ - 
1 or $\geq+1$, respectively. The gene IDs corresponding to the under- and overexpressed proteins were then imported into the PANTHER v.13.1 gene ontology classification system ${ }^{[102]}$.

\subsection{Results and discussion}

The aim of this study is to create a pipeline where MSI data is used to accurately guide the LMD system for further analysis on the very same tissue section with potential applications in biomedical research. This pipeline consists in several steps which are listed in the supplementary information 1.

\section{MSI of breast cancer tissue}

MSI of lipids was performed on a fresh-frozen breast cancer tissue section, which was mounted onto an LMD-compatible membrane slide to be able to use the same section for MSI and LMD. We used a high-pressure MALDI mass spectrometer, which leaves most of the membrane unaffected and therefore usable by an LMD system. Three co-registration steps had to be performed to couple the obtained MSI data to the LMD system (Figure 2.1).

\section{Co-registration of MSI and LMD}

The first step consisted of co-registering the MSI data to the high-resolution optical image of the tissue with matrix (Figure 2.1, I). To be most accurate and overcome limitations in vendor-shipped software, this was achieved by directly matching the coordinates of three manually selected MSI pixels with their corresponding visible laser-shot landmarks in the optical image (Supplementary Figure 1a). An affine geometric transformation was derived from these points and used to transform all MSI pixels into the coordinate system of the optical image (and vice versa). The co-registration error was estimated by counting the number of pixels in the optical image $(\sim 2 \mu \mathrm{m})$ from the center of the laser shot landmark to the corresponding MSI pixel (Supplementary Figure 1b). The error was on average $7.9 \mu \mathrm{m}$ in $\mathrm{x}$ and $4 \mu \mathrm{m}$ in y (Table 1).

\begin{tabular}{|c|c|c|c|c|}
\hline $\begin{array}{c}\text { Co- } \\
\text { registration } \\
\text { of ... }\end{array}$ & $\begin{array}{c}\ldots \text { Optical } \\
\text { image }- \\
\text { MSI data }\end{array}$ & $\begin{array}{c}\ldots \text { Optical } \\
\text { image }-\end{array}$ & $\begin{array}{c}\text {.. Optical } \\
\text { image }- \text { LMD }\end{array}$ & $\begin{array}{c}\text { Maximum } \\
\text { error } \\
\text { (assuming }\end{array}$ \\
\hline
\end{tabular}




\begin{tabular}{|c|c|c|c|c|}
\hline & & $\begin{array}{c}\text { H\&E } \\
\text { image }\end{array}$ & $\begin{array}{c}\text { (magnification } \\
\mathbf{5 x})\end{array}$ & $\begin{array}{c}\text { additive } \\
\text { effects) }\end{array}$ \\
\hline $\begin{array}{c}\text { Error in } \mathbf{X} \\
(\boldsymbol{\mu m})\end{array}$ & $\begin{array}{c}7.89 \pm 4.06 \\
\mathrm{SD}\end{array}$ & $\begin{array}{c}1.39 \pm 0.33 \\
\mathrm{SD}\end{array}$ & $3.46 \pm 2.62 \mathrm{SD}$ & $\begin{array}{c}12.74 \pm 4.84 \\
\mathrm{SD}\end{array}$ \\
\hline $\begin{array}{c}\text { Error in } \mathbf{Y} \\
(\boldsymbol{\mu m})\end{array}$ & $\begin{array}{c}3.96 \pm 4.32 \\
\mathrm{SD}\end{array}$ & $\begin{array}{c}1.39 \pm 0.50 \\
\mathrm{SD}\end{array}$ & $7.39 \pm 3.78 \mathrm{SD}$ & $\begin{array}{c}12.74 \pm 5.76 \\
\mathrm{SD}\end{array}$ \\
\hline
\end{tabular}

Table 1. Co-registration errors.

Abbreviations used: MSI, mass spectrometry imaging; LMD, laser microdissection; H\&E, hematoxylin and eosin; SD, standard deviation.

The second co-registration needed is between the optical and the H\&E image in order to incorporate the histological information into the data analysis (Figure 2.1, II). The manual selection of three control point pairs was based on the same features of the fiducial markers in both optical images, which enabled the creation of an affine geometric transformation. The manual selection of co-registration points induces an error which was estimated by performing five manual co-registrations of the optical image with itself and calculating the average of the Euclidean distances between all original and transformed positions. The average error was $1.4 \mu \mathrm{m}$ for both $\mathrm{x}$ and $\mathrm{y}$ (Table $1)$.

The fiducial markers were also used to translate coordinates from the optical image to the coordinate system of the LMD (Figure 2.1, III). Three landmark points were manually selected in the optical image for this purpose. One of these is used as origin point, which means that all other coordinates belonging to the two remaining landmarks and the regions of interest (ROIs) are recalculated with respect to that reference point. These new coordinates were then written into an XML file to import the ROIs into the LMD software. During the import process, the exact same teaching points, previously defined in the optical image, had to be selected in the LMD live image of the slide. The error of this co-registration step was estimated by comparing expected and observed distances between cut coregistered shapes and micrometersized Tipp-Ex spots $(\sim 3 \mu \mathrm{m})$ in the LMD live image (Supplementary Figure 2). The average error was $3.5 \mu \mathrm{m}$ in $\mathrm{x}$ and $7.4 \mu \mathrm{m}$ in y (Table 1). The error was evaluated at $5 \mathrm{x}$ magnification which corresponds to the lowest 
magnification level of the LMD. While this magnification enables a large field of view, which was necessary for the co-registration, it also provides the lowest detail level for matching the previously selected landmarks in the optical image to their representations in the LMD live image.

Important to mention that in all co-registration steps the teaching points were selected manually which influences the alignment quality of both coregistered objects. Moreover, the estimation of the reported errors in the optical images was based on visual evaluation which also introduces bias and error. We addressed this issue by repeating each co-registration at least three times (Table 1).

In summary, the co-registration error for each step was below $10 \mu \mathrm{m}$. We note that these errors could be reduced by using a higher magnification in the LMD (Supplementary Table 1) or a higher resolution of the optical images (Supplementary Table 2). We also want to point out that the reported errors are control point based and do not account for additional errors due to morphological deformations during histological staining. We expect that powerful elastic image registration using the tissue's own features, which must therefore be clearly visible in highly resolved MSI images, could decrease these detrimental effects ${ }^{[103]}$. Although it is not possible to evaluate if the errors in the three steps are additive or subtractive, we expect the coregistration error to be below 13 micrometers in both dimensions, considering additive error components (Table 1).

\section{Detection of molecular distinct tumor populations by MSI}

In this study, the usefulness and feasibility of the established MSI-LMD link is demonstrated by the investigation of intra-tumor heterogeneity in a breast cancer sample.

In order to investigate intra-tumor heterogeneity, a pathologist first delineated the tumor areas in the H\&E stained tissue section (Figure 2.2a). For high accuracy, these annotations were done on the high-resolution image in the scan viewer software (Pannoramic Viewer, 3D Histech). The annotations and the H\&E image were then imported into Matlab and coregistered to the MSI data. This allows exclusive selection of tumor specific MSI data. 

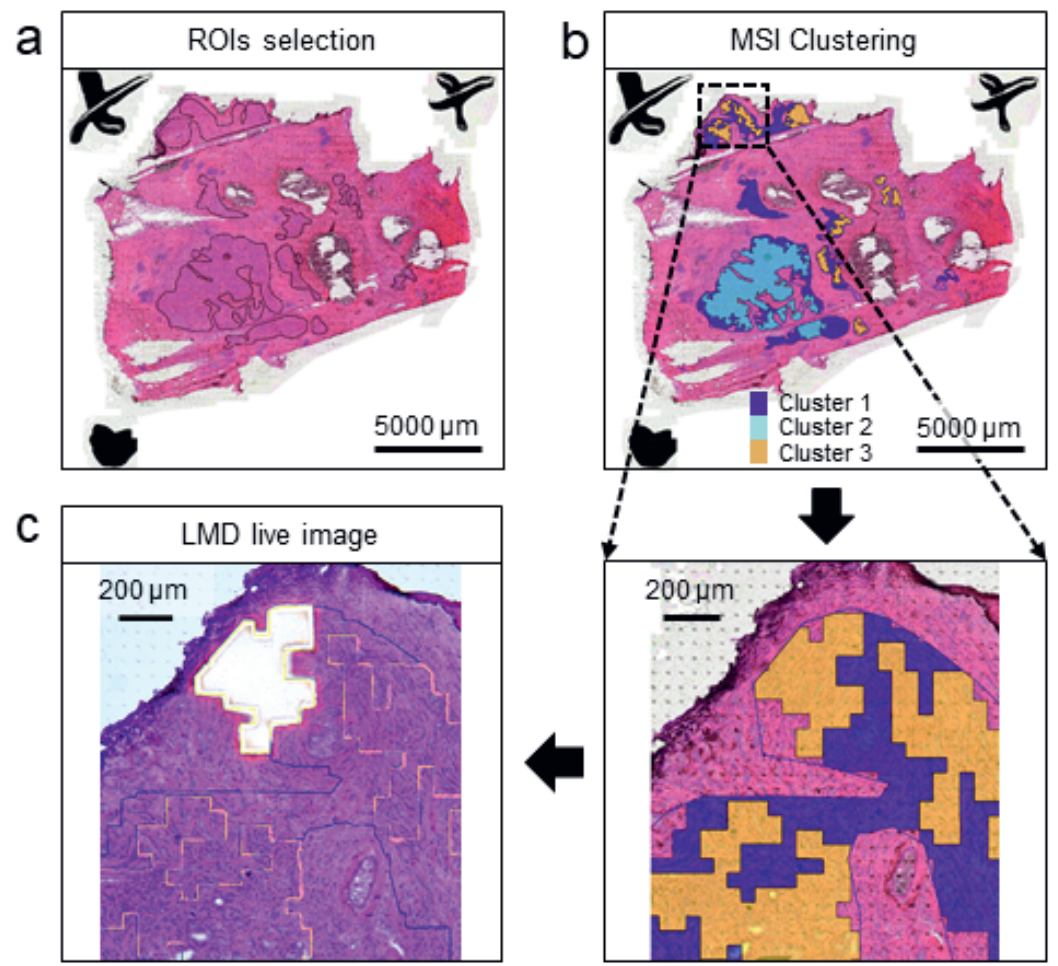

c
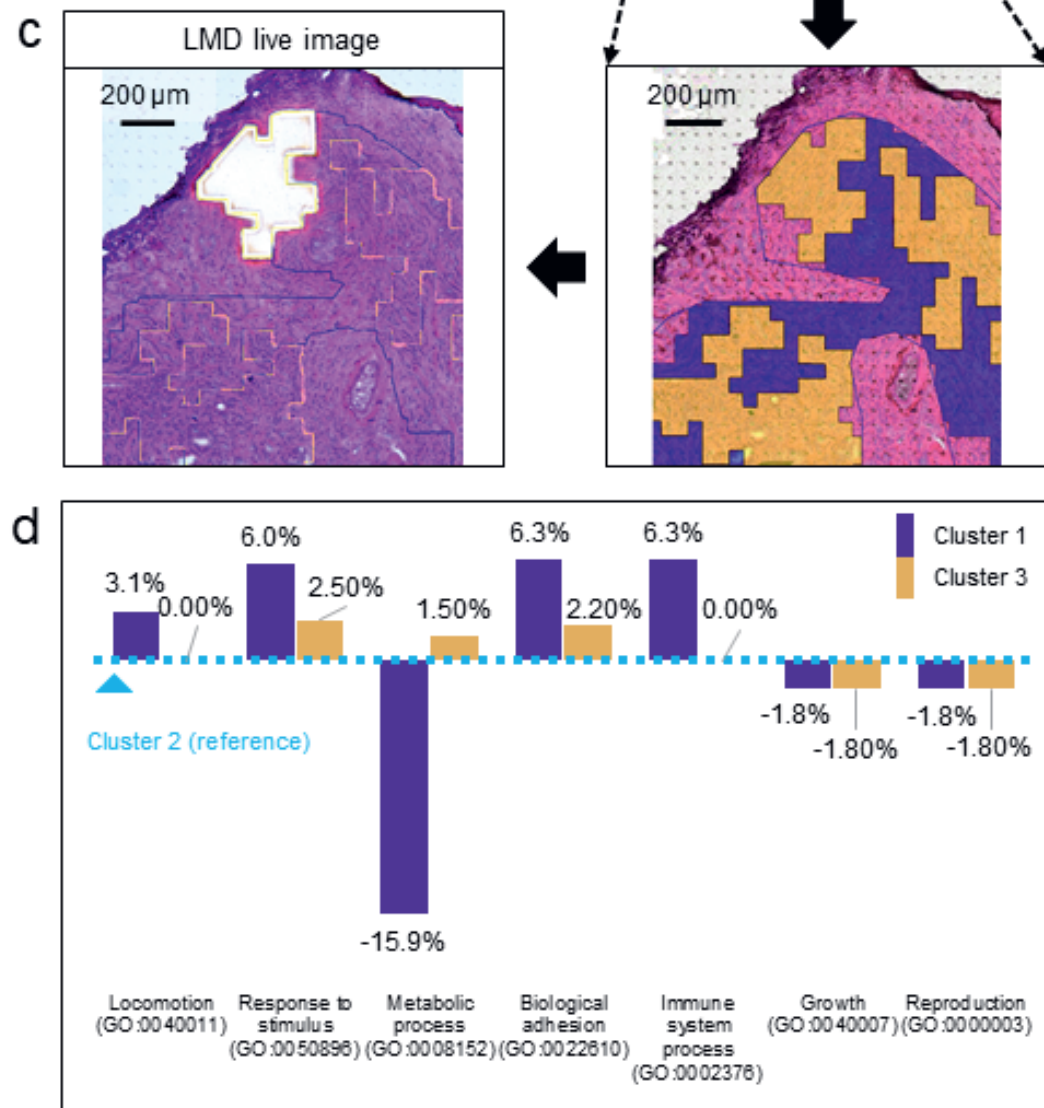

Figure 2.2. Laser microdissection of MSI-defined intratumor segments subsequently characterized by microproteomics.

(a) First, tumor areas were annotated by a pathologist on the H\&E image. (b) Then, mass spectrometry imaging (MSI) lipid data of the tumor was used to 
spatially segment the tumor areas into three clusters using non-negative matrix factorization. After image processing of the segments including smoothing and boundary detection (Supplementary Figure 3 and 4), the segmentation image was upscaled to the resolution of the H\&E image. (c) The segments' boundaries were finally transferred to the LMD software using the previously established co-registration pipeline. Each MSI cluster was then microdissected by the LMD system for the subsequent microproteomics analysis. This resulted in the identification and label-free quantification of over 1000 common proteins. Cluster exclusive over- and under-expressed proteins were submitted to gene ontology analysis (Supplementary Figure 5). (d) shows selected differences in molecular functions between the clusters (in percentage points with respect to cluster 2).

As previously demonstrated, unsupervised multivariate analysis can be used to reveal intra-tumor heterogeneity through MSI-based tissue segmentation ${ }^{[96]}$. Here, the tumor areas were partitioned applying the NNMF algorithm to the MSI data. The average Silhouette coefficient was maximized in order to determine the optimal number of segments. In a range from two to five, the optimal number of segments was found to be three (Supplementary Table 3).

Image processing was performed on the segmentation results in order to increase the practicability of microdissection. This included at first a smoothing of the segmentation image using the imopen Matlab function with a $2 \times 2$ square as structuring element (Supplementary Figure 3). The segmentation image was then divided into three binary images, each depicting the pixels belonging to one of the segments, and which were further processed individually (Supplementary Figure 4). This included the removal of impurities within the binary image by deleting small areas $(\leq 30$ pixels in the 4-connected neighborhood) using bwareaopen and filling holes in the 8connected neighborhood using imfill (Supplementary Figure 4). The individual binary images were then warped to the dimensions of the histological image using imwarp with nearest-pixel interpolation (Figure $2.2 \mathrm{~b}$ ). Once upscaled, the last step of the image processing was to detect the external boundaries of all regions belonging to a segment using bwboundaries (Supplementary Figure 4). Finally, the boundary coordinates of each MSI 
segment were recalculated with respect to the selected origin point present in the optical image and were used to generate the XML file in the LMDcompatible importat format.

\section{Laser microdissection and microproteomics characterization of MSI segments}

The ROIs were available and visible in the field of view of the LMD software after import of the MSI-based ROI information into the LMD system (Figure 2.2c). These ROIs were then micro-dissected (Figure 2.2c) and collected into tubes for a further molecular characterization of the different tumor cell populations represented by the MSI segments using quantitative 2D-LCMS/MS microproteomics.

A total of 1426 common proteins were identified among the MSI segments (Supplementary Table 4). After LFQ normalization, log2-transformation and standardization, 1040 proteins remained to characterize the molecular properties of the different tumor subpopulations (Supplementary Table 5). As expected when analyzing samples from the same tissue section, few proteins (on average 25.3) were found exclusively up- or downregulated in each MSI segment when using a $\mathrm{z}$-score threshold of +1 and -1 , respectively (Supplementary Figure 5a). The subsequent functional annotation based on those proteins showed that the three MSI segments mainly differed from each other in processes related to metabolic processes, biological adhesion, immune system process, response to stimulus, and locomotion (Figure $2.2 \mathrm{~d}$ and Supplementary Figure 5b). The observation of functional differences between the different tumor regions confirms the presence of molecular and functional intra-tumor heterogeneity in this breast cancer sample.

\subsection{Conclusion}

Mass spectrometry imaging (MSI) continues its development toward higher spatial resolution and cellular sensitivity but still lacks chromatographic separation to eliminate ion suppression. A transfer of spatial MSI information to a laser microdissection (LMD) system for the targeted isolation of cellular material followed by bottom-up proteomics must be correspondingly 
accurate. As MSI systems nowadays achieve resolutions around 10 micrometers, co-registration errors should ideally not be larger than a few MSI pixels. Here we achieved an accurate coupling of MSI to LMD with coregistration errors on a single MSI pixel level, namely below 13 micrometers. While here we focused on microproteomics experiments, the excised samples could be analyzed by any other omics technology compatible with MSI. Our approach ultimately brings together spatial and molecular information for a better understanding of in situ molecular mechanisms in complex tissues.

\section{Acknowledgments}

This research was financially supported in part through the LINK program of the Province of Limburg (The Netherlands). FD acknowledges the support of the Joint Imaging Valley program of the University of Liège and the Maastricht University. MML acknowledges the financial support of the European Union (ERA-NET TRANSCAN 2; Grant No. 643638). 
54 Chapter 2 - Precise co-registration of Mass Spectrometry Imaging 


\section{Chapter 3}

MS Imaging-guided Microproteomics for Spatial Omics on a

Single Instrument ${ }^{1}$

${ }^{1}$ F. Dewez, J. Oejten, C. Henkel, R. Hebeler, H. Neuweger, E. De Pauw, R. M. A. Heeren, B. Balluff. Proteomics, 2020. 


\subsection{Abstract}

Mass spectrometry imaging (MSI) allows investigating the spatial distribution of chemical compounds directly in biological tissues. As the analytical depth of MSI is limited, MSI needs to be coupled to more sensitive local extraction-based omics approaches to achieve a comprehensive molecular characterization.

For this it is important to retain the spatial information provided by MSI for follow-up omics studies. It has been shown that regiospecific MSI data can be used to guide a laser microdissection system (LMD) for ultra-sensitive LCMS analyses. So far, this combination has required separate and specialized MS instrumentation. Recent advances in dual-source instrumentation, harboring both MALDI and ESI sources, promise state-of-the-art MSI and liquid-based proteomic capabilities on the same MS instrument.

In this study, we demonstrate that such an instrument can offer both, fast lipidbased MSI at high mass- and high lateral resolution, and sensitive LC-MS on local protein extracts from the exact same tissue section.

\section{Abbreviations}

LFQ: Label-Free Quantification

LMD: Laser Microdissecton

MSI: Mass Spectrometry Imaging

PASEF: Parallel Accumulation-Serial Fragmentation

PC: Phosphatidylcholine

PCA: Principal component analysis

PC1: Principal Component 1

PC2: Principal Component 2

PEN: Polyethylene Naphtalate

SM: Sphingomyelin

TIMS: Trapped Ion Mobility Spectrometry

\subsection{Introduction}

Omics technologies are powerful approaches to comprehensively gather molecular information from biospecimens. There is a common trend in all omics fields to move towards spatially-aware analyses to better understand 
how cells work and behave molecularly in the neighborhood of other cells $[104,105]$.

Mass spectrometry imaging (MSI) is an omics technique that offers spatially resolved molecular analyses of tissues with high-throughput and high spatial resolution down to the single-cell level ${ }^{[106]}$. The fact that it does not need labeling of the molecules has facilitated the annotation of tissues beyond histology ${ }^{[107]}$. This unique capability is challenged by the limited analytical depth of MSI due to the absence of chromatographic separation which leads to a limited molecular characterization caused by local ion suppression ${ }^{[52]}$.

To obtain deeper insights into the local biochemical processes, MSI needs to be complemented with a more sensitive liquid-based approach such as liquid chromatography-mass spectrometry (LC-MS). Recently, matrix-assisted laser desorption/ionization (MALDI)-MSI has been used to guide a laser microdissection system (LMD) to dissect regions highlighted by MSI for their subsequent proteomic analysis by LC-MS [72, 79, 99].

The coupling of these two technologies necessitates optimal instrumentation capabilities for every component of the pipeline. State-of-the-art MSI instrumentation needs to provide fast acquisition rates at high mass and high spatial resolution, whereas the LC-MS system needs to provide high sensitivity from minute amounts of material since the microdissected regions can be very small (in the sub- $\mathrm{mm}^{2}$ scale). This has so far required specialized and therefore separate instrumentation.

Recent advances in MS instrumentation, however, promise to perform both state-of-the-art MALDI-MSI and LC-MS experiments on a single instrument. In this study, we use a hybrid-source system (timsTOF fleX, Bruker Daltonik, Bremen, Germany), which is equipped with a $10 \mathrm{kHz}$ MALDI laser for rapid MSI and an orthogonal electrospray source. The latter combines ion mobility separation (TIMS), which separates and accumulates ions for high-sensitivity, with the Parallel Accumulation Serial Fragmentation (PASEF) technology which synchronizes the quadrupole with the elution time of the TIMS for high-speed MS/MS acquisitions (up to $100 \mathrm{kHz}$ ) ${ }^{[108]}$. 
The aim of this study is to bring together the spatial molecular information provided by MALDI-MSI with the microproteomic characterization by LCMS on the exact same tissue section via LMD, which has never been performed on a single instrument before. This workflow is depicted in Figure 3.1 .

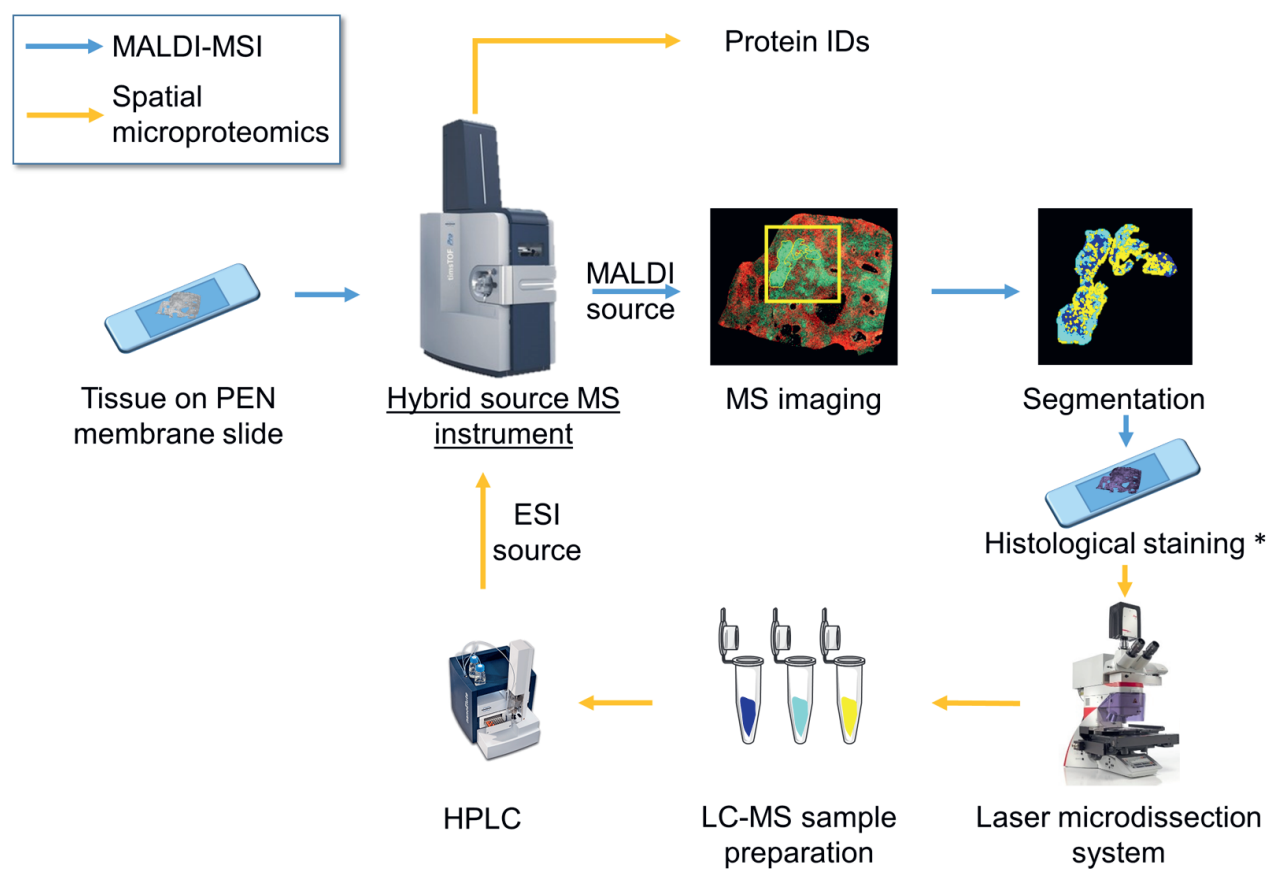

Figure 3.1. Spatial omics workflow on a single MS instrument.

A tissue section is mounted onto a PEN (Polyethylene Naphtalate) membrane slide. After matrix application, MS imaging (MSI) is performed. Multivariate clustering of the MSI spectra results in different spatial segments (here shown as blue, yellow, cyan) whose outlines can be accurately transferred to a laser microdissection (LMD) system done via a precise image registration of the optical image of the stained* sample with the MSI data and the live-view image in the LMD. This enables the microdissection of the segments whose material is then processed and submitted to HPLC-MS analysis resulting in the identification of proteins on the same instrument. *optional.

\subsection{Experimental section MALDI preparation}


First, MALDI-MSI was performed on a $12 \mu \mathrm{m}$-thick section from a breast cancer sample, which was collected by the Tissue Biobank of the University of Liège. The consent form was obtained from the involved patient and the study was approved by the Ethics Committee of the University Hospital Center of Liège. Importantly, the section was mounted on a PEN (Polyethylene Naphtalate) membrane slide, which is compatible with the employed MSI system and required for the later laser microdissection.

The section was dried in a desiccator for 30 minutes at room temperature before being coated with norharmane $(7 \mathrm{mg} / \mathrm{ml}$ in 2:1 Chloroform: methanol) for lipid MSI using the TM-sprayer (HTX technologies, Chapel Hill, NC, USA) with the following parameters: 12 layers, flow rate $=0.120 \mathrm{ml} / \mathrm{min}$, velocity $=1200 \mathrm{~mm} / \mathrm{min}$, and nozzle temperature $=30^{\circ} \mathrm{C}$. The MSI measurement was performed in positive ion mode at $50 \mu \mathrm{m}$ spatial resolution within a mass range of $m / z 300-1600$ at 25 pixels/second. After the MSI experiment, the sample was rinsed in $70 \%$ ethanol to remove the matrix and stained with only hematoxylin. After scanning of the slide with a highresolution scanner (M8 scanner, Freising, Germany), the tumor area was delineated by a trained pathologist.

\section{Data analysis}

The MSI data was loaded into SCilS Lab 2020a (Bruker Daltonik) for coregistration to the annotated histological image. Peak picking was performed on the exported average spectrum in mMass (v.5.5.0) with a minimum signal-to-noise threshold of three, a minimum relative basepeak intensity of $0.02 \%$, and a picking height of 80 . The annotated area was segmented by k-means clustering using all 994 peaks into three subpopulations that are not distinguishable on a histological level (Figure 3.2A-2B).

As the segmentation provides fine structures that are not easily processable by the LMD, the segmentation image needs to undergo image processing in Matlab R2018a (Math Works, Natick, MA, USA) as previously reported by us (Figure 3.2B) ${ }^{[72]}$. First, a smoothing with a neutral-density filter (imfilter) and a square filter of size $2 \times 2$ was accomplished providing smooth cutting lines to the LMD (Figure 3.2C). Although the LMD is able to dissect single cells, the vast number of small objects encountered (here 92 with less than 30 
pixels) makes a dissection infeasible. Small objects were therefore removed and assigned to the surrounding cluster (filling holes) (Figure 3.2D-2E). After up-scaling of the detected boundaries to the resolution of the optical image, the coordinates were transferred to the LMD software via an XML file (Figure $2 \mathrm{~F}-2 \mathrm{G}-2 \mathrm{H})$. The coregistration was performed using fiducial markers placed onto the slide prior to the MSI experiment and visible in the LMD system (Leica LMD 7000, Leica microsystems, Wetzlar, Germany).

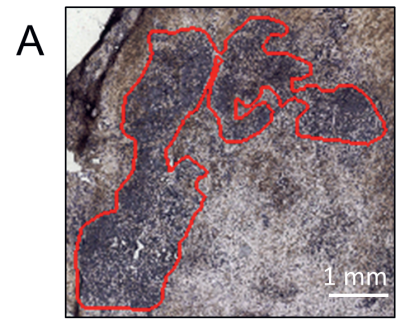

Tumor annotation

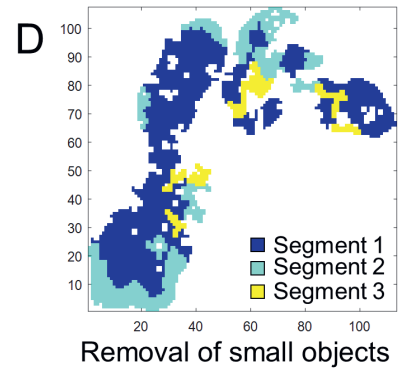

$\mathrm{G}$

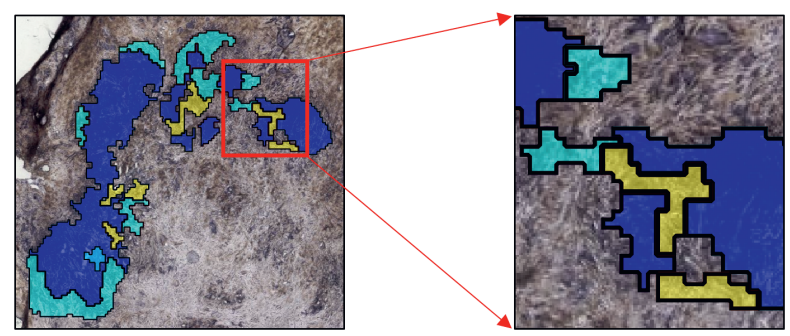

Upscaling to optical image resolution

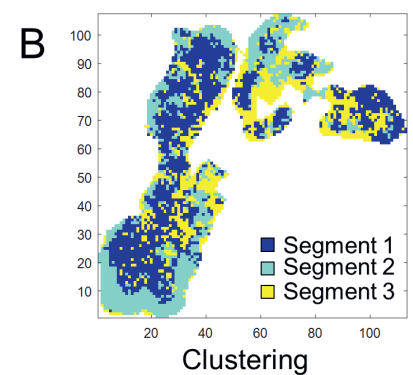

E

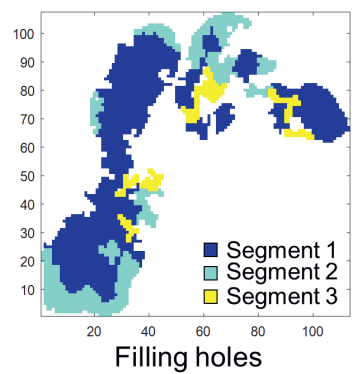

Figure 3.2. Image processing of mass spectrometry imaging data before laser

C

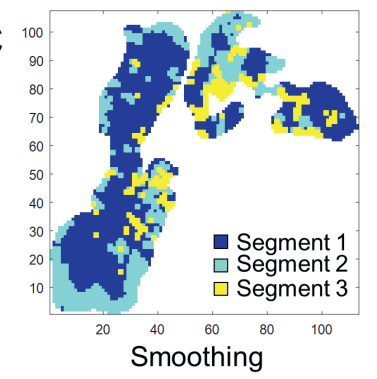

$\mathrm{F}$

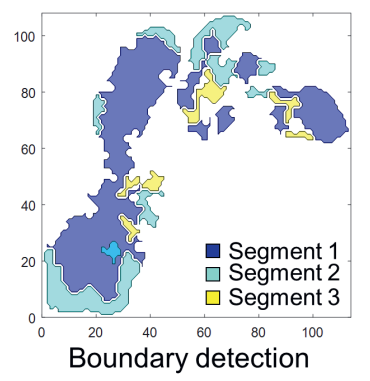

$\mathrm{H}$

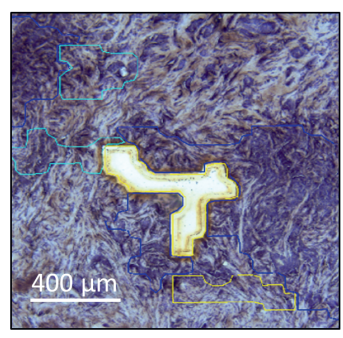

LMD live view microdissection (LMD).

The tumor area of a breast cancer sample was segmented using k-means algorithm (A, B) and these results underwent image processing to enable a viable microdissection of the segments. The image processing consisted of a sequential application of smoothing (C), removal of small objects (D), filling 
holes (E), and boundary detection (F). The boundaries of the segments were upscaled to the resolution of the optical image $(\mathrm{G})$. Finally, the regions belonging to the three segments were accurately coregistered and microdissected in the LMD system $(\mathrm{H})$

\section{LC-MS sample preparation and data analysis}

Three subregions ( 2000 cells) from every segment were randomly selected and microdissected for further analysis (details in Supplementary Information), making a total of 9 samples. These samples were individually prepared for LC-MS as previously described (details in Supplementary Information) ${ }^{[87]}$.

The samples were run in random order on a nanoElute HPLC system (Bruker Daltonik) using a one-column setup equipped with an Aurora $25 \mathrm{~cm} \mathrm{x} 75 \mu \mathrm{m}$ x $1.7 \mu \mathrm{m} \mathrm{C18} \mathrm{column} \mathrm{(IonOpticks,} \mathrm{Parkville,} \mathrm{Australia).} \mathrm{0.1 \%} \mathrm{formic} \mathrm{acid,}$ $2 \%$ acetonitrile in water was used as eluent $\mathrm{A}$ and $0.1 \%$ formic acid in acetonitrile as eluent B. Chromatographic separation of the peptides was carried out over a 100 minute non-linear gradient up to $37 \%$ eluent B at a flow rate of $400 \mathrm{nl} / \mathrm{min}$ and an oven temperature of $50^{\circ} \mathrm{C}$.

The CaptiveSpray nano source was used as inlet into the MS instrument operated with $3.0 \mathrm{~L} / \mathrm{min}$ dry gas at $180^{\circ} \mathrm{C}$ and $1.6 \mathrm{kV}$ capillary voltage. Data were acquired in the mass range of $m / z 100-1700$ and the mobility range was set to $0.6-1.61 / \mathrm{k} 0$. In the dual TIMS cell, the accumulation, as well as the ramp time, were set to $100 \mathrm{~ms}$. For MS/MS fragment spectra acquisition, one MS scan (100 ms) was followed by ten subsequent PASEF scans (each 100 $\mathrm{ms}$ ). The proteomics data has been deposited to the ProteomeXchange Consortium via the PRIDE partner repository with the dataset identifier 'PXD018735, [109].

MaxQuant (v.1.6.10.43) was used for protein identification and label-free quantification (LFQ). Database search was performed using the SwissProt human database (downloaded on February 12, 2020, with 42368 entries including isoforms) with a parent mass tolerance of $20 \mathrm{ppm}$, a fragment mass tolerance of $50 \mathrm{mDa}$, and a FDR $\leq 0.01$. Trypsin was chosen as proteolytic enzyme with a maximum of 2 missed cleavages. Carbamidomethylation of cysteine residues was set as fixed modification, acetylation of protein $\mathrm{N}$ termini and methionine oxidation as variable modifications. The 
identification was first performed on individual replicates providing on average 2000 protein identifications per replicate, giving evidence of the high-sensitivity of the LC-MS setup for the analysis of minute amounts of samples, and then on all three replicates from every segment using the 'matching between runs' feature (Figure 3.3A) (Supplementary Information Table 1). Based on a control tissue experiment of the same region and involving the same number of technical replicates, we observed no detrimental effect of the lipid MSI experiment on the number of identified proteins (Supplementary Information Figure 1). As expected when analyzing samples from the same tissue section, the overlap in identified proteins between the three segments was high with on average only $21.8 \%$ segmentexclusive identifications (Figure 3.3B).

LFQ calculations were performed on all replicates across all segments using the 'matching between runs' feature. Proteins identified as 'reverse', 'only identified by site' and 'potential contaminants', or with one or more zeroLFQ intensities across the replicates were removed from further analysis (Supplementary Information Table 1).

Principal Component Analysis (PCA) was performed on the z-scored and $\log 2$-transformed LFQ intensities in R (v3.6.2) which showed the presence of two molecular distinct segments (Figure 3.3C). PCA was also performed for the MSI lipid data in Matlab R2018a (Figure 3.3D) to identify lipid signals that are particular to each segment. A putative annotation of the 5 loadings with the highest contribution to the PCA was achieved by MetaboScape (v5.0, Bruker Daltonik) using LipidMaps (43,080 entries) with a mass tolerance of $2 \mathrm{mDa}$ (details in Supplementary Information). Putative annotations of $\mathrm{m} / \mathrm{z}$ 786.60, 734.57, 760.58, 788.62, and 703.58 correspond to phosphatidylcholine $\mathrm{PC}(36: 2), \quad \mathrm{PC}(32: 0), \quad \mathrm{PC}(34: 1), \quad \mathrm{PC}(36: 1), \quad$ and sphingomyelin $\operatorname{SM}(34: 1)$, respectively. Amongst these, other MSI studies have found $\mathrm{PC}(32: 0)$ and $\mathrm{PC}(34: 1)$ highly abundant in breast cancer tissues, and $\mathrm{PC}(34: 1), \operatorname{PC}(36: 2)$, and $\mathrm{PC}(36: 1)$ to be related to tumor grades [110]. Using LC-lipidomics, Hilvo et al. have also found high levels of PC(32:0) and $\operatorname{SM}(34: 1)$ to be associated with poor survival, which are lipids present at higher abundance in segment 3 (Figure 3.3D) ${ }^{[111]}$. 
We also performed statistical comparisons using t-tests to identify the most discriminating proteins between segments 1 and 2 versus segment 3. After multiple-testing correction (Benjamini-Hochberg method), 164 proteins were found significantly $(\mathrm{P} \leq 0.05)$ altered (Supplementary Information Table 2). We also found several proteins altered that are related to lipid metabolism. For instance, we observed the two proteins sphingosine-1-phosphate lyase 1 (SGPL1; $\mathrm{P}=0.086$ ), which is known to be increased in cancer ${ }^{[112]}$, and vesicleassociated membrane protein-associated protein $\mathrm{B} / \mathrm{C}(\mathrm{VAPB} ; \mathrm{P}=0.038)$ to be down-regulated in segment 3 . Since these proteins are involved in the breakdown and biosynthesis of sphingolipids, they could be related to the observed higher abundance of certain lipid species in segment 3 , such as $\mathrm{SM}(34: 1)$ (Figure 3.3D). We also observed the phospholipid transfer protein STA10 (STARD10; $\mathrm{P}=0.056$ ), which known to be overexpressed in breast cancers ${ }^{[113]}$, to be up-regulated in segments 1 and 2 compared to segment 3 . This could be related to the higher levels of several phospholipids in segments 1 and 2 such as $\mathrm{PC}(36: 2), \mathrm{PC}(34: 1)$, and $\mathrm{PC}(36: 1)$ (Figure 3.3D). This demonstrates how the presented workflow provides a useful tool to connect different MS-based omics data via the spatial context. 

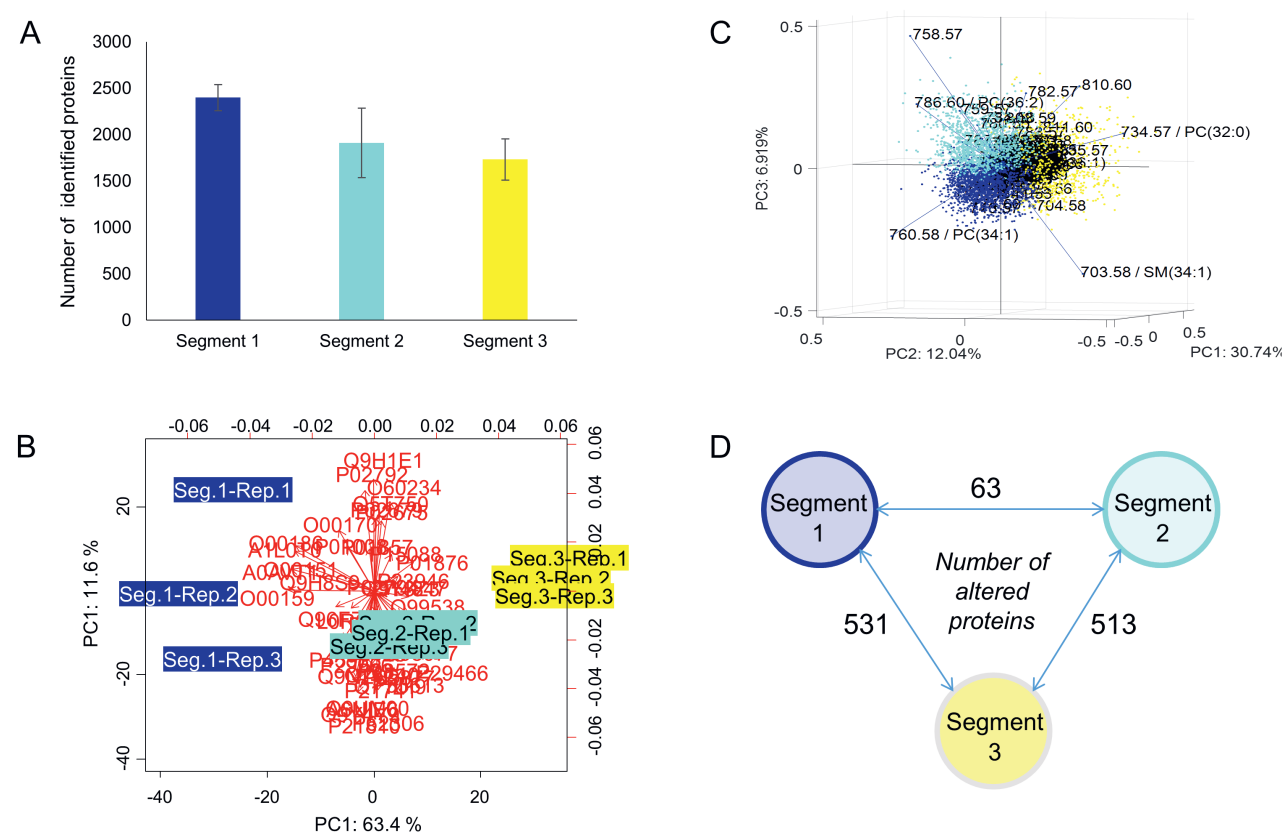

Figure 3.3. Molecular characterization of tumor segments by lipid and microproteomic analysis.

LC-MS of triplicate samples from every segment resulted in the identification of on average 2,000 proteins. Matching between runs feature enabled to identify on average 2500 proteins for each individual segment and 3040 proteins when grouping all segments (A). Comparison of identified proteins between the three segments showed high similarities between the three tumor subpopulations (B). Principal component analysis (PCA) was performed to assess the variance between segments (Seg.) and technical replicates (Rep.) on a protein level, which showed the presence of two segments (C). PCA was also performed on the lipid MSI data showing three segments in the 3dimensional PC space (data points in D). Putative annotations were done for the species with the highest loadings (arrows in D).

\subsection{Conclusion}

Other approaches in spatial omics pursue the systematic dissection of the tissue section in order to map protein abundances and biochemical processes in tissues, which is very time-consuming ${ }^{[14]}$. Our approach, in contrast, uses MSI as a screening tool to reveal first obvious molecular spatial differences 
in tissues to direct further investigations on the same instrument. While there are many non-commercial or commercial systems equipped with hybrid sources, this kind of experiment has never been reported previously. Moreover, the performance in both MALDI and LC-proteomics is comparable to specialized MS instrumentation for either part of the workflow. In conclusion, the present work combined the molecular spatial dimension provided by MSI with proteomics data obtained from locally microdissected material of the exact same tissue section on one single MS instrument.

\section{Acknowledgments}

This research was financially supported in part through the LINK program of the Province of Limburg (The Netherlands). F.D. received support from the Joint Imaging Valley program of the University of Liège and the Maastricht University. F.D. and B.B. received financial support from the European Union (ERA-NET TRANSCAN 2; Grant No. 643638). The authors thank Dr. Michael Herfs from the University of Liège, Belgium, for providing the sample. 
66 Chapter 3 - MS Imaging guided Microproteomics for Spatial Omics on a Single Instrument 


\section{Chapter 4}

Multilabel Per-pixel Quantitation in Mass Spectrometry Imaging ${ }^{1}$

${ }^{1}$ F. Dewez, E. De Pauw, R. M. A. Heeren, B. Balluff. Analytical Chemistry, 2021. 


\subsection{Abstract}

In quantitative mass spectrometry imaging (MSI), the gold-standard adds a single structural homologue of the target compound at known concentration to the sample. This internal standard enables to map the detected intensity of the target molecule against an external calibration curve. This approach, however, ignores local noise levels and disproportional ion suppression effects which might depend on the concentration of the target compound.

To overcome these issues, we propose a novel approach which applies several isotopically labeled versions, each at a different concentration, to the sample. This allows creating individual internal calibration curves for every MSI pixel. As proof-of-principle, we have quantified an endogenous peptide of histone $\mathrm{H} 4$ by MALDI-Q-MSI using a mixture of three isotopically labeled versions. The usage of a fourth label allowed us to compare the gold-standard to our multilabel approach.

We observed substantial heterogeneity in ion suppression across the tissue which disclosed itself as varying slopes in the per-pixel regression analyses. These slopes were histology-dependent and differed from each other by up to a factor of four. The results were validated by LC-MS exhibiting a high agreement between LC-MS and MALDI-Q-MSI (Pearson correlation $r=0.87$ ). A comparison between the multilabel and a single-label approach revealed a higher accuracy for the multilabel method when the local target compound concentration differed too much from the concentration of the single label.

In conclusion, we show that the multilabel approach provides superior quantitation compared to a single-label approach where the target compound is inhomogeneously distributed at a wide concentration range in the tissue.

\subsection{Introduction}

Mass spectrometry imaging (MSI) is an analytical technique that enables the label-free analysis of the spatial distribution of molecules within biological tissue sections ${ }^{[115]}$. MSI is widely used in biomedical research as discovery tool since it can directly access hundreds to thousands of endogenous molecules on-tissue $[116,117]$. In contrast, MSI is commonly used in 
pharmaceutical research and industry to determine the place of accumulation and metabolization of drugs in tissue ${ }^{[118]}$. In that context, the ability to absolutely and precisely quantify molecular abundances at a single-pixel level is of utmost interest.

Quantitative MSI (Q-MSI) has been one of the main continuous efforts and an active area of research in the MSI community over the last decade ${ }^{[119,120]}$. While different ionization methods are employed in MSI, matrix-assisted laser desorption/ionization (MALDI-) MSI remains the most widely used technique ${ }^{[121,122]}$. Thereby, MALDI-Q-MSI has to deal with fundamental aspects related to the MALDI process involving analyte extraction from the tissue/cells, crystallization, desorption, and ionization ${ }^{[52,123]}$. All these steps are influenced by the local chemical and biological environment which ultimately causes a variation on the detected ion intensity of the target molecule, referred to as matrix effect.

Several strategies were developed to address the issues of regional matrix effects, of which the on-control-tissue procedure remains the most common [53-56, 58]. This technique uses a structural analog or stable isotope of the compound of interest which is applied homogeneously across the tissue before the MSI experiment. Furthermore, spotting a serial dilution of this internal standard on a blank tissue adjacent to the target section creates an external calibration curve. After the experiment, the signal of this internal standard is used to normalize the signal intensity of the target compound in the tissue and the calibration curve. After normalization, the quantitation of the compound is achieved by mapping the normalized intensities of the target molecule to the normalized external calibration curve ${ }^{[57,124]}$. However, this approach ignores local noise levels and disproportional changes of ion suppression effects depending on the concentration of the target compound. In addition, the mapping to an external calibration curve can lead to errors in local quantitative information since the spots of the external calibration series have very likely undergone a different ionization suppression and matrixassisted desorption extraction process than most of the pixels in the target tissue, especially when the tissues are histologically heterogeneous. 
For this reason, we propose a novel quantification method that creates an internal calibration curve for every pixel in the target tissue and therefore accounts for local ionization biases. This is achieved by spraying a minimum of three isotopically labeled versions of the target compound, each at a different concentration, onto the tissue. With high-mass resolution MSI instrumentation this enables the creation of an internal calibration curve on every measured position on the very same tissue section.

We will demonstrate, using an endogenous peptide of histone $\mathrm{H} 4$ as target compound, that this will provide a more accurate way of quantitation by taking into account the regional ion suppression as well as tissue heterogeneity.

\subsection{Experimental section}

\section{Chemicals and reagents}

All solvents, if not stated otherwise, were purchased from Biosolve (France). The four isotopically labeled versions of the histone $\mathrm{H} 4$ peptide (HDNIQGITKPAIR-OH, $m / z=1325.7535)$ were synthesized by Pepscan Presto (The Netherlands) as follows: label L1: H-DNIQGITKPAIR*-OH $(\Delta \mathrm{m}+10$ $\mathrm{Da}), m / z=1335.7618$; label L2: H-DNIQGITKPAI*R-OH $(\Delta \mathrm{m}+7 \mathrm{Da}), m / z=$ 1332.7707; label L3: H-DNI*QGI*TKPAI*R-OH $(\Delta \mathrm{m}+21 \mathrm{Da}), m / z=$ 1346.8050; label L4: H-DNIQGI*TKPAI*R*-OH $(\Delta \mathrm{m}+24 \mathrm{Da}), m / z=$ 1349.7962. The mentioned theoretical $m / z$ values are based on $z=1$ through single protonation.

\section{Tissue preparation and on-tissue enzymatic digestion}

Colonic tissue from a pork was harvested in accordance to the Codes of Practice and local regulations in the Central Animal Testing Facilities (CPV) and the University of Maastricht based on the working protocol of Prof. Dr. Nicole D. Bouvy approved by the Animal Welfare Body (AWB) (Instantie voor Dierenwelzijn IvD) under the project license number PV 2017-021 AVD1070020174166. The tissue was snap-frozen in liquid nitrogen and stored at $-80^{\circ} \mathrm{C} .12 \mu \mathrm{m}$ thick sections were obtained from the sample on a cryostat and thaw mounted onto conductive ITO slides. Prior to trypsin application, the tissue sections were dried in a desiccator for 10 minutes at room temperature. 
The tissue sections were then washed 3 times in 100\% ethanol ( 2 min each) followed by 2 rinses in water ( $5 \mathrm{~min}$ each). To denature the proteins before trypsin application, antigen retrieval was performed with citric acid $10 \mathrm{mM}$, $\mathrm{pH} 6.0$ at $121^{\circ} \mathrm{C}$ for 20 minutes using the Antigen Retriever 2100 (Aptum Biologics, UK). This was followed by two $1 \mathrm{~min}$ washes in deionized water. After drying the samples, on tissue digestion was performed by applying 15 layers of $20 \mu \mathrm{g} / \mathrm{mL}$ porcine trypsin (Sigma-Aldrich, The Netherlands) dissolved in deionized water with a SunCollect sprayer (SunChrom, Germany) at a constant $10 \mu \mathrm{L} / \mathrm{min}$ flowrate, track spacing of $1 \mathrm{~mm}$, nozzle height of $25 \mathrm{~mm}$, and a nozzle speed of $900 \mathrm{~mm} / \mathrm{min}$. Samples were then incubated at $37^{\circ} \mathrm{C}$ overnight in a controlled digestion environment using the SunDigest incubation chamber (SunChrom, Germany).

\section{Application of labels and quantitative calculations}

The four standards were stored at $-80{ }^{\circ} \mathrm{C}$ in $5 \%$ acetonitrile at the concentration of $5 \mathrm{pmol} / \mu \mathrm{L}$. When spotting, $0.5 \mu \mathrm{L}$ were applied and the spot area was empirically determined to be on average $3.4 \mathrm{~mm}^{2}$ in size. On one tissue section, no labels were applied at all, which served as control sample. On another section, a dilution series of label L1 at concentrations 120, 62, 31, $15,77,38 \mathrm{fmol} / \mathrm{mm}^{2}$ was deposited as spots for the estimation of the concentration range of the target peptide. A second dilution series of label L1 was also prepared at concentrations $370,180,92,46,23,15,10 \mathrm{fmol} / \mathrm{mm}^{2}$ and spotted onto a third sample for the comparison between the single-label and the multilabel quantitation method. Labels L1, L2 and, L3 were mixed with the following ratios $1: 2,1: 8$, and 1:32, and applied onto a fourth tissue sample using the SunCollect (Sunchrom, Germany). Label 4 was diluted by a factor of 8 and separately applied using the same parameters onto both latter samples. In order to express the concentration in $\mathrm{fmol} / \mathrm{mm}^{2}$, we based our calculations on the spraying parameters. These included a fixed area of spraying set as $35 \times 30 \mathrm{~mm}$, a spraying velocity of $900 \mathrm{~mm} / \mathrm{min}$, a flowrate of $10 \mu \mathrm{L} / \mathrm{min}$, a total of 5 layers, and a line spacing of $2 \mathrm{~mm}$. Therefore, 15 lines were sprayed per layer with a spraying time of $0.039 \mathrm{~min}$ per line. The time per layer was then $0.583 \mathrm{~min}$ and $0.031 \mathrm{~min}$ for the horizontal and vertical dimensions, respectively, resulting in a total spraying time of 0.614 min per layer. Since the flow rate was $10 \mu \mathrm{L} / \mathrm{min}$, a volume of $6.14 \mu \mathrm{L}$ was 
applied per layer resulting in a total deposited volume of $30.72 \mu \mathrm{L}$. The deposited absolute amounts of labels L1, L2, and L3 were therefore 76806, 19201, and $4800 \mathrm{fmol}$, respectively. Finally, the concentrations in $\mathrm{fmol} / \mathrm{mm}^{2}$ were calculated by dividing these amounts by the spraying area. This resulted in concentrations of $73.2,18.3$ and, $4.6 \mathrm{fmol} / \mathrm{mm}^{2}$ for labels L1, L2, and L3, respectively. Following the same calculations for a spraying area of $65 \times 30 \mathrm{~mm}$ (both tissues), the concentration of label L4 was similar to the one of label L2, namely $17.9 \mathrm{fmol} / \mathrm{mm}^{2}$. Onto a fifth tissue section, labels L1, L2, and L3 were applied as described before for further LC-MS quantitation measurements.

\section{Matrix application and MSI experiments}

$50 \mathrm{mg} / \mathrm{mL}$ of 2.5 -dihydroxybenzoic acid matrix in $50 \%$ acetonitrile and $0.2 \%$ trifluoroacetic acid was sprayed in 3 layers using an HTX-TM sprayer (Chapel Hill, NC, USA) onto the tissue sections at $30^{\circ} \mathrm{C}$ with a constant flow rate of $0.1 \mathrm{ml} / \mathrm{min}$, a speed of $1200 \mathrm{~mm} / \mathrm{min}$ and a track spacing of $1 \mathrm{~mm}$. The tissue for the LC-MS measurements was sprayed at $50^{\circ} \mathrm{C}$.

MSI data were acquired on a Q-Exactive Orbitrap mass spectrometer (Thermo Fisher Scientific, Germany) equipped with a MALDI source (Spectroglyph LLC, WA, USA). The experiments were performed in positive ion mode at $100 \mu \mathrm{m}$ spatial resolution within a mass range of $m / z 1000-1500$. The spectral resolution was set to $240,000 \mathrm{FWHM}$ at $\mathrm{m} / \mathrm{z} 400$. MSI data were then exported to imzML format using the Image Insight software (Spectroglyph LLC, WA, USA).

MS/MS measurement of the Histone $\mathrm{H} 4$ peptide was performed within a mass range of $m / z 100-1500$ with a collision energy of $35 \mathrm{eV}$, a $0.5 \mathrm{Da}$ isolation window with an average of 25 scans.

\section{Histological staining}

After MSI experiments, the matrix was removed with $70 \%$ ethanol and the sections were stained with hematoxylin and eosin (H\&E) using a standard protocol. The tissues were scanned with an M8 microscope slide scanner (Precipoint, Germany).

\section{Data analysis}

72 Chapter 4 • Multilabel Per-pixel Quantitation in Mass Spectrometry Imaging 
The Thermo Fisher raw data were aligned to the corresponding position files in the Image Insight software (Spectroglyph, LLC, WA, USA) and exported from there as imzML file. MSI data were then imported into MATLAB R2018b (MathWorks, Natick, MA, USA) for data analysis. The Matlab code is provided in the online Supplementary information. Briefly, after importation as imzML, null spectra and $1 \%$ of pixels with the highest TIC values were removed. Then signals belonging to histone H4, labels L1, L2, L3 and, L4 were selected using the maximum intensity within a $\mathrm{m} / \mathrm{z}$ window of $\pm 15 \mathrm{ppm}$. Only pixels were considered for linear regression where all relevant signals of histone $\mathrm{H} 4$, label L1, label L2, and label L3 were detected. For the cross-validation of concentration prediction performance, outliers were removed using the isoutlier function in Matlab based on the median absolute deviations (default configuration).

\section{LC-MS experiments}

Sample preparation, LC-MS instrumentation, and data analysis are described in the Supplementary Information Method 1.

\subsection{Results and discussion}

In this study, we propose a novel per pixel quantitation method for MALDI mass spectrometry imaging (MALDI-Q-MSI) based on the use of several structural homologues of the target compound which are applied in different concentrations on the target sample. Due to the ease of label synthesis and its ubiquity, we decided to quantify and therefore create three stable isotopic versions (L1, L2, and L3) of a particular endogenous peptide of the protein histone H4. For a comparison with the state-of-the-art single-label method, we also spotted a dilution series of label L1 onto an adjacent tissue section placed next to the target tissue on the same slide and sprayed a fourth label 
(L4) on both tissue sections for the purpose of normalization. This resulted in the experimental setup depicted in Figure 4.1a.

Figure 4.1. Experimental setup and confirmation of the molecular identity of
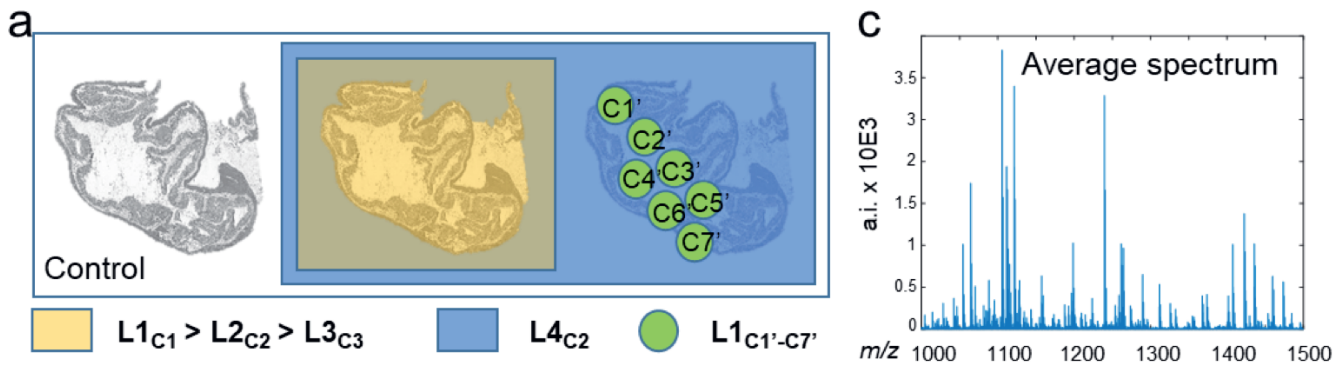

b

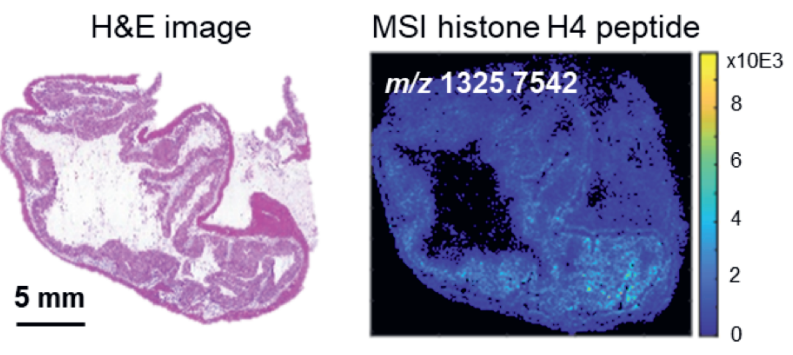

d

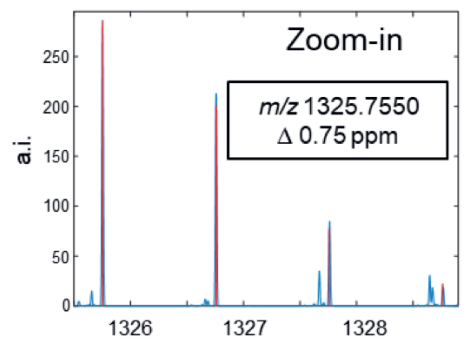

the target compound.

Three sections of the study tissue were placed on a slide. One served as control, one was sprayed with three differently labeled versions (L1, L2, and L3) of the target compound, each at a different concentration $(\mathrm{C} 1-\mathrm{C} 3)$, and a third tissue section was spotted with a seven-levels ( C1' $\left.^{-} \mathrm{C} 7^{\prime}\right)$ dilution series of L4. Finally, a forth label (L4) was applied at the same concentration as L2 (C2) on both adjacent tissue sections for normalization purposes. The tissue to study is a pig colon tissue of which a hematoxylin and eosin (H\&E) staining is shown in (b, left) and the MALDI-MSI image of the target histone H4 peptide in $(b$, right). The identification of the target peptide was performed on-tissue using high-mass accuracy delivered by a Q-exactive Orbitrap mass spectrometer with a mass error of $0.75 \mathrm{ppm}$ (c), by a comparison of the observed and the expected isotopic pattern (d), and MS/MS experiments (Supplementary Figure 1).

\section{Confirmation of the identity of the target peptide}

In MSI, on-tissue trypsin digestion enables the detection of one of the peptides of histone H4 (DNIQGITKPAIR, M=1324.7463) as already reported by 
Groseclose et al. ${ }^{[125]}$. In our tissue and MSI dataset of study (pig colon, Figure $4.1 \mathrm{~b}$ ), we corroborated the detection of the molecular ion $[\mathrm{M}+\mathrm{H}]+$ of histone H4 by high-mass accuracy at $\mathrm{m} / \mathrm{z} 1325.7550$ ( $\Delta=0.75 \mathrm{ppm}$, Figure $4.1 \mathrm{c})$, by congruence of the theoretical and the observed isotopic pattern (Figure 4.1d), and by on-tissue MS/MS measurements (Supplementary Figure 1). Since this peptide is unique to histone $\mathrm{H} 4$, it can be seen as representative for the entire histone $\mathrm{H} 4$ protein.

\section{Confirmation of $m / z$ channel-exclusivity of histone $\mathrm{H} 4$ labels}

Our method consists of applying several internal standards to the tissue. This harbors the danger that the signals of these labeled standards overlap with signals from endogenous molecules. In order to confirm the exclusivity of the respective $\mathrm{m} / \mathrm{z}$ channels for the applied labeled peptides, two tissue sections on one glass slide were simultaneously digested. Afterwards, one section was sprayed with the four isotope labels (L1 at $73.2 \mathrm{fmol} / \mathrm{mm}^{2}$, L2 and L4 at 18.3 $\mathrm{fmol} / \mathrm{mm}^{2}$, and L3 at $4.6 \mathrm{fmol} / \mathrm{mm}^{2}$ ) before matrix application and MSI measurements. Skyline spectra (a.k.a. maximum-based spectra) were created for the labeled and the control tissue and compared showing no endogenous peak interferences with the internal standards across all pixels of the samples (Figures 4.2a-2e).

\section{Determination of concentration range of histone $\mathrm{H4}$}

One crucial step in the proposed approach is to pre-determine the abundance range of the native histone $\mathrm{H} 4$ peptide on-tissue by MSI. This is to ensure that the intensities of the target peptide are always within the linearity of the calibration curve. Therefore, we deposited a dilution series $(120,62,31,15$, 7.7, and $3.8 \mathrm{fmol} / \mathrm{mm}^{2}$ ) of label L1 (H-DNIQGITKPAIR*-OH, $\Delta \mathrm{m}+10 \mathrm{Da}$ ) on tissue. The concentrations were expressed as fmol $/ \mathrm{mm}^{2}$ after gauging the average size of a spot from the detected signal in the MSI experiments (data not shown). The intensities for each of the individual dilutions together with the intensities of the native histone $\mathrm{H} 4$ peptide are shown in Figure 2f. This experiment enabled to choose those three concentrations $(62,15$, and 3.8 $\mathrm{fmol} / \mathrm{mm}^{2}$ ) that mostly tightely covered the complete concentration range of the target peptide in the tissue. 

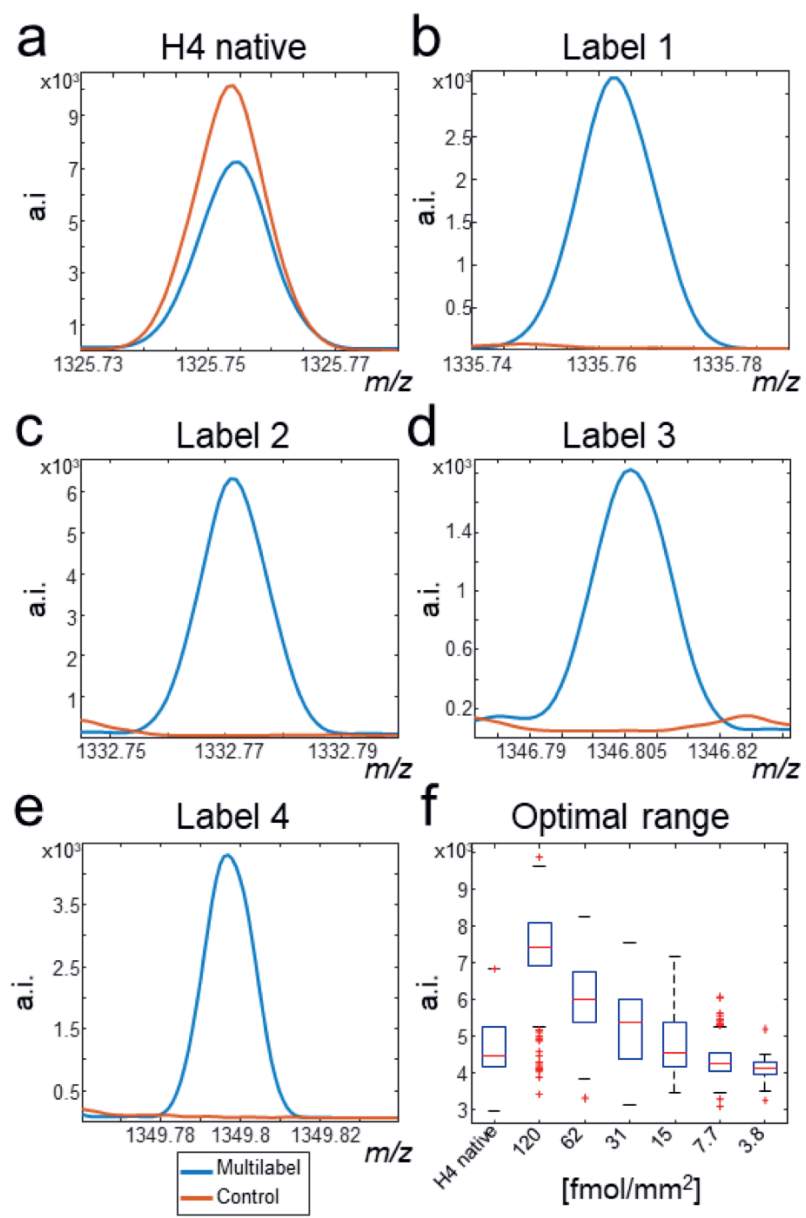

Figure 4.2. Signal exclusivity of isotopically labeled histone $\mathrm{H4}$ peptides.

Two tissue sections underwent tryptic digestion. One was afterwards sprayed with four different versions of the target molecule, the second acted as control. The presence of the target histone $\mathrm{H} 4$ peptide at $m / z 1325.7535$ was confirmed in both control as well as the multilabel sprayed experiments (a). The comparison of the skyline spectra between control and multilabel tissues gave evidence for the tissue-wide exclusivity of the respective $[\mathrm{M}+\mathrm{H}]^{+}$mass channels for the labels L1-L4 (b, c, d, e). In another experiment, a concentration range of label L1 was spotted onto another tryptic digested tissue in order to estimate the concentration range of the native histone $\mathrm{H} 4$ peptide (f). This enabled to determine the concentrations 62,15 , and 3.8 $\mathrm{fmol} / \mathrm{mm}^{2}$ to best cover the mass range of the target histone $\mathrm{H} 4$ peptide. 


\section{Multilabel per-pixel quantitation}

Using thes previous experiments as orientation, labels L1, L2, and L3 were sprayed in three different concentrations, $73.2,18.3$, and $4.6 \mathrm{fmol} / \mathrm{mm}^{2}$ respectively, on another tissue section. Figures $4.3 \mathrm{a}-3 \mathrm{~d}$ show the ion spatial distributions of the tryptic peptide of the endogenous histone $\mathrm{H} 4(\mathrm{~m} / \mathrm{z}$ 1325.7542), and the exogenous peptides belonging to label L1 $(\mathrm{m} / \mathrm{z}$ 1335.7624), label L2 ( $\mathrm{m} / z$ 1332.7711), and label L3 $(\mathrm{m} / z$ 1346.8057).

The detection and identity of the isotope labels L1, L2, and L3 was validated using high mass accuracy with mass deviations of $0.22,0.30$, and $0.52 \mathrm{ppm}$, respectively. Using a different concentration for every of the three labeled peptides allowed to fully cover the signal intensity range of the target peptide (Figure 4.3e).

Pixels in which all three labels could be detected thus enabled to create a local and per-pixel internal concentration curve using linear regression. Examples for such pixel-specific concentration curves are shown in Figure 4.3f, which allow to map the local target peptide intensity to its respective concentration. The regression analysis of our method provided for every pixel individual regression intercepts (Figure 4.3g), slopes (Figure 4.3h), and $\mathrm{R}^{2}$ values which took values from 0.92 to 1.00 (Supplementary Figure 2). Fluctuations in the slopes of the regression models were observed to correlate with different histological features of the tissue which reveal different degrees of regional ion suppression effects (Figure 4.3h). Like other studies before us ${ }^{[52,126]}$, this gives additional evidence for the existence of different local ionization biases which distort the interpretation of signal intensities but are accounted for by our method. In contrast, the intercepts -usually representing the noise levelwere homogeneous across the tissue (Figure 4.3g). The intercepts therefore also represent the theoretical minimum detectable concentrations which were calculated to be between 0 and $5 \mathrm{fmol} / \mathrm{mm}^{2}$ (Supplementary Figure 3).

Finally, absolute concentrations were calculated by mapping the intensity of the detected $\mathrm{H} 4$ signal to the internal per-pixel calibration curve for all individual pixels (Figure 4.3i). 

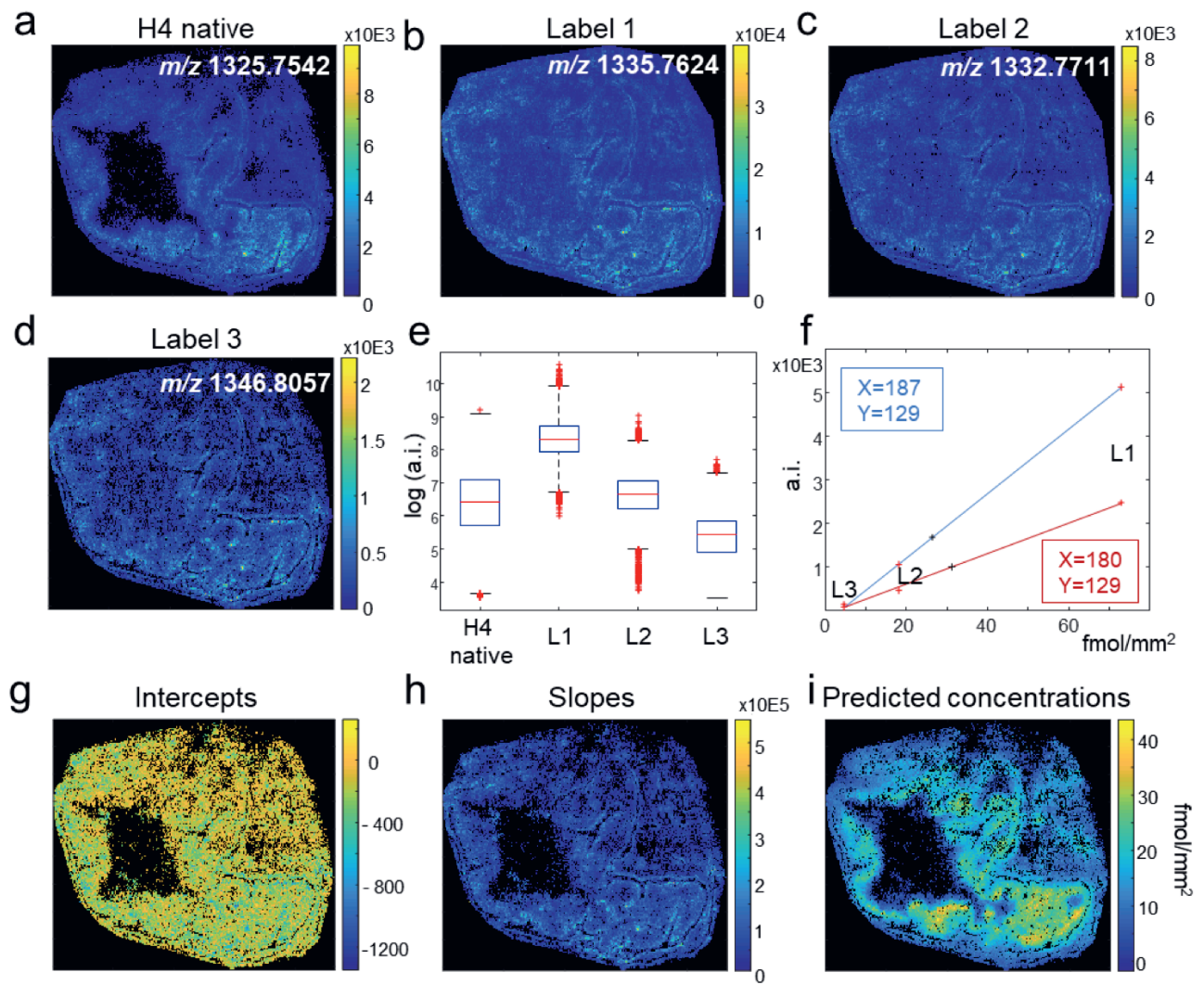

Figure 4.3. Multilabel approach to quantify the target endogenous peptide of histone $\mathrm{H} 4$ by mass spectrometry imaging (MSI).

A pig colon tissue was tryptically digested and sprayed with the labels L1 $(\mathrm{m} / \mathrm{z}$ 1335.7624), L2 $(\mathrm{m} / \mathrm{z} 1332.7711)$, and L3 $(\mathrm{m} / \mathrm{z} 1346.8057)$ at concentrations $73.2,18.3$, and $4.6 \mathrm{fmol} / \mathrm{mm}^{2}$. The molecular images of the native $\mathrm{H} 4$ peptide and the labels L1-L4 delivered by MALDI-MSI are shown in (a), (b), (c), and (d), respectively. The three labels sprayed in previously optimized concentrations (Figure 4.2f) enabled to cover the whole intensity range of the target histone $\mathrm{H} 4$ peptide (e). These labels enabled the creation of internal calibration curves for every individual pixel of which two examples are shown for two different pixels with their $\mathrm{X}$ and $\mathrm{Y}$ coordinate in red and blue (f). Visualizing each pixel's individual intercept (g) and regression slope $(\mathrm{h})$ revealed their correlation to the inherent morphological features of the tissue. Finally, the absolute concentrations of peptide histone H4 were calculated and mapped for every individual pixel (i). 


\section{Comparison with single-label method}

Several quantitative MALDI-Q-MSI methodologies have been developed to quantify molecules within tissue sections. The recent state-of-the-art quantitation approach consists of depositing a dilution series of a structural analog or a stable isotope version of the target compound on a control tissue adjacent to the target sample enabling the establishment of a calibration curve. Then, the detected intensities of the target molecule and the calibrants are normalized to a second internal standard which has been applied to both samples ${ }^{[55]}$.

From a theoretical point of view, this method suffers from two disadvantages: first, a calibration curve is deposited on a consecutive section resulting in uncomparable local desorption and ionization efficiencies. This could lead to a variation in the signal response influencing the quantitative calculations. Second, the normalization using the label on the target tissue works with a proportional slope and no intercept which does not reflect the potentially nonlinear dynamics of ion suppression across the concentration range of the target compound.

To compare our results to this approach, a dilution series of label L1 was spotted onto a tissue section adjacent the tissue section which had been sprayed with the three labels. Both sections were then covered by label L4 for normalization purposes. This enabled the creation of an external 7-point calibration curve which had been normalized by the detected label L4 intensities (Figures 4.4a and 4.4b). A linear model was chosen over a nonlinear model $\left(\mathrm{y}=\mathrm{a}^{*} \mathrm{~b}^{\mathrm{x}}+\mathrm{c}\right)$ based on the root mean square deviation (RMSE) which was only slightly lower for the non-linear model $\left(\mathrm{RMSE}_{\text {linear }}=2.91 \mathrm{vs}\right.$. $\mathrm{RMSE}_{\text {non-linear }}=2.78$ ). Absolute concentrations were calculated by mapping the label L4-normalized intensities of the histone $\mathrm{H} 4$ signal to this external 7point calibration curve of the adjacent tissue (Figure 4.4c and 4.4d).

When comparing the two methods and their predicted concentration, the medians of both methods were found in the same range (between 13 and 20 $\mathrm{fmol} / \mathrm{mm}^{2}$ ). The main difference was observed in the variance of the predicted concentrations. The multilabel method covered a wider range of concentrations from 0 to $43 \mathrm{fmol} / \mathrm{mm}^{2}$ whereas the lowest value for the single method was $16 \mathrm{fmol} / \mathrm{mm}^{2}$ (Figure 4.4e). The cause for this lower limit is the 
negative intercept of the linear regression model which leads to this value when the intensity is zero (Figure 4.4b). In order to locate the differences, we plotted the ratio of the predicted concentrations calculated by the multilabel versus the single-label method. Interestingly, the major difference in predicted quantities was found in the mucosa of the colon with predicted concentrations up to two times higher in the multilabel method (Figure 4.4f). In order to better understand the causes of these differences in predictions and the reliability of each of the results, we compared the two methods in more detail by validating them on known compounds with known concentrations.
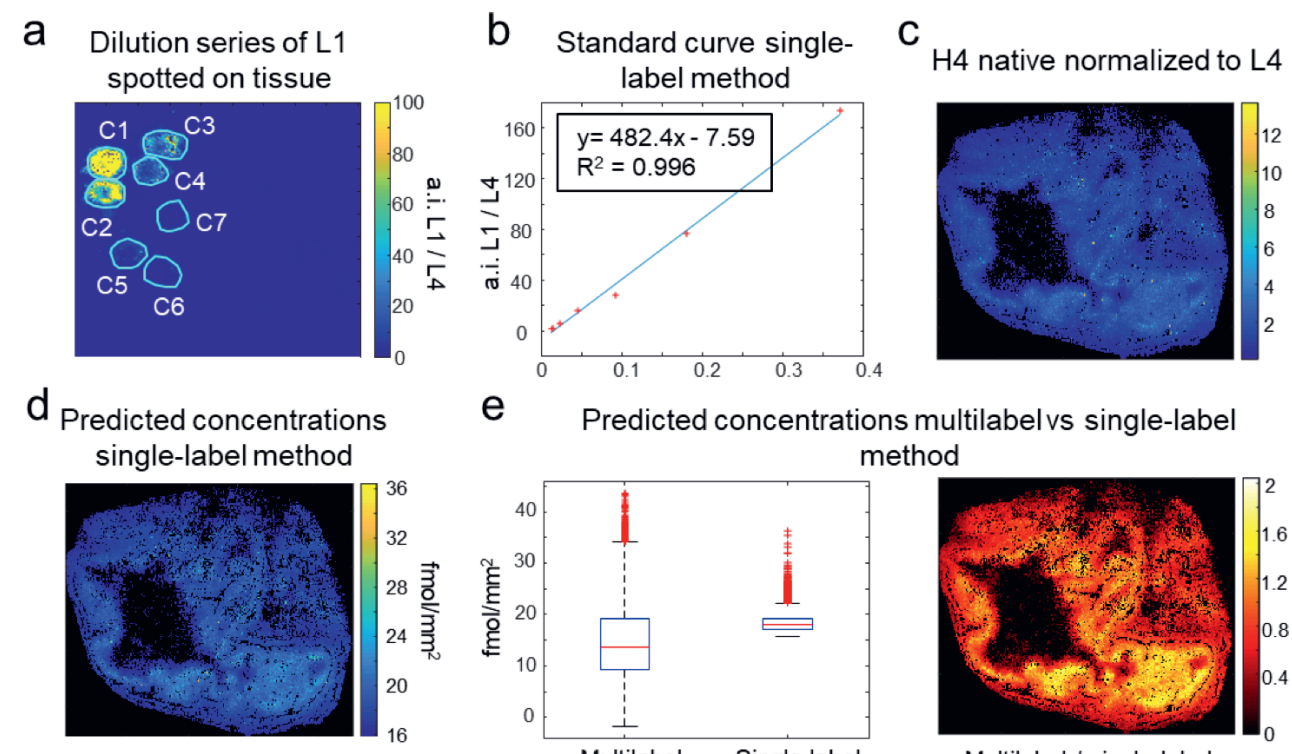
e Predicted concentrations multilabel vs single-label method
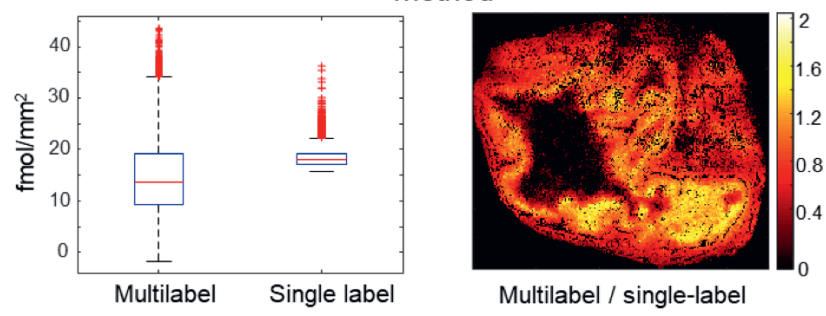

Figure 4.4. Comparison of single-label vs. multilabel method.

A concentration series of label L1 was spotted on a blank colon tissue section (a). Linear regression was used to obtain a calibration curve with an $\mathrm{R}^{2}$ of 0.996 (b). The signal of the target histone $\mathrm{H} 4$ peptide on the target tissue was normalized by the signal of label L4 which had been additionally sprayed onto the target tissue (c). (d) Absolute quantities of the histone H4 peptide were calculated by mapping the L4-normalized $\mathrm{H} 4$ peptide intensities to the external calibration curve from (b). The predicted concentrations by the single-label and multilabel methods across the tissue section were compared (e). Visualizing the ratios of the predicted concentrations per pixel enabled to 
localize the main differences between the two methods in the mucosa of the colon (f).

\section{Cross-validation of single-label and multilabel methods}

In order to validate both analytical approaches, we used a cross-validation approach where the single-label and multilabel methods were used to predict the absolute known concentrations of labels L1 (highest concentration), L2 (middle concentration), and L3 (lowest concentration). The cross-validation of the multilabel method was carried out in two ways: in a leave-on-label-out fashion where all permutations of two labels were used for linear regression to predict the concentration of the left out label; and a residual analysis of the three-label approach. For all three cross-validation approaches, ratios were calculated between the predicted and expected (theoretical) concentrations (Figure 4.5). The single-label method estimated the concentrations of labels L1, L2 and, L3 with mean ratios of $0.41( \pm 0.04 \mathrm{SD}), 1.00( \pm 0.04 \mathrm{SD})$, and $3.61( \pm 0.07 \mathrm{SD})$, respectively. The use of two labels improved the overall prediction accuracy with mean ratios of $1.42( \pm 0.32 \mathrm{SD}), 0.78( \pm 0.14 \mathrm{SD})$, and 2.03 ( $\pm 0.59 \mathrm{SD})$ for labels L1, L2, and L3, respectively. However, the two-point strategy resulted in a higher variance especially for the prediction of labels with the highest and lowest concentrations (L1 and L3) due to their location outside the calculated regression curve. Finally, the multilabel method predicted the concentrations of labels L1, L2 and L3 most accurately with mean ratios of $1.01( \pm 0.004 \mathrm{SD}), 0.87( \pm 0.08 \mathrm{SD})$, and $1.41( \pm 0.25 \mathrm{SD})$. Of particular note, the prediction accuracy of label L2 (middle concentration) was similar among all strategies showing the importance of the optimization

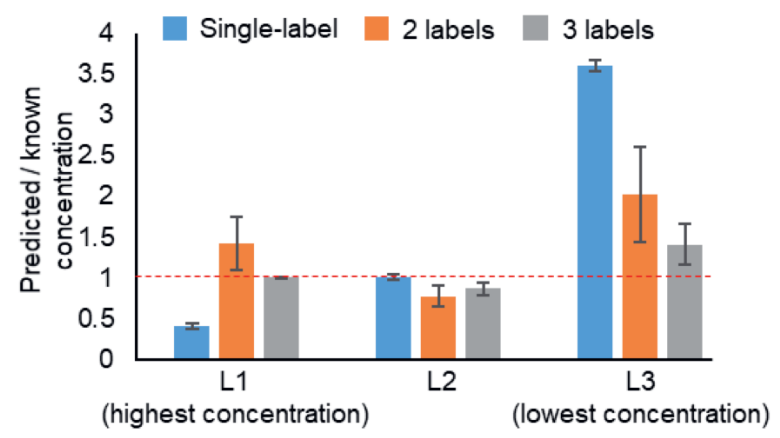

of the label concentrations. 
Figure 4.5. Cross-validation of the single-label, two labels, and three-label methods.

All three methods were used to estimate the known concentrations of labels L1 (highest concentration), L2 (middle concentration), and L3 (lowest concentration). Ratios between known and predicted concentrations were calculated after removal of outliers using the median absolute deviations method (Supplementary Figure 4).

The cross-validation showed that the accuracy of the single-label method depends on the concentration of the target compound where higher concentrations are underestimated and lower concentrations are overestimated (Figure 4.5). In fact, this underestimation might have happened in the mucosa region (Figure 4.4f) which presumably contains the highest amount of histones due to the high cell density in this area. Like histones, the concentrations of molecules in biological tissues are expected to range several orders of magnitude across the tissue (Figure 4.3e), which makes the singlelabel approach only suited for quantities that are close to the single label's concentration. Then, the single-label method is not only more accurate but also shows a lower variance in accuracy (Figure 4.5).

The multilabel method, in contrast, offers the advantage by the use of several labels to address the variation in concentration of target compounds in the tissue, ultimately resulting in higher accuracies. This is not always an advantage. The distribution of regression-residuals from the curve is reflected in the higher variance and slightly lower accuracy of the multilabel method when predicting the known concentrations (Figure 4.5). Compared to the single-label method, the multilabel method is, therefore, less suited for cases where the target compound is expected to be homogeneously distributed across the tissue.

\section{LC-MS-based validation of multilabel method}

Both presented approaches share the limitation that the applied standards and the endogenous compounds might undergo different mass transfer kinetics from the cells to the MALDI matrix ${ }^{[58]}$. This is due to the different localizations of the endogenous compounds in the cellular environment (membrane, cytoplasm, nucleus) compared to the most superficially localized 
standards. To investigate this effect, we performed LC-MS which should not suffer from this differential extraction.

These experiments were performed on a tissue section after multilabel MALDI-Q-MSI. For this, tissue material was collected from six different areas with known amounts of L1, L2, and L3 and predicted absolute amounts of histone H4 based on multilabel MALDI-Q-MSI (Figure 4.6a). Every region was analyzed separately by LC-MS and absolute amounts of the $\mathrm{H} 4$ peptide were determined using internal calibration curves based on the signals of L1, L2, and L3. Comparing the absolute amounts of histone $\mathrm{H} 4$ approximated by MALDI-Q-MSI and LC-MS revealed a high agreement (Pearson correlation $r=0.87$ ) between both approaches (Figure 4.6b). This shows the high recovery of the target peptide by our MALDI-based multilabel approach.

a

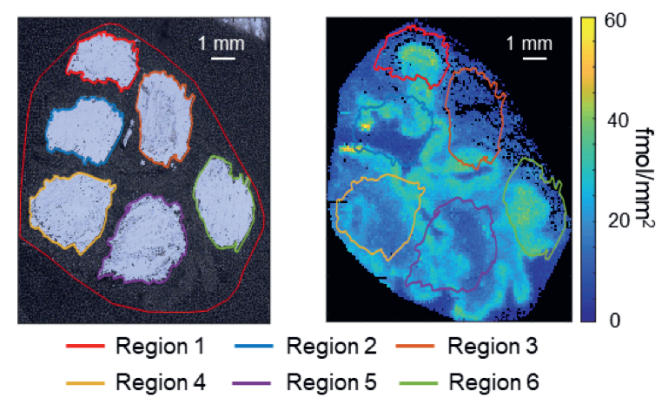

b

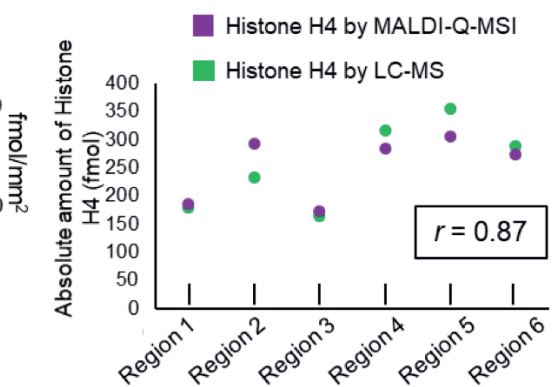

Figure 4.6. LC-MS quantitation after multilabel MALDI-Q-MSI.

Six different areas were collecting by scratching them off the tissue (a, left). The regions were coregistered to the MALDI-Q-MSI data in order to calculate the absolute amount of histone $\mathrm{H} 4$ related to the area of the individual regions (a, right). Absolute amounts of histone $\mathrm{H} 4$, based on the LC-MS, were predicted using labels L1, L2 and L3 signals for the establishment of internal calibration curves of the individual regions. A Pearson correlation coefficient $r$ of 0.87 showed a high agreement between the predicted absolute amounts of histone H4 by MALDI-Q-MSI and LC-MS using (b).

\section{The number of data points and the regression function}


In both analytical methods (single-label vs. multilabel) regressions functions are used to predict concentrations of the target molecule. These functions are derived from a set of data points representing intensities of known concentrations. The number and quality of data points will hence influence the calibration curve and therefore the calculations of the quantified compound. In optimum circumstances, the creation of this calibration curve requires a large number of data points. One of the main advantages of the single-label method is to have a calibration curve with (virtually) unlimited number of points on the second tissue - the number is naturally limited by the size of the slide. In the multilabel method, there are fewer data points available and this can potentially pose difficulties if the responses differ from a linear trend ${ }^{[127]}$. In order to investigate this in our case, we have prepared and performed multilabel MALDI-Q-MSI on a consecutive section using a different high-mass resolution FT-ICR-based mass analyzer (Solarix, Bruker Daltonik). The predicted concentrations between both mass spectrometers (Orbitrap and Solarix) delivered similar results giving evidence for the applicability of the presented approach on different instrumentation (Supplementary Figure 5).

Next, we investigated other potential limitations arising from the concentration of the labels for constructing the calibration curve. In the case of a very low abundant target compound, one label would need to be lower in concentration than the target molecule. This is to ensure that its signal is always within the linear range of the regression. However, this harbors the danger that this very low concentrated label cannot be detected anymore by MSI. In our example, the lowest concentrated label (L3, $4.6 \mathrm{fmol} / \mathrm{mm}^{2}$ ) was detected in $81 \%$ of all pixels.

We also investigated if a structural homologue at high concentration could compete with the target compound during ionization, and thereby if the quantity of sprayed label-material onto tissue could affect the detected intensity of the target compound (here: the endogenous peptide histone $\mathrm{H} 4$ ). To do so, three consecutive tissue sections were sprayed with the same label at three different concentrations $\left(73.2,18.3,4.6 \mathrm{fmol} / \mathrm{mm}^{2}\right)$. The results show that the quantity and presence of the label did not affect the intensity of the histone $\mathrm{H} 4$ peptide and therefore does not constitute a limiting factor (Supplementary Figure 6). 
Another limitation in the number of labels is related to the possibility of their creation. In our study, we decided to quantify a peptide because the aminoacid-based building-block nature of peptides allowed a cheap and easy synthesis of several distinct isotopically labeled versions of our target. Likewise, our approach can be translated to MALDI-Q-MSI studies of small compounds taking into consideration that the synthesis of several labeled versions of small molecules could be technically challenging and consequently expensive.

\subsection{Conclusions}

We demonstrated in our proof-of-concept study that the novel use of multiple labels as internal standards provides an improved solution for local differences in ionization efficiency to quantify more accurately target compound concentrations. This makes this new MALDI-Q-MSI method especially suited for heterogeneous biological tissues with wide-ranged concentrations of the target compound.

\section{Acknowledgments}

This research was financially supported in part through the LINK program of the Province of Limburg (The Netherlands). FD received support from the Joint Imaging Valley program of the University of Liège and the Maastricht University. FD and BB received financial support from the European Union (ERA-NET TRANSCAN 2; Grant No. 643638). We thank Professor Bouvy from Maastricht University, the Netherlands, for providing the pig tissue. 
86 Chapter 4 • Multilabel Per-pixel Quantitation in Mass Spectrometry Imaging 


\section{Chapter 5}

Impact 
This $\mathrm{PhD}$ thesis describes diverse research topics where public and private partnerships are employed to obtain relevant scientific impacts. In this chapter, the direct/short-term impact of the results in this thesis on science and society are discussed. In particular the economic impact for companies directly involved in the newly developed spatial omics workflow. The advantages of a new quantitative approach with potential applications in pharmaceutical research and application are discussed in detail. The longterm impact of this work improved understanding and scientific insights on diseases that will translate to in fine patient care. Finally, I will discuss and expand the potential applications of my work to various fields.

\section{Scientific impact}

The work described in this thesis is a major step forward in establishing a link between spatial information in biological tissue specimens and omics approaches. When combined, these provide comprehensive local molecular information on quantities and identities of hundreds to thousands of molecules. In chapter 2, two different technologies, MSI and LC-MS, are brought together by creating an open-source computer program that enables the transfer of spatial molecular information from MSI to a laser microdissection system with an accuracy at the single-cell level. Indeed, mass spectrometry imaging has spread as a great analytical tool employed in more and more different research areas such as pharmaceutical industries, biomedical research, biomarker discoveries, fundamental research, or art. The conscious choice to use an open source approach intends to increase the scientific availability of this approach and could augment its impact across a wide range of research fields.

During my PhD, I also worked on one of the most important topics in MSI; quantitative MSI. While regular MSI is now well established and constitutes a powerful tool in biomedical research, quantitative MSI is still controversial due to technical challenges. In chapter 4, a multi-label per pixel quantitation method in mass spectrometry imaging is described that could provide quantitative information at a single-cell level. Here, the endogenous peptide of the histone $\mathrm{H} 4$ protein in colon pig tissue is successfully quantified. This protein was used as proof of principle for our novel strategy but could easily be disseminated for the quantification of small molecules, peptides, or 
proteins. One interesting application would be the quantitative study of antibodies, a growing class of biopharmaceuticals with a major impact in oncology, immunology, and chronic inflammatory diseases.

\section{Economic impact}

The in-house script developed and employed in chapters $\mathbf{2}$ and $\mathbf{3}$ will be now integrated into commercial data analysis software such as Scils Lab (Bruker, Germany) or LipostarMSI (Molecular Horizon, Perugia, Italy) or be used as a free tool and could constitute a pipeline daily applied in research centers. In this research, I developed this workflow on three distinct instruments that enable, MSI, laser microdissection, and LC-MS respectively. I performed the MSI experiment on a Synapt G2-Si (Waters, England) and the LC-MS analysis with a Q-exactive Orbitrap (Thermo Fisher Scientific, USA). In chapter 3, I simplified the developed pipeline to be compatible with a single state-of-the-art MSI instrument in collaboration with Bruker Daltonics. Bruker Daltonics is one of the leading companies in MS based molecular imaging research and develops high-performance scientific instruments with high analytical value. This public-private collaboration allowed me to gain knowledge about instrumentation specificities of a newly developed instrument and share my insight for the implementation of this pipeline. As part of the knowledge dissemination, the newly developed TimsTof flex (Bruker, Germany), a mass spectrometer equipped with a dual-source: a MALDI (Matrix-Assisted Laser Desorption and ionization) source and an ESI (electrospray) source was used to evaluate the innovative protocols developed in this thesis. This mass spectrometer enables to perform rapid experiments with high-speed and high sensitivity. Bruker now refers to this workflow as MALDI Guided SpatialOMx ${ }^{\circledR}$ on their official website and is available to any scientist in the world that is interested in cellular processes and disease progression. This pipeline could be applied to any type of heterogeneous materials and constitutes the next-generation method for in-situ characterization of tissue.As a result of this collaboration, a paper was published (Chapter 3 of this thesis) in addition to an application note (https://www.bruker.com/en/applications/academia-life-

science/imaging/maldi-imaging/SpatialOMx.html) and finally, grant support 
materials. The impact of this scientific endeavor is demonstrated to go beyond merely publishing papers.

\section{Societal impact}

In this paragraph, the translational aspects of my work are discussed in a clinical context. In the second part, I would like to speculate and discuss the future possible applications of my research in a broader perspective.

As shown in chapter 3, I highlighted intratumor heterogeneity in breast tumor tissue sections. Intratumor heterogeneity refers to a mix of cells with different genetic and non-genetic molecular profiles. This has an impact on the disease outcome of the patient including prognosis, response to chemotherapy, or relapse. Therefore, the investigation of intratumor heterogeneity is of utmost interest for the scientific community to better understand the evolution of cancer. A label-free approach to reveal intra-tumor heterogeneity by MSI as shown in this thesis has the ability to improve prognostics and predictive accuracy of disease phenotypes by allowing physicians to better analyze positive effects of therapies while minimizing deleterious side effects. Moreover, a spatial multi-omics approach developed in this thesis with really high throughput capabilities developed in the future would be compatible in a clinically relevant timeframe and will constitute a great tool possibly implemented into already existing molecular pathology tools.

While a global picture is needed to better understand disease processes, a more targeted approach is sometimes required. Chapter $\mathbf{4}$ offers a novel approach that could help pharmaceutical industries to investigate the efficacy or the toxicity of their developed drugs. For instance, as stated in "next generation antibody drugs: the pursuit of the "high-hanging fuit", antibodies are the most growing drug class that have a major impact on human health, such as oncology, autoimmunity, and chronic inflammatory diseases. My research in chapter 4 could help to better understand their mechanisms of action and could extend their therapeutic applications.

Medical treatment is going towards personalized medicine for the best possible outcomes. However, this new approach relies on scientific breakthroughs to diagnose how individual molecular and genetic profiles influence certain diseases. Therefore, scientific research and technology 
improvement have a direct impact on clinical research and in fine on patient care.

My $\mathrm{PhD}$ was executed in a life sciences context with a focus on biomedical research and clinical settings. However, my work has a wide range of potential applications that are not directly related to health sciences. In the food industry, MSI has gained interest in the past decade and thus potential applications for my newly developed workflow. Indeed, it is of utmost interest to identify and visualize the distribution of molecular food components to improve quality, food safety and, nutritional content. For instance, this workflow could help to study and identify micronutrients such as vitamins or minerals, endogenous toxins, or exogenous contaminants in plants. This in addition to the evaluation of conventional molecular classes such as lipids, metabolites, and proteins.

The study of biofilm and complex microbial could also be a potential application of my research. Indeed, understanding the chemical processes involved in microbial communities could help to elucidate antibiotic resistance that would allow the development of new treatment approaches. This could also enable to better understand the effect of climate change on these microbiomes and understand the changing environmental challenges impacting agriculture and bioenergy.

The impact of our research associated with high-quality education and open science are essential to resolve societal challenges. This impact results from the professional interaction of academics with society in order to contribute outside the field of science. The complexity resides in the assessment of this impact. Indeed, it is difficult to observe the effect of our fundamental research on a short- mid- or long-term timescale that results in applications. Maastricht University defines the impact of education and research into three different categories: output which is the direct profit (public presentations, graduation of students, softwares etc...), outcome which corresponds to mid-term effect (patents, impact on policy design etc...), societal and economic (results of output and outcome such as adopted policy, influencing local, regional and national politics etc...). Regarding the work in this thesis, the impact is, for now, a direct output with scientific publications, public presentations, 
computer tools and it will be used for use and dissemination of research results both within and outside academia. 


\title{
Chapter 6
}

\author{
Discussion and Outlook
}




\subsection{Discussion}

Over the past years, mass spectrometry imaging (MSI) has been employed as high-throughput technology offering a spatially resolved analysis and a correlation of proteomic or metabolomic patterns to distinct populations of cells or individual cells. However, the analytical depth of MSI is still limited and requires extra efforts from sample preparation, instrumental improvement to data analysis to obtain a better molecular characterization of the tissue samples. Moreover, ion suppression and other effects in MSI hamper reliable quantitative studies.

In chapters 2 and 3, I established a spatial omics workflow that combines MSI and liquid- chromatography mass spectrometry (LC-MS) which enables to obtain identities and quantitative information of thousands of molecules in a spatially resolved manner. In chapter 4 , I addressed the second mentioned issue by developing a new targeted quantitative approach that quantifies a compound at MSI pixel level. Nevertheless, there still remain many different aspects that need to be addressed.

\section{Spatial Omics workflow}

\section{Molecular sample alterations by the workflow}

Sample stabilization for archivation and sample preparation for mass spectrometry imaging have consequences on the type and the depth of molecular information retrievable by the spatial omics workflow, more precisely by the subsequent omics technology employed (Figure 6.1).

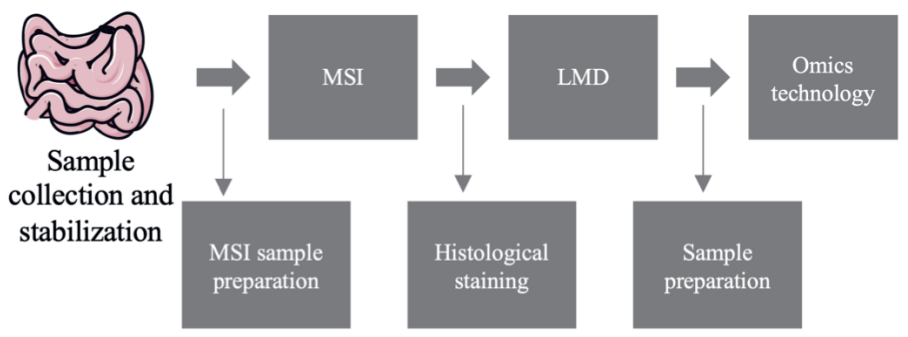

Figure 6.1. Spatial omics workflow.

Abbreviations: MSI, mass spectrometry imaging; LMD, laser microdissection. 
In all my studies, I disposed of fresh frozen samples which were provided by a pathologist. This enables the analysis of a broad range of biomolecules by MSI ranging from metabolites, over lipids, to proteins. But, as explained in chapter 1, histological samples are usually stabilized by formalin fixation and paraffin embedding (FFPE) and constitute the major fraction of samples in tissue biobanks for clinical research. For MSI analyses of these types of samples the removal of paraffin is required which implies the risk of removing (mostly non-polar) endogenous molecules. Hence, some classes of molecules are preferred when dealing with FFPE materials such as proteins (after tryptic digestion), endogenous peptides, or metabolites ${ }^{[30,128,129]}$. The sample stabilization type can also have consequences on the type of omics technology that can be employed after MSI. In the case of FFPE material, many omics technologies would be available such as proteomics, genomics, or transcriptomics ${ }^{[87,130,131] .}$

In chapters 2 and 3, MALDI-MSI has been employed to map the tissue which implies the use of a high-energy UV laser. While it can not be excluded that this laser irradiation might affect the molecular content, Dilillo et al. have observed no information loss in microproteomics experiments after MALDIMSI ${ }^{[79]}$. In chapter 3, I also compared processed (after MALDI MSI sample preparation and experiment) vs unprocessed samples and did not observe any detrimental effect on the number of protein identifications after MSI sample preparation and MSI analysis (see supplementary figure 1 in 7.2. "MS imaging-guided microproteomics for spatial omics on a single instrument"). However, many factors related to the technical setup such as the spatial resolution (density of irradiation points), the laser's intensity, the mode of acquisition (discrete or continuous laser shots) may have an influence on the protein recovery. To answer these questions requires separate efforts beyond my studies.

Nevertheless, an important factor is also the type of sample glass slide to carry the samples. In my presented approach samples were deposited on membrane slides that make the microdissection by the LMD more feasible. However, these slides are not compatible with some TOF-based instruments that require an electrical surface and therefore conductive slides. Mezger et al. have recently demonstrated the possibility of using conductive slides in this spatial omics workflow by ablating the tissue with the LMD followed by bottom-up 
proteomics ${ }^{[132]}$. However, this approach could induce tissue degradation resulting in fewer protein identifications (results differ by one order of magnitude) which can have tremendous consequences in the case of the study of low-abundant proteins detection.

\section{Histological tissue stainings}

Histological stainings provide information to study tissue characteristics and microscopic structures of the cells. In this thesis, hematoxylin and eosin (H\&E) or hematoxylin alone were used on breast tissue sections to identify tumor areas and restrict the analysis to these regions. However, also these stainings can have a detrimental effect on the subsequent proteomics experiments. The literature is ambiguous about the effect of eosin on proteomics analysis. Some papers recommend the omission of the eosin staining ${ }^{[133,134]}$ but others do not ${ }^{[135,136]}$. Mezger et al have also observed a reduction in the number of identified proteins when using H\&E staining [132]. In summary, the effect of histological stainings on the target molecular class needs to be investigated for every workflow individually with respect to the analytical techniques used and the target molecular class.

\section{Precise coregistration between MALDI-MSI and laser microdissection}

Laser microdissection has been developed to manually cut out regions of interest or even single cells based on histological or fluorescent staining to further analyze these samples by LC-MS ${ }^{[137-139]}$.

Recently, MSI has been proposed as another imaging technique to guide a laser microdissection system. In these few studies so far, MSI combined with laser microdissection system (LMD) has been used to enable differentiated liquid-based LC-MS experiments of colorectal liver metastases or breast tumors ${ }^{[78,140]}$. Until now, no coregistration errors and no information on the co-registration process were reported. At the same time, MSI and LC-MS have become capable to analyze single-cells ${ }^{[141-145]}$. Recent advances in MSI can even achieve subcellular spatial resolution with pixel sizes of 600 nanometers ${ }^{[106,146,147]}$. These instruments are still in development and not yet commercialized but demonstrate the interest of the scientific community to obtain information at or beyond the single-cell scale. To be in concordance with these technical improvements, the transfer of information from an MSI 
system to the LMD system needs to be accordingly accurate. To address this challenge, I have developed and presented in chapter $\mathbf{2}$ a workflow that enables the coregistration of MSI data to a LMD with high accuracy $(13 \mu \mathrm{m})$ achieving pixel size available on the state-of-the-art of most commercial instruments (range of $5-20 \mu \mathrm{m}$ ) ${ }^{[148,149]}$. This accuracy was also achieved because the same tissue section for both MSI and LC-MS experiments was used. This reduced and minimized potential sources of error when using consecutive tissue sections. The co-registration procedure used in chapter 2 was performed using a $5 \mathrm{x}$ magnifying objective lens under the microscope of the LMD which is equipped with a range of dedicated objectives from $5 \mathrm{x}$, $10 x, 20 x, 40 x$ to $63 x$. I have gathered indications that a co-registration with a higher magnification would also result in a higher accuracy (see supporting information in 7.1. "Precise co-registration of mass spectrometry imaging, histology, and laser microdissection-based omics").

Another important aspect in both studies is the co-registration process. Indeed, the co-registrations errors reported in this work refer to technical deviations introduced by the co-registration process itself based on human factor (selection of control points), resolution of images, geometric transformations, etc. Moreover, these co-registrations processes do not take into account additional errors due to morphological deformations during histological staining which would require more advanced coregistration tools such as non-rigid registration technique.

\section{Omics technologies}

In chapters 2 and 3, I focused my post-MSI investigation on the protein level for the investigation of intratumor heterogeneity in breast cancers. Indeed, the proteome is dynamic, executing and controlling the vast majority of biological processes. In both chapters, I optimized the microproteomics protocol to 2,000 cells (corresponding to $0.1 \mathrm{~mm}^{2}$ ) which was a good balance between sensitivity and feasibility and resulted in decent protein coverage/detection with a minimum of $1,500-2,000$ protein identifications per run. In contrast, regions of less than $0.1 \mathrm{~mm}^{2}$ were difficulty visible in the tube after microdissection which made it unfeasible to process and analyze less material. 
While my focus was on proteins, the post-MSI experiment of this spatial omics workflow could be applied to any type of omics technology as long as this technology is compatible with the previous MSI experiment and H\&E staining. Some adjustments might be required such as the omission of the histological staining in the case of the study of the metabolome due to the removal of small metabolites during the different washes. Next-generation sequencing technologies are also a possible option to obtain information on the DNA or RNA level from the different cell subpopulations.

This spatial omics workflow allows us to collect a huge amount of data using different modalities of omics data such as transcriptomics, genomics, and proteomics. This provides definitely a more complete picture of the biological processes and a better understanding of the complexity of biological systems. However, the integrative analysis of these multi-layer datasets remains challenging due to technical aspects such as the compatibility of methods in the workflow and suitable data analysis techniques. For example, in the spatial omics workflow presented in this thesis, the main challenges for the integration of the data were the use of two different ionization methods (MALDI for MSI and ESI for LC-MS) and the study of two different classes of molecules, namely lipid data generated by MSI and proteomics data generated by LC-MS. On one hand, the difficulty resides in the degree of overlap of the data obtained either by MALDI or ESI. For instance, Bodnar et al observed an overlap of $63 \%$ of proteins identified by LC-MS and MALDI-MS with both unique peptides and proteins for each method ${ }^{[150]}$. On the other hand, the second difficulty is the integration of lipid data with protein identities and quantities obtained by LC-MS. While some platforms already exist such as Galaxy or Bioconductor that allow to analyze large biomedical datasets such as genomics, proteomics, metabolomics, or imaging $[151,152]$, there is still a lack in protein-lipid interaction databases.

While instruments equipped with hybrid sources are commercially/noncommercially available, this spatial omics workflow on a single MS instrument was for the first time performed in chapter 3 with high performance for either part of the workflow (MALDI-MSI and LC-MS). I believe that the commercial availability of such an instrument will increase the use of this workflow due to the complementary of these two approaches. Indeed, the spatial omics workflow allows integrating the spatial information 
and the identities of thousands of molecules from the same molecular class or different molecular classes of which either holds great promise for the understanding of complex and local biological processes.

\section{Quantitative MSI}

While MSI provides spatial information on molecules, it falls short in their identification and quantitation. I therefore also established a new quantitative method for MSI using a set of labels of the target molecule.

\section{Single-label vs multi-label}

One of the advantages of MSI, compared to other tissue imaging techniques is, that it is a label-free technique. This has led to the spread of this technique in pharmaceutical research for drug discovery, drug disposition, or pharmacodynamics ${ }^{[153-155]}$. In contrast, one of the drawbacks of MSI is that it is a semi-quantitative method whereas often absolute quantification is required in pharmaceutical research and development. Nevertheless, quantitative MSI (Q-MSI) is not straightforward due to technical aspects such as analyte extraction efficiency, desorption, ionization, or ion competition because of the absence of chromatographic separation.

The use of internal standards can correct these mentioned factors. In chapter 4, I developed a new quantitative method that makes use of several isotope versions of a target molecule that were sprayed onto a tissue. This enables the creation of calibration curves at every measured position for further calculation of the quantities that take into consideration local differences in ionization efficiency. One crucial aspect is thereby the fit of the calibration function to the relationship between concentration and measured intensity based on regression analyses.

\section{Linearity of the calibration curves}

Regression functions are established from a set of data points representing intensities of the known concentrations. The single-label method offers the possibility to create an unlimited number of these data points. I demonstrated that its accuracy depends on the concentration range of the target compound where concentrations that are too far away from the applied standard were 
either underestimated or overestimated. That is why in the multi-label approach, the first step is to estimate the concentration coverage of the target compound. As shown in chapter 4, an inadequate concentration coverage leads to calibration curves that are out of linearity with therefore inaccuracies in the calculations of quantities. Moreover, in the case of low abundant target molecules, one of the labels would need to be even lower in concentration than the target molecule. This can result in the absence of detection or an increased influence of the noise in the signal of that lowest-concentration label in many pixels which could prevent the creation of reliable calibration curves at those pixels.

\section{A generic solution in Q-MSI?}

This new MALDI-Q-MSI can be in principle considered a generic solution but suffers from a major limitation namely the creation of a set of different labels. The main challenge remains the creation of several isotopes of the target molecule. Analogs of the molecule of interest are considered most effective for quantitation. Those analogs can differ in atoms, functional groups, or substructures. Many aspects need to be considered to synthesize such a structural analog such as the natural abundance of the molecule, the position of the labeling, structural uniqueness, stability, number of synthesis steps etc. Considering all these aspects can lead to very costly synthesis procedures, especially for small molecules.

In chapter 4, the amino-acid-based building-block nature of peptides allowed to obtain cheaply several distinct isotopically labeled versions of my target by synthesis. Although most quantitative MSI studies focus on small molecules, pharmaceutical companies are becoming of increasing interest in clinical diagnostics and therapy (for instance, the PSMA peptide ligands for radio-labeled prostate cancer therapy). The proposed technique can in principle also be used for small proteins and lipids; the modular setup of those molecular classes allows a more easy way of label synthesis.

\subsection{Outlook}

\section{Perspective of Spatial Omics workflow}

In this work, I have combined MALDI-MSI and LC-MS-based proteomics to better characterize tumor subpopulations in breast cancer tissue sections. 
These two techniques are perpetually improving and evolving towards better spatial resolution, better mass resolution, and better sensitivity/specificity. In the light of these developments, existing and new challenges will need to be addressed to improve the demonstrated spatial omics workflow which will be anticipated in the following paragraphs:

\section{Co-registration accuracy}

In this thesis, I achieved an accurate coupling of MSI to LMD with coregistration errors below $13 \mu \mathrm{m}$ which is in concordance with current daily spatial resolutions employed and available in the MSI community (namely 20 to $50 \mu \mathrm{m}$ ). However, as the spatial resolution of MSI and the laser microdissection systems are going towards subcellular resolution, the accuracy of co-registration between MSI data and other imaging modalities would need to follow the same trend. However, achieving such precise coregistration remains a real challenge. Scupakova et al achieved a coregistrations error below single-cell level using two types of co-registration approaches ${ }^{[73]}$. First, they performed a coarse co-registration by using fiducial markers that can be assimilated to the recognized procedure by the MSI community followed by a fine co-registration procedure using an automated intensity-based approach. The use of fiducial markers does not guarantee an accurate co-registration since they do not account for tissue deformations after MSI caused by, for instance, the histological staining. However, this approach requires a lot of manual interaction and cannot be applied in the context of daily usage. An automated and accurate coregistration procedure will become a new challenge in the future that would need to be tackled by the MSI community in order to correctly interpret or transfer MSI data.

\section{Need of systematic use of quality controls in MSI and LC-MS}

As mentioned throughout this thesis, this spatial omics workflow would constitute a great tool to study biological processes involved in cells or implemented in the future in clinical applications for biomarker discovery or therapeutic targets. To do so and obtain reliable and generalizable results, it becomes necessary to analyze large cohorts of samples and patients with statistical tools. During my $\mathrm{PhD}$, I analyzed 13 samples of 
cholangiocarcinomas at the level of the metabolites by MSI and restricted my statistical analysis to the tumor areas in order to investigate intratumor heterogeneity (Figure 6.2).

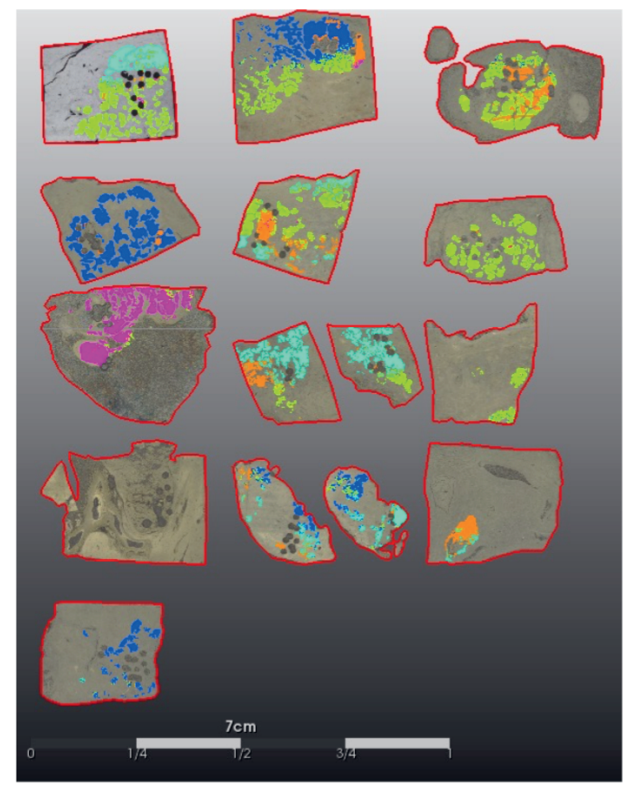

Figure 6.2. Simultaneous clustering of $\mathbf{1 3}$ cholangiocarcinomas samples.

A cohort of 13 cholangiocarcinomas samples was analyzed by MALDI-MSI at the metabolite level. After annotation of the tumor areas, a simultaneous clustering k-means was performed to highlight molecular intratumor heterogeneity across all samples.

One of the most important aspects when analyzing intra-tumor heterogeneity across different patients is to perform the segmentation simultaneously for all datasets in order to reveal tumor populations that are relevant for a larger group of patients with a certain clinical characteristic. In this perspective, it becomes crucial that technical variation is reduced to a maximum in order to enable a reliable and technically unbiased analysis to ultimately draw scientific conclusions. Indeed, many parameters can vary resulting in a lack of reproducibility such as sample preparation, MS-data acquisition, or data analysis. Adding to variability within a laboratory, variation can also happen among laboratories. For instance, in the LC-MS community, Bell et al revealed different results depending on the laboratory where the analysis had been performed ${ }^{[156]}$. Both techniques are very popular in the scientific 
community and have led to the development of a wide range of instrumentation and protocols. Therefore, there is an urgent need for systematic use of quality controls (QC) associated with standardized procedures in MSI and LC-MS.

These quality controls can be defined by setting guidelines and standards for scientific practice which require a large-scale effort by the communities (MSI and LC-MS). Practical considerations in QC would be to evaluate every part of the experiment from sample preparation, over instrument performance, to data analysis, but also evaluate the robustness by performing the experiments in different centers. For instance, over the recent past years, several multicenter studies were performed by the MSI community trying to assess various MSI capabilities showing the potential of MSI as robust method ${ }^{[157-159]}$. The same efforts were made by the LC-MS community towards this direction $[160$, 161]. These efforts are encouraging and increase the awareness of the problem by the different communities leading and helping to move towards discussion and possible measures of QC that would contribute to more reliability and transparency of MS studies.

\section{Multi-omics data handling}

As mentioned previously, biological processes are complex and require an integrative approach that combines multi-omics data such as the presented spatial omics workflow to understand the relationships between the biomolecules and their functions. Many studies have already shown the importance of combining omics data that leads to a better understanding of the studied system ${ }^{[162-164]}$. However, the coupling of spatial omics data with other non-spatial omics technologies is quite recent and the biggest challenge, in the near future, will reside in the analysis, the integration and, the interpretation of these data. Indeed, the newly developed platform will need to deal with huge amount of data generated by high-throughput technologies that enable the analysis of large cohort of samples and to deal with the heterogeneity in individual omics data sets. The file format of the individual omics data is also an important parameter because the omics data are generated using wide range of different platforms requiring a preprocessing that includes data filtering, normalization and, quality checks. Another aspect of multi-omics data interpretation would be the integration of non-omics data 
such as clinical information. Indeed, currently, there is currently no platform that enables the integration of multi-omics data with clinical data or other non-omics data as recently reviewed by Subramanian et al [165]. This association would constitute a very powerful tool in biomedical research.

\section{Perspective of quantitative MSI}

Quantitative MSI (Q-MSI) has been an expanding field in MSI over the years. It has demonstrated powerful capabilities and has widely increased its applications in pharmaceutical research and development. In this thesis, I quantified a tryptic peptide of the protein histone $\mathrm{H} 4$ which was used as proofof-principle. However, there is a growing interest in pharmaceutical research to target proteins due to their potential therapeutic roles. For instance, antibodies have a major impact on human health and could be used as antibody-drug conjugates to facilitate more effective delivery. In addition to that, it is interesting to note that the whole-body autoradiography which is the gold standard quantitative method that enables to quantify and localize molecules is mainly employed for the study of small molecules, therefore, the study of these proteins and their spatial distribution in tissues is of utmost interest.

However, Q-MSI suffers from the same obstacles as MSI in terms of method validation, standardization of sample preparation, data acquisition, and quality of the data. This standardization of MSI methods is in progress and would benefit in establishing Q-MSI as a robust method that would not need validation through other techniques ${ }^{[166,167]}$. Therefore, more validations are still required in order to comply with regulatory guidelines. The US Food and Drug Administration (FDA) has some recommendations to validate a bioanalytical method. The method needs to have appropriate sensitivity to measure different levels of the target molecule, repeatable high linearity and repeatable over replicate samples ${ }^{[168]}$. This includes having quality controls that assess the precision and the accuracy of the method and the stability of the sample. FDA provides recommendations for chromatographic assays but these criteria can only be partially translated to Q-MSI such as the calibration curve should be prepared in the same biological matrix with at least 7 points ( 6 points +1 blank). This is currently neither the case for the approach I presented (3-point calibration) nor for the single label method (not same 
biological matrix). Therefore Q-MSI now only fails from a validation point of view of the method. Thus, Q-MSI will become a gold standard method when the MSI community will have been able to demonstrate and validate their method using powerful quality control enabling to assess the precision and the accuracy of their measurement.

In this thesis, I have demonstrated two approaches that enable obtaining spatial and quantitative information in heterogeneous tissues. On one hand, I obtained this information for thousands of molecules using the spatial omics workflow. On the other hand, I employed a more targeted approach by MALDI-Q-MSI using different isotope versions of a target molecule. Both approaches constitute useful tools and building blocks for the next generation of MSI studies for a more comprehensive and quantitative molecular characterization of heterogeneous tissues and cells. 
106 Chapter 6 • Discussion and Outlook 


\section{Chapter 7}

Appendix 


\subsection{Precise co-registration of mass spectrometry imaging, histology, and laser microdissection-based omics.}

Supplementary Information:

The supplementary protocol 1 can be downloaded here (Dewez et al, 2019).

The supplementary figures 1-5 can be downloaded here (Dewez et al, 2019).

The supplementary tables 1-5 can be downloaded here (Dewez et al, 2019).

\subsection{MS imaging-guided microproteomics for spatial omics on} a single instrument.

Supplementary Information:

The supplementary information can be downloaded here (Dewez et al, 2020)

The supplementary figures 1 can be downloaded here (Dewez et al, 2020).

The supplementary tables 1-2 can be downloaded here (Dewez et al, 2020).

\subsection{Multi-label per pixel quantitation in Mass Spectrometry}

\section{Imaging}

Supplementary Information:

The Matlab code can be downloaded here (Dewez et al, 2021).

The supplementary method 1 can be downloaded here (Dewez et al, 2021).

The supplementary figures 1-6 can be downloaded here (Dewez et al, 2021). 


\section{Summary}

Molecular interactions are fundamental for an organism to live, reproduce or interact with its environment. These biological processes are characterized by complex interactions that occur in and between cells. Cells are the smallest units of life and constitute the "building blocks of life". In multicellular organisms, cells organize themselves spatially to form tissues and organs with each their dedicated biological function. Hence, the investigation of cellular processes requires an approach that takes the spatial context of the cells and thus the thousands of biomolecules into consideration. High-throughput technologies with spatially resolved capabilities are therefore required to identify and quantify these biomolecules.

Matrix-assisted laser desorption ionization mass spectrometry imaging (MALDI-MSI) is a molecular imaging technique that extends the analytical capability of mass spectrometry to spatially resolved analysis of tissue sections. The strengths of MALDI-MSI are the simultaneous analysis of hundreds to thousands of compounds with the possibility of combining its data with other imaging modalities or analytical methods. The combination of MALDI-MSI with analytical methods is of great interest as MALDI-MSI consists of the direct analysis from tissue section without the use of separation steps. This specificity can result in a poor molecular characterization and the detection of mainly abundant molecules. Therefore a coupling with other analytical techniques that are extraction-based approaches and, therefore, more sensitive such as liquid-chromatography mass spectrometry (LC-MS) has the potential of becoming a powerful complementary tool in translational biomedical research. However, this coupling requires the microdissection of the regions of interest, which are highlighted by MSI, by a laser microdissection system (LMD) while retaining the spatial information. Moreover, accurate co-registration between the MSI data and the LMD system is required due to technological advances in MALDI-MSI that now reach single-cell level. In chapter 2 , I achieved an accuracy of $13 \mu \mathrm{m}$ that corresponds to resolutions employed routinely in MALDI-MSI. In this chapter, MALDI-MSI of lipids followed by a segmentation were performed on a breast cancer tissue. After image processing, the coordinates of the MSI- 
detected segments were accurately transferred to the laser microdissection system for subsequent analysis. This work constitutes the first study that reports the accuracy of a coupling between MSI and a laser microdissection system. In chapter 3, I applied this approach to perform a multivariate spatial and quantitative characterization of molecular intratumor heterogeneity in tumor breast samples. First, I analyzed a tissue section at lipid level by MALDI-MSI revealing spatial and molecularly distinct tumor cell clusters that were further submitted to LC-MS. This provided quantitative information of several thousand proteins which enabled to deeply delve into the proteome of these cell subpopulations. Moreover, in this chapter, we employed the state-of-the-art mass spectrometer that enables to perform MALDI-MSI and LC-MS experiments on a single instrument.

MALDI-MSI is a semi-quantitative method due to fundamental chemical processes of the MALDI approach. This technique involves analyte extraction, crystallization, desorption, ionization efficiency, and ion suppression accentuated by the absence of chromatographic separation. Therefore, obtaining absolute quantitative data remains challenging. These challenges can be, in part, overcome by the use of an internal standard which is a structural analog or a stable isotope of the molecule of interest. This internal standard is then sprayed on top of the tissue section. In chapter 4, I developed a new spatial univariate quantitative method that makes use of several isotopic labeled versions of a molecule of interest. These standards are homogeneously sprayed in different concentrations onto the tissue. This enables the creation of internal calibration curves at every MSI pixel that reflects and accounts for the difference in signal response due to local histology-dependent ion suppression. This new multi-label approach enables to quantify more accurately target compound concentrations in heterogeneous biological tissues.

This thesis demonstrates two different approaches to obtain quantitative data from heterogenous tissue in a spatially resolved context. On one hand, this work presents a spatial omics workflow that enables to obtain the spatial distribution with quantitative information of thousands of biomolecules, albeit with the use of dissected material. On the other hand, the thesis presents 
a more targeted approach that enables to quantify a target compound within heterogeneous cell populations. Both approaches could constitute powerful analytical tools to obtain more accurate and more comprehensive information on the location and abundances of molecules within specific cells. 


\section{Samenvatting}

Moleculaire interacties zijn fundamenteel voor een organisme om te leven, zich te reproduceren of te interageren met hun omgeving. Deze biologische processen zijn gekenmerkt door complexe interacties die plaats vinden in en tussen cellen. Cellen zijn de kleinste levende eenheden en vormen de 'bouwstenen van het leven'. In meercellige organismen zijn cellen namelijk in staat om zichzelf ruimtelijk te organiseren in de vorm van weefsels en organen waarbij elke cel zijn eigen biologische functie heeft. Onderzoek naar cellulaire processen heeft er bijgevolg alle belang bij dat de ruimtelijke ordening van de cellen alsook de duizenden biomoleculen bewaard kan blijven. High-Throughput technologieën die de ruimtelijke oriëntatie behouden, zijn bijgevolg essentieel om biomoleculen niet alleen te identificeren maar ook te kwantificeren.

MALDI-MSI is een moleculaire beeldvormingstechniek die gebruik maakt van de analytische methode van massa spectrometrie en deze verder uitbreidt naar hun ruimtelijke ordening in het weefsel. MALDI-MSI is in staat om honderden tot duizenden componenten gelijktijdig te analyseren. MSI data kan gecombineerd worden met andere beeldvormingstechnieken of andere analytische methodes. De combinatie van MALDI-MSI met andere analytische methoden is van uitermate belang aangezien MALDI-MSI bestaat uit de directe analyse van weefsel secties zonder gebruik te maken van enige scheidingsstappen. Deze specificiteit kan resulteren in slechte moleculaire karakterisering en detectie van enkel de meest abundante moleculen.

MSI combineren met andere analytische technieken die gebaseerd zijn op extractie en daardoor meer gevoelig zijn zoals bijvoorbeeld 
vloeistofchromatografie - massa spectrometrie, kunnen een meerwaarde vormen in translationeel biomedisch onderzoek. Deze combinatie vereist echter de microdissectie van de door MSI gemarkeerde interessegebieden met behulp van een laser microdissectie systeem (LMD). Tijdens dit proces wordt de ruimtelijke informatie behouden. Dit proces vereist accurate co-registratie tussen de MSI data en het LMD systeem. Door technologische ontwikkelingen kan MALDI-MSI een zeer hoge resolutie bereiken tot op het niveau van één enkele cel. In hoofdstuk 2 kon ik een nauwkeurigheid van 13 $\mu \mathrm{m}$ bereiken. Dit komt overeen met resoluties die routinematig worden gebruikt in MALDI-MSI. In dit hoofdstuk, MALDI-MSI van lipiden gevolgd door segmentatie werd uitgevoerd op borstkanker weefsel. Na het verwerken van de afbeeldingen werden de coördinaten van de door MSI gedetecteerde segmenten nauwkeurig getransfereerd naar het LMD systeem voor verdere analyse. Dit werk rapporteert als eerste de nauwkeurigheid van de combinatie van MSI en LMD. In hoofdstuk 3 heb ik deze benadering toegepast op tumorweefsel van borstkanker om zo intratumorale heterogeniteit op een multivariate, ruimtelijke en kwantitatieve manier te karakteriseren. Eerst heb ik een weefsel sectie geanalyseerd op lipiden met MALDI-MSI waarbij zo de ruimtelijk, moleculaire en duidelijk te onderscheiden tumor cellen clusters zichtbaar werden. Deze tumorcellen werden dan verder geanalyseerd met LCMS. De combinatie van MALDI-MSI met LC-MS zorgde voor kwantitatieve informatie van enkele duizenden proteïnen. Deze gedetailleerde informatie maakt het mogelijk zich te verdiepen in het proteoom van deze cel subpopulaties. Bovendien hebben we in dit hoofdstuk gebruik gemaakt van een state-of-the-art massa spectrometer dat in staat is om MALDI-MSI en LC-MS experimenten in één enkel instrument uit te voeren. 
MALDI-MSI kan beschouwd worden als een semi-kwantitatieve methode veroorzaakt door de fundamentele chemische processen van het MALDI proces. Deze processen omvatten analiet extractie, kristallisatie, desorptie, ionisatie efficiëntie en ion-suppressie die dan nog eens versterkt worden door de afwezigheid van chromatografische scheiding. Absolute kwantitatieve data met behulp van MSI blijft een uitdaging, doch kan dit deels opgelost worden door gebruik te maken van interne standaarden. Deze interne standaard kan een structureel analoog zijn of een stabiel isotoop van het specifiek molecule. Deze standaard worden dan gesprayd bovenop het weefsel. In hoofdstuk 4 hebben wij een nieuwe ruimtelijke univariate kwantitatieve methode ontwikkeld die gebruik maakt van verschillende isotoop gelabelde versies van een specifiek molecuul. Deze werden homogeen in verschillende concentraties op het weefsel gesprayd. Met behulp van deze methode is het mogelijk om voor elke MSI-pixel interne calibratie curven te maken. Deze curven weerspiegelen en houden rekening met het verschil in signaalrespons ten gevolge van lokale ion-suppressie. Op die manier is het mogelijk om de exacte concentratie van het specifiek molecule te bepalen.

Dit proefschrift beschrijft twee verschillende benaderingen om kwantitatieve gegevens te verkrijgen uit heterogeen weefsel waarbij de ruimtelijke informatie behouden blijft. Aan de ene kant presenteert dit werk een ruimtelijke 'omics' workflow die het mogelijk maakt om niet alleen de ruimtelijke distributie van duizenden biomoleculen te verkrijgen maar ook kwantitatieve informatie, al dan niet door gebruik te maken van ontleed materiaal. Anderzijds, presenteert het een meer gerichte aanpak die het mogelijk maakt om een specifiek molecule van belang te kwantificeren 
binnen heterogene cel populaties. Beide benaderingen zouden krachtige analytische instrumenten kunnen vormen om meer nauwkeurig en uitgebreide informatie te verkrijgen over de plaats en de abundanties van verschillende moleculen binnen specifieke cellen. 


\section{References}

[1] E. Gubb, R. Matthiesen, Methods Mol Biol 2010, 593, 1.

[2] N. Cancer Genome Atlas Research, Nature 2011, 474, 609.

[3] T. Simoes, S. C. Novais, T. Natal-da-Luz, B. Devreese, T. de Boer, D. Roelofs, J. P. Sousa, N. M. van Straalen, M. F. L. Lemos, Sci Rep 2018, 8, 11376.

[4] A. Ebrahim, E. Brunk, J. Tan, E. J. O'Brien, D. Kim, R. Szubin, J. A. Lerman, A. Lechner, A. Sastry, A. Bordbar, A. M. Feist, B. O. Palsson, Nat Commun 2016, 7, 13091.

[5] E. C. Stack, C. Wang, K. A. Roman, C. C. Hoyt, Methods 2014, 70, 46.

[6] D. Wang, S. Bodovitz, Trends Biotechnol 2010, 28, 281.

[7] W. Chen, S. Li, A. S. Kulkarni, L. Huang, J. Cao, K. Qian, J. Wan, Biotechnol J 2020, 15, e1900262.

[8] C. X. Zhu, S. Preissl, B. Ren, Nature Methods 2020, 17, 11.

[9] W. Wien, Annalen der Physik 1898, 301, 440.

[10] M. Maia, F. Monteiro, M. Sebastiana, A. P. Marques, A. E. N. Ferreira, A. P. Freire, C. Cordeiro, A. Figueiredo, M. Sousa Silva, EuPA Open Proteom 2016, 12 , 4.

[11] A. Secher, C. D. Kelstrup, K. W. Conde-Frieboes, C. Pyke, K. Raun, B. S. Wulff, J. V. Olsen, Nat Commun 2016, 7, 11436.

[12] D. C. Liebler, L. J. Zimmerman, Biochemistry 2013, 52, 3797.

[13] R. Lakshmanan, J. A. Loo, Int J Mass Spectrom 2019, 435, 136.

[14] J. Lenco, M. Vajrychova, K. Pimkova, M. Proksova, M. Benkova, J. Klimentova, V. Tambor, O. Soukup, Anal Chem 2018, 90, 5381.

[15] P. Chaurand, S. A. Schwartz, R. M. Capriolo, Anal Chem 2004, 76, 87A.

[16] M. Stoeckli, P. Chaurand, D. E. Hallahan, R. M. Caprioli, Nat Med 2001, 7, 493.

[17] Y. Schober, S. Guenther, B. Spengler, A. Rompp, Rapid Communications in Mass Spectrometry 2012, 26, 1141. 
[18] M. C. Djidja, S. Francese, P. M. Loadman, C. W. Sutton, P. Scriven, E. Claude, M. F. Snel, J. Franck, M. Salzet, M. R. Clench, AXRAAA 2009, 9, 2750.

[19] S. Lou, B. Balluff, A. H. G. Cleven, J. V. M. G. Bovee, L. A. McDonnell, J Am Soc Mass Spectrom 2017, 28, 376.

[20] A. Ly, A. Buck, B. Balluff, N. Sun, K. Gorzolka, A. Feuchtinger, K. P. Janssen, P. J. Kuppen, C. J. van de Velde, G. Weirich, F. Erlmeier, R. Langer, M. Aubele, H. Zitzelsberger, L. McDonnell, M. Aichler, A. Walch, Nat Protoc 2016, 11, 1428.

[21] M. Rujoi, R. Estrada, M. C. Yappert, Anal Chem 2004, 76, 1657.

[22] S. R. Ellis, M. R. L. Paine, G. B. Eijkel, J. K. Pauling, P. Husen, M. W. Jervelund, M. Hermansson, C. S. Ejsing, R. M. A. Heeren, Nat Methods 2018, 15, 515.

[23] M. Karas, F. Hillenkamp, Anal Chem 1988, 60, 2299.

[24] F. Hillenkamp, M. Karas, R. C. Beavis, B. T. Chait, Anal Chem 1991, 63, 1193A.

[25] H. R. Morris, T. Paxton, A. Dell, J. Langhorne, M. Berg, R. S. Bordoli, J. Hoyes, R. H. Bateman, Rapid Commun Mass Spectrom 1996, 10, 889.

[26] D. R. Allen, B. C. McWhinney, Clin Biochem Rev 2019, 40, 135.

[27] B. K. Kaletas, I. M. van der Wiel, J. Stauber, J. D. Lennard, C. Guzel, J. M. Kros, T. M. Luider, R. M. Heeren, AXRAAA 2009, 9, 2622.

[28] J. Malm, D. Giannaras, M. O. Riehle, N. Gadegaard, P. Sjovall, Anal Chem 2009, 81, 7197 .

[29] R. J. A. Goodwin, J Proteomics 2012, 75, 4893.

[30] R. Casadonte, R. M. Caprioli, Nat Protoc 2011, 6, 1695.

[31] R. Kruse, J. V. Sweedler, J Am Soc Mass Spectrom 2003, 14, 752.

[32] S. A. Schwartz, M. L. Reyzer, R. M. Caprioli, J Mass Spectrom 2003, 38, 699.

[33] R. Lemaire, M. Wisztorski, A. Desmons, J. C. Tabet, R. Day, M. Salzet, I. Fournier, Anal Chem 2006, 78, 7145.

[34] M. R. Groseclose, M. Andersson, W. M. Hardesty, R. M. Caprioli, J Mass Spectrom 2007, 42, 254. 
[35] L. Maneta-Peyret, P. Compere, P. Moreau, G. Goffinet, C. Cassagne, Histochem $J 1999,31,541$.

[36] E. H. Seeley, S. R. Oppenheimer, D. Mi, P. Chaurand, R. M. Caprioli, J Am Soc Mass Spectrom 2008, 19, 1069.

[37] P. Chaurand, J. L. Norris, D. S. Cornett, J. A. Mobley, R. M. Caprioli, Journal of Proteome Research 2006, 5, 2889.

[38] M. Andersson, M. R. Groseclose, A. Y. Deutch, R. M. Caprioli, Nat Methods 2008, 5, 101.

[39] A. Ljungdahl, J. Hanrieder, M. Falth, J. Bergquist, M. Andersson, PLoS One 2011, 6, e25653.

[40] K. Kakimoto, S. Takekoshi, K. Miyajima, R. Y. Osamura, J Mol Histol 2008, $39,389$.

[41] K. Erich, D. A. Sammour, A. Marx, C. Hopf, Biochim Biophys Acta Proteins Proteom 2017, 1865, 907.

[42] R. Zenobi, R. Knochenmuss, Mass Spectrometry Reviews 1998, 17, 337.

[43] M. L. Reyzer, Y. Hsieh, K. Ng, W. A. Korfmacher, R. M. Caprioli, J Mass Spectrom 2003, 38, 1081.

[44] T. C. Rohner, D. Staab, M. Stoeckli, Mech Ageing Dev 2005, 126, 177.

[45] R. M. Caprioli, T. B. Farmer, J. Gile, Anal Chem 1997, 69, 4751.

[46] J. A. Hankin, R. M. Barkley, R. C. Murphy, J Am Soc Mass Spectrom 2007, 18, 1646.

[47] J. Yang, R. M. Caprioli, Anal Chem 2011, 83, 5728.

[48] R. Lemaire, J. C. Tabet, P. Ducoroy, J. B. Hendra, M. Salzet, I. Fournier, Anal Chem 2006, 78, 809 .

[49] E. Gemperline, S. Rawson, L. Li, Anal Chem 2014, 86, 10030.

[50] L. R. S. Huizing, S. R. Ellis, B. W. A. M. M. Beulen, F. P. Y. Barre, P. B. Kwant, R. J. Vreeken, R. M. A. Heeren, Clin Mass Spectrom 2019, 12, 7.

[51] K. Scupakova, B. Balluff, C. Tressler, T. Adelaja, R. M. A. Heeren, K. Glunde, G. Ertaylan, Clin Chem Lab Med 2020, 58, 914.

[52] A. J. Taylor, A. Dexter, J. Bunch, Anal Chem 2018, 90, 5637. 
[53] M. R. Groseclose, S. Castellino, Anal Chem 2013, 85, 10099.

[54] T. Porta, A. Lesur, E. Varesio, G. Hopfgartner, Anal Bioanal Chem 2015, 407, 2177.

[55] J. G. Swales, A. Dexter, G. Hamm, A. Nilsson, N. Strittmatter, F. Michopoulos,

C. Hardy, P. Morentin-Gutierrez, M. Mellor, P. E. Andren, M. R. Clench, J. Bunch, S. E. Critchlow, R. J. A. Goodwin, Anal Chem 2018, 90, 6051.

[56] J. J. van Kampen, P. C. Burgers, R. de Groot, T. M. Luider, Anal Chem 2006, 78,5403 .

[57] F. P. Barre, B. Flinders, J. P. Garcia, I. Jansen, L. R. Huizing, T. Porta, L. B. Creemers, R. M. Heeren, B. Cillero-Pastor, Anal Chem 2016, 88, 12051.

[58] Q. Wu, S. S. Rubakhin, J. V. Sweedler, Anal Chem 2020, 92, 6613.

[59] G. Hamm, D. Bonnel, R. Legouffe, F. Pamelard, J. M. Delbos, F. Bouzom, J. Stauber, J Proteomics 2012, 75, 4952.

[60] S. O. Deininger, D. S. Cornett, R. Paape, M. Becker, C. Pineau, S. Rauser, A. Walch, E. Wolski, Anal Bioanal Chem 2011, 401, 167.

[61] T. Alexandrov, M. Becker, S. O. Deininger, G. Ernst, L. Wehder, M. Grasmair, F. von Eggeling, H. Thiele, P. Maass, J Proteome Res 2010, 9, 6535.

[62] R. J. Carreira, R. Shyti, B. Balluff, W. M. Abdelmoula, S. H. van Heiningen, R. J. van Zeijl, J. Dijkstra, M. D. Ferrari, E. A. Tolner, L. A. McDonnell, A. M. van den Maagdenberg, J Am Soc Mass Spectrom 2015, 26, 853.

[63] N. Verbeeck, R. M. Caprioli, R. Van de Plas, Mass Spectrom Rev 2020, 39, 245.

[64] E. A. Jones, A. van Remoortere, R. J. van Zeijl, P. C. Hogendoorn, J. V. Bovee, A. M. Deelder, L. A. McDonnell, PLoS One 2011, 6, e24913.

[65] P. Chaurand, S. A. Schwartz, D. Billheimer, B. J. Xu, A. Crecelius, R. M. Caprioli, Anal Chem 2004, 76, 1145.

[66] K. Schwamborn, R. C. Krieg, M. Reska, G. Jakse, R. Knuechel, A. Wellmann, International Journal of Molecular Medicine 2007, 20, 155.

[67] A. C. Crecelius, D. S. Cornett, R. M. Caprioli, B. Williams, B. M. Dawant, B. Bodenheimer, J Am Soc Mass Spectrom 2005, 16, 1093. 
[68] V. M. S. Paresh M. Patel International Journal of innovative research \& development $\mathbf{2 0 1 4}$.

[69] W. M. Abdelmoula, R. J. Carreira, R. Shyti, B. Balluff, R. J. van Zeijl, E. A. Tolner, B. F. Lelieveldt, A. M. van den Maagdenberg, L. A. McDonnell, J. Dijkstra, Anal Chem 2014, 86, 3947.

[70] W. M. Abdelmoula, K. Skraskova, B. Balluff, R. J. Carreira, E. A. Tolner, B. P. Lelieveldt, L. van der Maaten, H. Morreau, A. M. van den Maagdenberg, R. M. Heeren, L. A. McDonnell, J. Dijkstra, Anal Chem 2014, 86, 9204.

[71] W. M. Abdelmoula, M. S. Regan, B. G. C. Lopez, E. C. Randall, S. Lawler, A. C. Mladek, M. O. Nowicki, B. M. Marin, J. N. Agar, K. R. Swanson, T. Kapur, J. N. Sarkaria, W. Wells, N. Y. R. Agar, Anal Chem 2019, 91, 6206.

[72] F. Dewez, M. Martin-Lorenzo, M. Herfs, D. Baiwir, G. Mazzucchelli, E. De Pauw, R. M. A. Heeren, B. Balluff, Anal Bioanal Chem 2019, 411, 5647.

[73] K. Scupakova, F. Dewez, A. K. Walch, R. M. A. Heeren, B. Balluff, Angew Chem Int Ed Engl 2020.

[74] S. Klein, M. Staring, K. Murphy, M. A. Viergever, J. P. Pluim, IEEE Trans Med Imaging 2010, 29, 196.

[75] X. Papademetris, A. P. Jackowski, R. T. Schultz, L. H. Staib, J. S. Duncan, Med Image Comput Comput Assist Interv 2001, 3216, 763.

[76] M. Abdel-Basset, A. E. Fakhry, I. El-Henawy, T. Qiu, A. K. Sangaiah, J Med Syst 2017, 41, 197.

[77] R. Van de Plas, J. Yang, J. Spraggins, R. M. Caprioli, Nat Methods 2015, 12, 366.

[78] D. Alberts, C. Pottier, N. Smargiasso, D. Baiwir, G. Mazzucchelli, P. Delvenne, M. Kriegsmann, D. Kazdal, A. Warth, E. De Pauw, R. Longuespee, Proteomics Clin Appl 2018, 12 .

[79] M. Dilillo, D. Pellegrini, R. Ait-Belkacem, E. L. de Graaf, M. Caleo, L. A. McDonnell, Journal of Proteome Research 2017, 16, 2993.

[80] C. J. Ong, Q. X. Tan, H. J. Lim, N. B. Shannon, W. K. Lim, J. Hendrikson, W. H. Ng, J. W. S. Tan, K. K. N. Koh, S. D. Wasudevan, C. C. Y. Ng, V. Rajasegaran, 
T. K. H. Lim, C. K. Ong, O. L. Kon, B. T. Teh, G. H. C. Tan, C. S. Chia, K. C. Soo, M. C. C. Teo, Sci Rep 2020, 10, 682.

[81] S. Valleix, G. Verona, N. Jourde-Chiche, B. Nedelec, P. P. Mangione, F. Bridoux, A. Mange, A. Dogan, J. M. Goujon, M. Lhomme, C. Dauteuille, M. Chabert, R. Porcari, C. A. Waudby, A. Relini, P. J. Talmud, O. Kovrov, G. Olivecrona, M. Stoppini, J. Christodoulou, P. N. Hawkins, G. Grateau, M. Delpech, A. Kontush, J. D. Gillmore, A. D. Kalopissis, V. Bellotti, Nat Commun 2016, 7, 10353.

[82] D. C. Hondius, P. van Nierop, K. W. Li, J. J. Hoozemans, R. C. van der Schors, E. S. van Haastert, S. M. van der Vies, A. J. Rozemuller, A. B. Smit, Alzheimers Dement 2016, $12,654$.

[83] S. K. Maier, H. Hahne, A. M. Gholami, B. Balluff, S. Meding, C. Schoene, A. K. Walch, B. Kuster, Mol Cell Proteomics 2013, 12, 2901.

[84] S. Neupert, H. A. Johard, D. R. Nassel, R. Predel, Anal Chem 2007, 79, 3690. [85] M. B. Strader, D. L. Tabb, W. J. Hervey, C. Pan, G. B. Hurst, Anal Chem 2006, $78,125$.

[86] S. C. Kim, Y. Chen, S. Mirza, Y. Xu, J. Lee, P. Liu, Y. Zhao, J Proteome Res 2006, $5,3446$.

[87] R. Longuespee, D. Alberts, C. Pottier, N. Smargiasso, G. Mazzucchelli, D. Baiwir, M. Kriegsmann, M. Herfs, J. Kriegsmann, P. Delvenne, E. De Pauw, Methods 2016, 104, 154.

[88] M. Yamashita, J. B. Fenn, The Journal of Physical Chemistry 1984, 88, 4451.

[89] S. Banerjee, S. Mazumdar, Int J Anal Chem 2012, 2012, 282574.

[90] I. K. Chu, C. K. Siu, J. K. C. Lau, W. K. Tang, X. Y. Mu, C. K. Lai, X. H. Guo, X. Wang, N. Li, Y. Xia, X. L. Kong, H. B. Oh, V. Ryzhov, F. Turecek, A. C. Hopkinson, K. W. M. Siu, International Journal of Mass Spectrometry 2015, 390, 24.

[91] I. A. Papayannopoulos, Mass Spectrometry Reviews 1995, 14, 49.

[92] H. Liu, R. G. Sadygov, J. R. Yates, 3rd, Anal Chem 2004, 76, 4193. 
[93] D. Chelius, P. V. Bondarenko, J Proteome Res 2002, 1, 317.

[94] J. Cox, M. Y. Hein, C. A. Luber, I. Paron, N. Nagaraj, M. Mann, Mol Cell Proteomics 2014, 13, 2513.

[95] L. A. McDonnell, R. M. A. Heeren, Mass Spectrometry Reviews 2007, 26, 606.

[96] B. Balluff, C. K. Frese, S. K. Maier, C. Schöne, B. Kuster, M. Schmitt, M. Aubele, H. Höfler, A. M. Deelder, A. J. R. Heck, P. C. W. Hogendoorn, J. Morreau, A. F. Maarten Altelaar, A. Walch, L. A. McDonnell, The Journal of Pathology 2015, 235,3 .

[97] N. H. Patterson, E. Yang, E. A. Kranjec, P. Chaurand, Bioinformatics 2019, 35, 1261 .

[98] B. Heijs, W. M. Abdelmoula, S. Lou, I. H. Briaire-de Bruijn, J. Dijkstra, J. V. Bovee, L. A. McDonnell, Anal Chem 2015, 87, 11978.

[99] D. Alberts, C. Pottier, N. Smargiasso, D. Baiwir, G. Mazzucchelli, P. Delvenne, M. Kriegsmann, D. Kazdal, A. Warth, E. De Pauw, R. Longuespée, PROTEOMICS - Clinical Applications 2018, 12, 1700062.

[100] R. Longuespée, D. Alberts, C. Pottier, N. Smargiasso, G. Mazzucchelli, D. Baiwir, M. Kriegsmann, M. Herfs, J. Kriegsmann, P. Delvenne, E. De Pauw, Methods 2016, 104, 154.

[101] S. Tyanova, T. Temu, P. Sinitcyn, A. Carlson, M. Y. Hein, T. Geiger, M. Mann, J. Cox, Nat Methods 2016, 13, 731.

[102] H. Mi, A. Muruganujan, J. T. Casagrande, P. D. Thomas, Nat Protoc 2013, 8, 1551 .

[103] C. W. Wang, S. M. Ka, A. Chen, Sci Rep 2014, 4, 6050.

[104] A. Stahlberg, M. Kubista, P. Aman, Expert Rev Mol Diagn 2011, 11, 735.

[105] A. Grunberger, W. Wiechert, D. Kohlheyer, Curr Opin Biotechnol 2014, 29, 15 .

[106] M. Niehaus, J. Soltwisch, M. E. Belov, K. Dreisewerd, Nat Methods 2019, 16, 925. 
[107] B. Balluff, C. K. Frese, S. K. Maier, C. Schone, B. Kuster, M. Schmitt, M. Aubele, H. Hofler, A. M. Deelder, A. Heck, Jr., P. C. Hogendoorn, J. Morreau, A. F. Maarten Altelaar, A. Walch, L. A. McDonnell, J Pathol 2015, 235, 3.

[108] J. M. Spraggins, K. V. Djambazova, E. S. Rivera, L. G. Migas, E. K. Neumann, A. Fuetterer, J. Suetering, N. Goedecke, A. Ly, R. Van de Plas, R. M. Caprioli, Anal Chem 2019, 91, 14552.

[109] Y. Perez-Riverol, A. Csordas, J. Bai, M. Bernal-Llinares, S. Hewapathirana, D. J. Kundu, A. Inuganti, J. Griss, G. Mayer, M. Eisenacher, E. Perez, J. Uszkoreit, J. Pfeuffer, T. Sachsenberg, S. Yilmaz, S. Tiwary, J. Cox, E. Audain, M. Walzer, A. F. Jarnuczak, T. Ternent, A. Brazma, J. A. Vizcaino, Nucleic Acids Res 2019, 47, D442.

[110] X. Mao, J. He, T. Li, Z. Lu, J. Sun, Y. Meng, Z. Abliz, J. Chen, Sci Rep 2016, $6,21043$.

[111] M. Hilvo, C. Denkert, L. Lehtinen, B. Muller, S. Brockmoller, T. SeppanenLaakso, J. Budczies, E. Bucher, L. Yetukuri, S. Castillo, E. Berg, H. Nygren, M. Sysi-Aho, J. L. Griffin, O. Fiehn, S. Loibl, C. Richter-Ehrenstein, C. Radke, T. Hyotylainen, O. Kallioniemi, K. Iljin, M. Oresic, Cancer Res 2011, 71, 3236.

[112] K. Moro, T. Kawaguchi, J. Tsuchida, E. Gabriel, Q. Qi, L. Yan, T. Wakai, K. Takabe, M. Nagahashi, Oncotarget 2018, 9, 19874.

[113] N. C. Murphy, A. V. Biankin, E. K. Millar, C. M. McNeil, S. A. O'Toole, D. Segara, P. Crea, M. A. Olayioye, C. S. Lee, S. B. Fox, A. L. Morey, M. Christie, E. A. Musgrove, R. J. Daly, G. J. Lindeman, S. M. Henshall, J. E. Visvader, R. L. Sutherland, Int J Cancer 2010, 126, 1445.

[114] P. D. Piehowski, Y. Zhu, L. M. Bramer, K. G. Stratton, R. Zhao, D. J. Orton, R. J. Moore, J. Yuan, H. D. Mitchell, Y. Gao, B. M. Webb-Robertson, S. K. Dey, R. T. Kelly, K. E. Burnum-Johnson, Nat Commun 2020, 11, 8.

[115] L. A. McDonnell, R. M. Heeren, Mass Spectrom Rev 2007, 26, 606.

[116] J. L. Norris, R. M. Caprioli, Chem Rev 2013, 113, 2309.

[117] P. M. Vaysse, R. M. A. Heeren, T. Porta, B. Balluff, Analyst 2017, 142, 2690. 
[118] B. Prideaux, M. Stoeckli, J Proteomics 2012, 75, 4999.

[119] S. R. Ellis, A. L. Bruinen, R. M. Heeren, Anal Bioanal Chem 2014, 406, 1275.

[120] S. Schulz, M. Becker, M. R. Groseclose, S. Schadt, C. Hopf, Curr Opin Biotechnol 2019, 55, 51.

[121] L. Signor, E. Varesio, R. F. Staack, V. Starke, W. F. Richter, G. Hopfgartner, J Mass Spectrom 2007, 42, 900.

[122] A. Nilsson, R. J. Goodwin, M. Shariatgorji, T. Vallianatou, P. J. Webborn, P. E. Andren, Anal Chem 2015, 87, 1437.

[123] R. Knochenmuss, F. Dubois, M. J. Dale, R. Zenobi, Rapid Communications in Mass Spectrometry 1996, 10, 871.

[124] T. E. Fehniger, A. Vegvari, M. Rezeli, K. Prikk, P. Ross, M. Dahlback, G. Edula, R. Sepper, G. Marko-Varga, Anal Chem 2011, 83, 8329.

[125] M. R. Groseclose, P. P. Massion, P. Chaurand, R. M. Caprioli, AXRAAA 2008, 8,3715 .

[126] I. Lanekoff, S. L. Stevens, M. P. Stenzel-Poore, J. Laskin, Analyst 2014, 139, 3528 .

[127] D. Abu Sammour, C. Marsching, A. Geisel, K. Erich, S. Schulz, C. Ramallo Guevara, J. H. Rabe, A. Marx, P. Findeisen, P. Hohenberger, C. Hopf, Sci Rep 2019, 9, 10698.

[128] H. C. Diehl, B. Beine, J. Elm, D. Trede, M. Ahrens, M. Eisenacher, K. Marcus, H. E. Meyer, C. Henkel, Analytical and Bioanalytical Chemistry 2015, 407, 2223.

[129] M. B. O'Rourke, M. P. Padula, C. Smith, P. Youssef, S. Cordwell, P. Witting, G. Sutherland, B. Crossett, J Vis Exp 2018.

[130] P. Robbe, N. Popitsch, S. J. L. Knight, P. Antoniou, J. Becq, M. He, A. Kanapin, A. Samsonova, D. V. Vavoulis, M. T. Ross, Z. Kingsbury, M. Cabes, S. D. C. Ramos, S. Page, H. Dreau, K. Ridout, L. J. Jones, A. Tuff-Lacey, S. Henderson, J. Mason, F. M. Buffa, C. Verrill, D. Maldonado-Perez, I. Roxanis, E. Collantes, L. Browning, S. Dhar, S. Damato, S. Davies, M. Caulfield, D. R. Bentley, J. C. Taylor, C. Turnbull, A. Schuh, G. Project, Genet Med 2018, 20, 1196. 
[131] A. K. Turnbull, C. Selli, C. Martinez-Perez, A. Fernando, L. Renshaw, J. Keys, J. D. Figueroa, X. He, M. Tanioka, A. F. Munro, L. Murphy, A. Fawkes, R. Clark, A. Coutts, C. M. Perou, L. A. Carey, J. M. Dixon, A. H. Sims, BMC Bioinformatics 2020, 21,30 .

[132] S. T. P. Mezger, A. M. A. Mingels, O. Bekers, R. M. A. Heeren, B. CilleroPastor, Anal Chem 2021, 93, 2527.

[133] J. R. Wisniewski, P. Ostasiewicz, M. Mann, J Proteome Res 2011, 10, 3040.

[134] V. Patel, B. L. Hood, A. A. Molinolo, N. H. Lee, T. P. Conrads, J. C. Braisted, D. B. Krizman, T. D. Veenstra, J. S. Gutkind, Clin Cancer Res 2008, 14, 1002.

[135] R. A. Craven, N. Totty, P. Harnden, P. J. Selby, R. E. Banks, Am J Pathol 2002, 160, 815 .

[136] S. Mukherjee, J. Rodriguez-Canales, J. Hanson, M. R. Emmert-Buck, M. A. Tangrea, D. A. Prieto, J. Blonder, D. J. Johann, Jr., Methods Mol Biol 2013, 1002, 71.

[137] Z. Ezzoukhry, E. Henriet, F. P. Cordelieres, J. W. Dupuy, M. Maitre, N. Gay, S. Di-Tommaso, L. Mercier, J. G. Goetz, M. Peter, F. Bard, V. Moreau, A. A. Raymond, F. Saltel, Nat Commun 2018, 9, 2031.

[138] T. Garcia-Berrocoso, V. Llombart, L. Colas-Campas, A. Hainard, V. Licker, A. Penalba, L. Ramiro, A. Simats, A. Bustamante, E. Martinez-Saez, F. Canals, J. C. Sanchez, J. Montaner, Mol Cell Proteomics 2018, 17, 175.

[139] E. Cuadrado, A. Rosell, A. Penalba, M. Slevin, J. Alvarez-Sabin, A. OrtegaAznar, J. Montaner, J Proteome Res 2009, 8, 3191.

[140] A. Turtoi, A. Blomme, D. Debois, J. Somja, D. Delvaux, G. Patsos, E. Di Valentin, O. Peulen, E. N. Mutijima, E. De Pauw, P. Delvenne, O. Detry, V. Castronovo, Hepatology 2014, 59, 924.

[141] C. Lombard-Banek, S. Reddy, S. A. Moody, P. Nemes, Mol Cell Proteomics 2016, 15, 2756.

[142] K. Nakatani, Y. Izumi, K. Hata, T. Bamba, Mass Spectrom (Tokyo) 2020, 9 , A0080. 
[143] M. E. Duenas, J. J. Essner, Y. J. Lee, Sci Rep 2017, 7, 14946.

[144] T. L. Colliver, C. L. Brummel, M. L. Pacholski, F. D. Swanek, A. G. Ewing, N. Winograd, Anal Chem 1997, 69, 2225.

[145] M. Kompauer, S. Heiles, B. Spengler, Nat Methods 2017, 14, 90.

[146] A. Zavalin, E. M. Todd, P. D. Rawhouser, J. Yang, J. L. Norris, R. M. Caprioli, J Mass Spectrom 2012, 47, 1473.

[147] A. Zavalin, J. Yang, R. Caprioli, J Am Soc Mass Spectrom 2013, 24, 1153.

[148] N. Ogrinc Potocnik, T. Porta, M. Becker, R. M. Heeren, S. R. Ellis, Rapid Commun Mass Spectrom 2015, 29, 2195.

[149] M. E. Belov, S. R. Ellis, M. Dilillo, M. R. L. Paine, W. F. Danielson, G. A. Anderson, E. L. de Graaf, G. B. Eijkel, R. M. A. Heeren, L. A. McDonnell, Anal Chem 2017, 89, 7493.

[150] W. M. Bodnar, R. K. Blackburn, J. M. Krise, M. A. Moseley, J Am Soc Mass Spectrom 2003, 14, 971.

[151] E. Afgan, D. Baker, B. Batut, M. van den Beek, D. Bouvier, M. Cech, J. Chilton, D. Clements, N. Coraor, B. A. Gruning, A. Guerler, J. Hillman-Jackson, S. Hiltemann, V. Jalili, H. Rasche, N. Soranzo, J. Goecks, J. Taylor, A. Nekrutenko, D. Blankenberg, Nucleic Acids Res 2018, 46, W537.

[152] W. Huber, V. J. Carey, R. Gentleman, S. Anders, M. Carlson, B. S. Carvalho, H. C. Bravo, S. Davis, L. Gatto, T. Girke, R. Gottardo, F. Hahne, K. D. Hansen, R. A. Irizarry, M. Lawrence, M. I. Love, J. MacDonald, V. Obenchain, A. K. Oles, H. Pages, A. Reyes, P. Shannon, G. K. Smyth, D. Tenenbaum, L. Waldron, M. Morgan, Nat Methods 2015, 12, 115.

[153] R. J. Goodwin, J. Bunch, D. F. McGinnity, Adv Cancer Res 2017, 134, 133.

[154] T. Rao, Y. Shao, N. Hamada, Y. Li, H. Ye, D. Kang, B. Shen, X. Li, X. Yin, Z. Zhu, H. Li, L. Xie, G. Wang, Y. Liang, Anal Chim Acta 2017, 952, 71.

[155] N. Sun, I. E. Fernandez, M. Wei, Y. Wu, M. Aichler, O. Eickelberg, A. Walch, Histochem Cell Biol 2016, 145, 201.

[156] A. W. Bell, E. W. Deutsch, C. E. Au, R. E. Kearney, R. Beavis, S. Sechi, T. Nilsson, J. J. Bergeron, H. T. S. W. Group, Nat Methods 2009, 6, 423. 
[157] T. J. Dekker, B. D. Balluff, E. A. Jones, C. D. Schone, M. Schmitt, M. Aubele, J. R. Kroep, V. T. Smit, R. A. Tollenaar, W. E. Mesker, A. Walch, L. A. McDonnell, J Proteome Res 2014, 13, 4730.

[158] R. Lazova, E. H. Seeley, H. Kutzner, R. A. Scolyer, G. Scott, L. Cerroni, I. Fried, M. E. Kozovska, A. S. Rosenberg, V. G. Prieto, B. M. Shehata, M. M. Durham, G. Henry, J. L. Rodriguez-Peralto, E. Riveiro-Falkenbach, J. T. Schaefer, R. Danialan, S. Fraitag, S. Vollenweider-Roten, A. Sepehr, M. Sangueza, N. Hijazi, Y. Corredoira, R. Kowal, O. M. Harris, F. Bravo, A. S. Boyd, R. Gueorguieva, R. M. Caprioli, J Am Acad Dermatol 2016, 75, 1176.

[159] A. M. Porcari, J. Zhang, K. Y. Garza, R. M. Rodrigues-Peres, J. Q. Lin, J. H. Young, R. Tibshirani, C. Nagi, G. R. Paiva, S. A. Carter, L. O. Sarian, M. N. Eberlin, L. S. Eberlin, Anal Chem 2018, 90, 11324.

[160] R. A. Bradshaw, A. L. Burlingame, S. Carr, R. Aebersold, Mol Cell Proteomics 2006, $5,787$.

[161] J. E. Elias, S. P. Gygi, Nat Methods 2007, 4, 207.

[162] S. Chakraborty, M. I. Hosen, M. Ahmed, H. U. Shekhar, Biomed Res Int 2018, $2018,9836256$.

[163] B. Zhang, J. Wang, X. Wang, J. Zhu, Q. Liu, Z. Shi, M. C. Chambers, L. J. Zimmerman, K. F. Shaddox, S. Kim, S. R. Davies, S. Wang, P. Wang, C. R. Kinsinger, R. C. Rivers, H. Rodriguez, R. R. Townsend, M. J. Ellis, S. A. Carr, D. L. Tabb, R. J. Coffey, R. J. Slebos, D. C. Liebler, C. Nci, Nature 2014, 513, 382. [164] S. Ren, Y. Shao, X. Zhao, C. S. Hong, F. Wang, X. Lu, J. Li, G. Ye, M. Yan, Z. Zhuang, C. Xu, G. Xu, Y. Sun, Mol Cell Proteomics 2016, 15, 154.

[165] I. Subramanian, S. Verma, S. Kumar, A. Jere, K. Anamika, Bioinform Biol Insights 2020, 14, 1177932219899051.

[166] O. J. R. Gustafsson, L. J. Winderbaum, M. R. Condina, B. A. Boughton, B. R. Hamilton, E. A. B. Undheim, M. Becker, P. Hoffmann, Gigascience 2018, 7. [167] L. A. McDonnell, A. Rompp, B. Balluff, R. M. Heeren, J. P. Albar, P. E. Andren, G. L. Corthals, A. Walch, M. Stoeckli, Anal Bioanal Chem 2015, 407, 2035. 
[168] FDA, Bioanalytical Method Validation: Guidance for Industry: https://wwwfdagov/downloads/drugs/guidances/ucm070107Pdf 2018. 


\section{List of publications}

Precise co-registration of mass spectrometry imaging, histology, and laser microdissection-based omics.

F. Dewez, M. Martin-Lorenzo, M. Herfs, D. Baiwir, G. Mazzucchelli, E. De Pauw, R. M. A. Heeren, B. Balluff, Anal Bioanal Chem 2019, 411, 5647.

MS Imaging-Guided Microproteomics for Spatial Omics on a Single Instrument.

F. Dewez, J. Oejten, C. Henkel, R. Hebeler, H. Neuweger, E. De Pauw, R. M. A. Heeren, B. Balluff, Proteomics 2020, 20, e1900369.

Multilabel Per-Pixel Quantitation in Mass Spectrometry Imaging.

F. Dewez, E. De Pauw, R. M. A. Heeren, B. Balluff, Anal Chem 2021, 93, 1393.

Atheroma-Specific Lipids in $\operatorname{ldlr}(-/-)$ and apoe(-/-) Mice Using 2D and 3D Matrix-Assisted Laser Desorption/Ionization Mass Spectrometry Imaging. J. Cao, P. Goossens, M. Martin-Lorenzo, F. Dewez, B. S. R. Claes, E. A. L. Biessen, R. M. A. Heeren, B. Balluff, J Am Soc Mass Spectrom 2020, 31, 1825.

Morphometric Cell Classification for Single-Cell MALDI-Mass

Spectrometry Imaging.

K. Scupakova, F. Dewez, A. K. Walch, R. M. A. Heeren, B. Balluff, Angew Chem Int Ed Engl 2020, 59, 17447. 
Protection of the Ovine Fetal Gut against Ureaplasma-Induced

Chorioamnionitis: A Potential Role for Plant Sterols.

C. van Gorp, I. H. de Lange, O. B. Spiller, F. Dewez, B. Cillero Pastor, R.

M. A. Heeren, L. Kessels, N. Kloosterboer, W. G. van Gemert, M. L.

Beeton, S. J. Stock, A. H. Jobe, M. S. Payne, M. W. Kemp, L. J.

Zimmermann, B. W. Kramer, J. Plat, T. Wolfs, Nutrients 2019, 11.

Integrative Clustering in Mass Spectrometry Imaging for Enhanced Patient Stratification

B. Balluff, A. Buck, M. Martin-Lorenzo, F. Dewez, R. Langer, L. A.

McDonnell, A. Walch, R. M. A. Heeren, Proteomics Clin Appl 2019, 13, e1800137.

Faster raster matrix-assisted laser desorption/ionization mass spectrometry imaging of lipids at high lateral resolution.

F. Barré, B. Rocha, F. Dewez, M. Towers, P. Murray, E. Claude, B. CilleroPastor, R. Heeren, T. Porta Siegel, International Journal of Mass

Spectrometry 2019, 437, 38. 


\section{Acknowledgements}

With the acknowledgments, this is where our journey ends. The obtention of my $\mathrm{PhD}$ is definitely a personal achievement and I am really proud of its completion. However, everyone knows that you can not complete it alone. With these following lines, I would like to end this thesis by thanking all the people who crossed my path and helped me to achieve this long journey.

Ron, I don't have enough words to express all my gratitude and I want to thank you for these 4 years. You have been a real source of inspiration for me and I value a lot these 4 years with you as promotor. I appreciate the time you spent with us, your PhD students, which is something extremely valuable in such a big laboratory M4I. These regular meetings helped me a lot to enhance my scientific curiosity. Besides your considerable scientific knowledge, your quality of orator was to me absolutely impressive and showed me, even more, the importance of scientific presentations. I value also a lot your always positive attitude that was motivating in situations where I could not see the end of the tunnel anymore. I spent 4 amazing years at M4I and this is thanks to you.

Benjamin, How lucky I am to have you as supervisor? I want to thank you for these 4 years. I still remembered the phone call at the end of my internship at M4I asking me if I would be interested in a $\mathrm{PhD}$ position. And here we are now 4 years later. I will be forever grateful to you for having given me this opportunity. I can tell you that you are a great supervisor by your patience, your precious help, and all the time spent with me to overcome all problems we have encountered during these 4 years. I hope that you are now proud of me while completing this $\mathrm{PhD}$.

Florian, Bon, we first met somewhen in 2014? As you know, my first impression was: "I can not be friend with this guy" and here we are almost 7 years later !! I have been your paranymph, you will be mine !! I will be forever thankful for your phone call when I was desperately looking for an internship because this opportunity has definitely given me the chance to pursue my career with this $\mathrm{PhD}$ at M4I. I spent 4 amazing years with you but this was 
only the beginning of a long long long bro/friendship. I want to thank you for your support, the high standards that you put in anything you undertake (this is a real source of inspiration) (t'enflammes pas par contre), your creativity and more in general for all the great moments we spent together (football, gym, dinner, chocolaaaaaate). I still remember one evening when we had dinner with Maxime at your place and you told us what you have been through at the beginning of your professional football player career, since this night, I understand a bit better some traits of your character. Thanks again for everything and now, I look forward to having you behind me holding my thesis for one hour.

Maxime, mon copaaaaaiiiinnnnn, as you said to me in your thesis, I can also say it here: everyone would need a friend like you. Thanks for the support during these 4 years, this was really important to me and help me a lot. Especially, I appreciate your calmness and serenity in all situations and I am jealous of your organizational skills. We had so much fun during these 4 years. If I would need to mention one of them, I would say Dubrovnik. I think this was really the beginning of our friendship and I will remember it forever. Thanks for everything again, and of course, these 4 years at M4I were just a beginning. Bon, a bit more text messages would be nice haha.

Pmax, we have been in the same office for more than 4 years. Therefore, I have so many things to share with you. Everything started when I was staying late at M4I because I did not have the internet at my place and you? Just because you needed to work every evening as you did during your entire $\mathrm{PhD}$ ... Retrospectively, this was one of the best moments during my time at M4I. Then, we moved to our brand new office for the rest of our PhDs. In this office, many interesting discussions but also many arguments. But now, I can say that thanks to you I have become a better scientist but also a better person. I will be forever grateful for that.

Jianhua, I should better say Huahua, I am so happy to have met you and to have shared 4 years with you at M4I. You are just an extraordinary person so please never change (bon, sometimes maybe a bit less rude). I will never forget your first week at M4I and the only question at that time: "what s your 
name again" but also the famous pink dress haha. Besides these fun facts, thanks a lot for your communicative cheerfulness that was really helpful for me when I was not motivated anymore. Thanks for all dinners you prepare for us (I swear you will have it your French dinner). I will cite you for my last sentence about you, something that depicts you well: "In Europe, we eat to be able to work. In China, we work to have the pleasure to eat".

Marta, everyone would need to have someone like you when starting a PhD. I will be forever grateful for all your scientific inputs and all your help during the first years of my $\mathrm{PhD}$. I don't think you can realize how helpful it was for me. Especially when things were not going well, you were always there to have comforting comments and constructive discussions. I know that I can trust you in any situation and that's something really valuable in a friendship. Thanks also for all the evenings and the dinners. You could be the perfect friend if you would not be a Real Madrid fan ...

Tiffany, thanks for everything Tiff for these 4 years. We shared so much during these 4 years. Thanks a lot for all your great support and your knowledge of all the scientific instruments at M4I. I will never forget all the great moments we shared, the gym (bon ok it was maybe twice in 4 years haha), the squash, all the evenings but also all the dinners. We were the two last French from our French group to leave the boat, so I have the feeling that our friendship grew even bigger towards the end. Thanks my Tiff.

Naomi and Britt, my dutch friends. Thanks for your help and your support during my $\mathrm{PhD}$. You have definitely played a big part in its completion and I will be forever thankful for that. It was great to work with you. Thanks also, both of you, for your dutch classes despite my poor level. I will for sure remember all the events we shared outside of the lab, this will be etched in my memories forever. You are just two amazing persons and I am lucky to call you friends.

Bea and Berta, with Marta, you were the Spanish atmosphere at M4I. Before my $\mathrm{PhD}$, I was already a big fan of Spain and Spanish people but this is even more true now after meeting you. Bea, like Huahua, your communicative 
cheerfulness is just amazing, never in a bad mood (or you hide it very well haha), this is something really valuable in a group. (the pronunciation of "syringe" will resonate in my head forever). Thanks for everything. Berta, my journey at M4I started with you as my supervisor during my internship. Thanks for your patience and your help during my internship but also during my PhD while working on the CoreLab. I will never forget you.

As I said above, a $\mathrm{PhD}$ is a long journey that you not complete alone. Now, I would like to thank all the people that made my daily life at M4I way easier: Nina (see you soon in Lille), Shane, Andrew, Anjusha, Michele, Frans, Darya, Stephanie, Klara, Sylvia (especially thanks for all your help with the synapt), Rob, Pieter K, Lieke, Helen, Mirella, Ronny (thanks so much for your support, especially at the end of my $\mathrm{PhD}$ when it was the most difficult), Eva, Laura, Michiel, Roel, Anne, Joel, Bryn (my Brynou, I can just confirm what Florian had said in his thesis, you're the nicest person ever, thanks so much for your help), Sebastian, Ian, Axel, Lennart, Philippe, Jo, Isabeau (thanks again for my summary), Aljoscha, Fabian, Gert, Lucia, Ana, Kasper (good luck my padawan) and Charles (too bad, you have not joined M4I earlier but this is not really a problem, we will see each other in Lille. Especially a big thank for all the help at the end of my PhD). Thanks for your help, your ideas, thanks for having made of M4I, a place I will never forget.

Thank people from IDEE. Without you, some days would have been definitely longer. Etienne, thank you very much for all the time we spent in front of the Synapt trying to align the laser. You re such a good person, even if we were working, we always had a lot of fun. Thanks for everything, I will never forget you. Also thank Simon and Caro for all your awesome technical support.

Sanaz and Renée, I could not have wished better office mates than you. Thanks for all the discussions and all the fun we had during these 4 years. It was an honor to share the office with queen Sanaz, your dedication to work was impressive to me but above all a real inspiration. Renée, thanks for your fun and your jokes. You are definitely part of my journey and I will never forget you. 
My Chinese friends, Lin, Chang, Peilang, and Yuandi, thanks for your positive attitude. I am so grateful to have met you and I look forward to go to China with you. You are just awesome people and I will cherish all the memories I have with you forever.

I would also thank people from the Surgery department. Romy, Ralph, Sander, Annet, Audrey, Cathy, Chantal, Mirjam, Aurelia, Kees, Anne, Bas, and Mo.

Especially thank Evie, Marissa and Yvonne for all the fun with the foosball table.

I would like to thank also people from Liege and the mass spectrometry lab. Thanks Professor Edwin De Pauw to have given me the opportunity to get and complete this $\mathrm{PhD}$. Thanks, Loic, Gabriel, Dominique for your great support and your help during these 4 years. Thanks Lisette, Nancy for your help while I was learning about sample preparation in proteomics. Thanks Mathieu, France, Sophie, Andrea for our nice talks about science.

I will finish this part of my acknowledgment in English by thanking Alain Creissen. Thanks for everything, I loved working with you and thanks for all the opportunities and all the trust you gave me.

Ma thèse a duré 4 ans mais je n'y serai jamais parvenu sans ma famille ni mes amis et c'est pour cela que je me devais de vous remercier.

Pierre Lamouroux et Amaury, j'espère que vous êtes fiers d'avoir un copain docteur en sciences. Même si on ne s'est pas énormément vus durant ces 4 ans, j'ai toujours pensé à vous et je voulais que vous sachiez que vous êtes très importants pour moi. Pierre et Brian, sans aucun doute, mes plus longues amitiés, on se connait depuis qu'on a 2 ans et alors que nous approchons les 30 ans, nous sommes toujours en contact. Je suis tellement heureux de vous avoir en tant qu'amis et je suis sûr que cette amitié est loin d'être finie. 
Camille, si je devais remercier quelqu'un du plus profond de mon cœur, c'est bien toi. Merci pour ton soutien, ta patience pendant ces 4 années. Je n'ai pas toujours été facile à cause du stress et de la situation donc je te tire clairement mon chapeau d'avoir enduré cela pendant 4 longues années. Ce dont je suis sur maintenant, c'est que la thèse n'était qu'une infime étape de notre vie commune et que de très beaux jours sont devant nous.

Pour finir, j'aimerais terminer avec ma famille. Vanessa, tu es un exemple pour moi, je suis fier de toi et de tout ce que tu as accompli. Tu es ma grande sœur et tu as toujours été la pour moi. Ta force de caractère est un exemple pour moi et m'a beaucoup aidée à finir cette thèse. Tu as eu 3 jolis enfants, Talia, Naomi et Victor, qui font maintenant partie de moi et de ma vie. J'espère que quand vous serez plus grands, vous lirez cette thèse en étant fiers de votre parrain/tonton. Je vous aime tellement.

Papa, Maman, rien n'aurait été possible sans vous. Vous êtes mes piliers, votre soutien inconditionnel, votre éducation, vos principes de vie ont fait de moi l'homme que je suis aujourd'hui. Un énorme merci pour tout ce que vous avez fait pour moi. Je vous aime.

Grand-père Gustave, à mon plus grand regret, on ne s'est jamais connu mais je voulais te dire que je suis fier de porter ton prénom. Grand-mère Simone, j'étais petit quand tu nous as quittée mais j'ai encore tellement de souvenir avec toi... J'espère que de là où vous êtes, vous êtes fiers de moi. Grand-père Gérard, je suis également si fier de porter ton prénom. Malheureusement, tu ne seras pas là pour mon titre de Docteur, j'imagine que cela aurait été la preuve ultime pour te démontrer que je suis capable de donner les noms des formules chimiques. Vous me manquez tellement. Grand-mère Josiane, je t'aime tellement grand-mère, tu n'imagines même pas à quel point. Tu es un exemple pour moi et je suis le petit fils le plus heureux au monde à tes côtes.

I will finish my acknowledgment by something I would have preferred not to do. Marty, I can not still realize. We shared one of my best memories in Maastricht, being with you paranymphs of Florian and this will be etched in my memories forever. I miss you so much the beast. 


\section{Curriculum Vitae}

\section{Frédéric Gustave Gérard Dewez}

I was born on January $21^{\text {st }}, 1991$ in Douai (France).

After high school, I obtained my bachelor's degree in cell biology and physiology at the University of Lille.

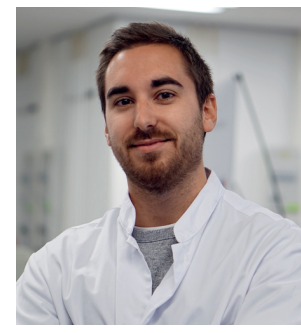

Afterward, I joined the genomics and proteomics master program at the University of Lille. At the end of the first year, I decided to perform a research internship at the Institute of Veterinary Pathology in Zurich where I studied and characterized the effect of Penicillin G on Chlamydia Pecorum porcine strains.

With an interest growing in the technique of mass spectrometry, I pursued my education by joining the second year of the master's degree specialized in proteomics. I, finally, obtained my master's degree by accomplishing a 6 months internship at Maastricht MultiModal Molecular Imaging Institute (M4I) in Maastricht under the supervision of Dr. Florian Barré and Dr. Berta Cillero-Pastor where I optimized several protocols for the comprehensive analysis of Diffuse Large B cells lymphomas by mass spectrometry imaging.

Under the supervision of Prof. Ron Heeren, Assistant professor Benjamin Balluff, and Prof. Edwin DePauw, I accepted a PhD position to study intratumor heterogeneity in breast cancer at M4I and Mass Spectrometry Lab (Liège, Belgium) within the Imaging Valley Program. The aim of the research was to create a pipeline between mass spectrometry imaging (MSI) and micro-proteomics in order to gain deeper insights into the biology of these tumors.

I will now pursue my career as field support scientist at Leica Biosystems. 
